\title{
The Largest Feasible Steerable Telescope
}

From the very earliest stages, planning for NRAO included the construction of a very large fully steerable radio telescope with a diameter up to 1000 feet. However, following the 140 Foot debacle, there was no support for funding such an ambitious and risky construction program. After the construction of the 300 Foot Transit Telescope with its limited capabilities, NRAO initiated the Largest Fully Steerable Telescope (LFST) program to design and potentially construct a very large fully steerable radio telescope. The LFST team produced a series of designs for a 300 foot antenna capable of working at $1 \mathrm{~cm}$ wavelength, a 64 meter antenna working to $3 \mathrm{~mm}$ wavelength, and finally a 25 meter telescope working to $1 \mathrm{~mm}$ wavelength, but none of them were ever built. Although every review of the needs of radio astronomy supported the construction of a large fully steerable radio telescope, there was always a higher priority - the VLA, the VLBA, and most recently ALMA. In 1988, an NSF review committee recommended that the 27-year-old NRAO 300 Foot Transit Telescope be closed in order to provide funds for operating other new astronomical facilities. However, when the 300 Foot Telescope unexpectedly collapsed in November 1988, it was reported in the media as a national disaster for U.S. astronomy. West Virginia's Senator Robert Byrd demanded that the telescope be replaced. Although the NSF had other plans, Byrd included \$75M in the 1989 Emergency Supplemental Appropriations Bill. The new 100 meter Green Bank Telescope would not be completed until the year 2000, and only after contentious litigation as to who was responsible for the delays and nearly factor of two increase in cost.

\subsection{Early Discussions}

Probably the first use of a parabolic dish for radio astronomy was in 1933 by John Kraus and Arthur Adel, who used a 1 meter diameter search-light mirror to try to detect the Sun at $20 \mathrm{GHz}(1.5 \mathrm{~cm})$ (Kraus 1984, p. 59). Although 
they correctly speculated that sunspots might be regions of enhanced radio emission, they were unsuccessful due to the poor sensitivity of their receiver. As reported in a series of articles in the popular magazine Radio-Craft, even earlier, small parabolic dishes had been used for both transmitting and receiving radio waves in a variety of laboratory experiments and for communications over some tens of miles. ${ }^{1}$ These pioneering programs were made at what were then called "ultra-short wavelengths" below 1 meter. In 1928, Fredrick Kolster of Palo Alto, California applied for a patent for a radio beacon to be used to guide airplanes to safe landings during periods of poor visibility. Kolster proposed using a small antenna at the focal point of a paraboloid to concentrate the radiation into a relatively small beam. ${ }^{2}$ Even earlier, in 1888, during his pioneering experiments to demonstrate the existence of the electromagnetic waves predicted by James Maxwell, Heinrich Hertz used cylindrical parabolic reflectors to both transmit and receive radio signals generated by a spark gap.

When Grote Reber decided to follow up on Karl Jansky's discovery of cosmic radio emission at $20 \mathrm{MHz}$ (15 meters), he recognized that a large parabolic dish would provide the most flexible opportunities, including the ease of changing frequency bands (Reber 1958). Reber's home-built dish became a prototype for later generations of antenna designs ranging from the familiar small consumer TV receiving dishes to the Jodrell Bank 250 foot telescope and German 100 meter steerable dishes to the ill-fated Sugar Grove 600 foot antenna. Starting with the 1964 Whitford Report (Whitford 1964), all of the National Academy of Sciences reviews of astronomy (Greenstein 1973; Field 1983), as well as the two NSF Dicke Committees (Dicke 1967, 1969), recognized the need for a large general purpose fully steerable parabolic dish for radio astronomy. But there was always another higher priority radio astronomy project that took precedence, and it would take a freak 1988 accident, a determined Green Bank scientist, and an influential, strong-minded US Senator before American astronomers would have a large fully steerable dish for radio astronomy.

Although Grote Reber's 32 foot radio telescope, described in Chap. 1, was not the first use of a parabolic radio reflector, in 1937 Reber's telescope was the largest parabolic antenna ever built. During WWII German engineers went on to build thousands of 3 meter (9 foot) diameter Würzburg antennas and hundreds of the so-called "Giant Wurzburg," 7.4 meter (23 foot) radar dishes, many of which found a home doing radio astronomy after the end of war hostilities (Sullivan 2009, p. 78). However, it would not be until 1951 that a larger purpose-built radio telescope would be erected on top of the Naval Research Laboratory building overlooking the Potomac River. The NRL 50 foot fully steerable dish had a very precise surface and made some of the first radio astronomy observations at millimeter wavelengths, although at the time, the limited sensitivity of millimeter wave receivers restricted millimeter observations to the thermal radiation from a few planets and H II regions.

Motivated primarily by the need for better angular resolution, as early as 1946 Grote Reber conceived an ambitious project to build a 200 foot diameter 
steerable antenna essentially based on his Wheaton design. Realizing the advantages of a fully steerable antenna, but also recognizing the complexity and cost of a 200 foot equatorially mounted telescope, he suggested using an altazimuth (alt-az) mount and an innovative analogue coordinate converter to provide a capability for tracking celestial sources. Reber assumed a maximum frequency of $3 \mathrm{GHz}(10 \mathrm{~cm})$ limited by electronics that might be available in the "visible future." In a letter to Otto Struve, Reber estimated that a 200 foot antenna could be built for $\$ 100,000 .^{3}$

Nearly a decade later, Reber prepared a more detailed design of a 220 foot steerable antenna with a surface accuracy of about $3 \mathrm{~mm}$, including sketches of all joints, a complete parts list, and a small model. By this time the cost had risen to $\$ 650,000$ plus the unspecified cost of the drive system. Reber also outlined how he would extend the design to apertures up to 500 foot or more with a corresponding decrease in surface accuracy, and sketched the design of a 750 foot fixed spherical reflector mounted in a natural hole in the ground, such as Meteor Crater near Winslow, Arizona or Crater Elegante in Mexico. ${ }^{4}$ This concept was later developed by Bill Gordon for the 1000 foot dish near Arecibo, Puerto Rico (Sect. 6.6). A year later, Reber argued that instead of the intermediate sized 140 Foot Radio Telescope, AUI should build a 600 foot diameter fully steerable antenna, which he estimated could be built for $\$ 10$ million. $^{5}$

With great prescience Reber sketched out many concepts for a fully steerable paraboloid that were rediscovered by others only much later. This included the realization that a structure that is strong enough not to bend will not fall; that due to turbulence, a wire mesh dish will not survive wind speeds greater than $20 \mathrm{mph}$ any better than a solid surface; and that some antenna bending under gravity is not a problem, provided that the dish structure maintains a parabolic shape. Reber also made the innovative suggestion to mechanically adjust the dish structure using what he called "equalizers" to compensate for gravitational deformations, a concept that would not be successfully implemented for nearly another half century. He also suggested locating the antenna on a cliff looking to the south. In this way, he argued, the effect of sidelobes seeing the ground would be kept to a minimum when the antenna was pointed at the center of the Galaxy which would be low in the sky toward the southern horizon.

Reber unsuccessfully tried to interest the Carnegie Institution's Department of Terrestrial Magnetism, Harvard, MIT, the Office of Naval Research, and the NSF, as well as the nascent NRAO, in building his 220 foot radio telescope design. But Reber felt that his presentations were not taken seriously, no doubt, at least in part, due to his reluctance to follow what had by that time become fairly routine formal procedures to apply for NSF grant support. Only the New York-based Research Corporation found Reber's ideas of sufficient interest to provide modest support amounting to less than $\$ 250,000$ over a 30 -year period starting in 1951. However, the Research Corporation was interested in funding people, not big expensive facilities such as a large steerable radio telescope. 


\subsection{International Challenges}

Elsewhere in the world, radio astronomers were actively planning to build ever larger radio telescopes.

Bernard Lovell's Ambitious Plans for Jodrell Bank Following the successful completion of his 250 foot Mark I radio telescope in 1957, Bernard Lovell ambitiously began to think about building an even larger radio telescope. The Mark IV radio telescope was conceived as a fixed parabaloid, perhaps 1,500 to 15,000 feet across and up to 500 feet high. The 125 by 83 foot Mark II and Mark III telescopes were built as prototypes of the planned Mark IV instrument, and were used together with the Mark I as part of the very effective Jodrell Bank radio interferometry programs described in Chap. 2. But faced with increased competition for funds from Martin Ryle's group at Cambridge and Stanley Hey's group at Malvern, as well as growing government interest in participating in an international radio astronomy program such as the Benelux Cross, the funding for the ambitious Mark IV design study was repeatedly delayed, and never materialized. However, encouraged by hopes of funding from the United States, Lovell and Charles Husband conceived plans for a radio telescope "at least half the size of the visionary Mark IV," which Lovell named the "Mark V." Lovell's clearly stated goal was to build "the maximum possible size of dish for the money available," although this would mean compromising the accuracy and thus the shortest operating wavelength (Lovell 1985, p. 37).

By 1965, Lovell and Husband had a conceptual design for a 400 foot diameter telescope, which Husband estimated could be built for just over $£ 4$ million. Further engineering studies were developed by both Husband \& Company and by Freeman Fox, who had designed both the Australian 210 foot antenna and the Canadian 150 foot radio telescope at Algonquin Park. During a visit to Harvard and MIT, Lovell became aware of the CAMROC design for a large radome-enclosed radio telescope (Sect. 9.5). Although the American scientists and engineers argued that an enclosed antenna could be built for much lower cost than one open to the environment, the CAMROC cost estimate was four times larger than the estimates for Lovell's Mark V antenna. The large discrepancy worried Lovell, but he was reassured by a meeting with the director of the National Science Foundation, after which Lord Francis Fleck said, "The NSF freely admit their dearth of genius by contrast which has led to expenditure far in excess of the British for far less results." (Lovell 1985, p. 27).

With the increasing emphasis on shorter wavelengths, especially by the emerging cadre of young radio astronomers interested in molecular spectroscopy, the original Mark V design goal of full efficiency at $21 \mathrm{~cm}$ no longer seemed adequate. However, the construction of a radio telescope of the proposed Mark V dimensions and capable of operation at such short centimeter wavelengths at a cost within the expected ceiling of $£ 4.5$ million, seemed to be an insurmountable challenge. Lovell apparently seemed unaware until 1968 of the developments in the homologous design concept, and of the already well 
advanced plans of German radio astronomers to construct a 100 meter radio telescope near Bonn to operate at wavelengths as short as one centimeter (see below). The projected price of only DM 32 million (equivalent then to about £3.4 million or $\$ 8$ million) dismayed Lovell and his Jodrell Bank colleagues, who were skeptical of the German claims. When he later learned that the German telescope performed as expected, Lovell claimed that following the UK drive to join the European Common market, the pressure to collaborate with Germany killed his Mark V ambitions. Perhaps as a result of keeping his cards close to his chest and his failure to maintain usual scientific contact with his international colleagues, Lovell appeared to be surprisingly naïve about the German plans until he read of their completion in Nature. ${ }^{6}$ The most optimistic Mark V scenario called for an antenna that was 2.5 to 5 times less accurate than the German telescope, depending on elevation and wind, and would not be operational until at least five years after the Bonn telescope. As related by Lovell, even the Jodrell staff were "rebellious" and recognized the futility of pursuing the Mark V concept (Lovell 1985, p. 104).

By late 1970, there was a further increase in the estimated (but acknowledged by Husband as not firm) cost of the Mark V radio telescope to nearly $£ 8$ million. Increased costs, the change of the UK government, Lovell's impending retirement, and decreasing prospects of support for new scientific projects, led to the abandonment of the Mark $\mathrm{V}$ project and its subsequent resurrection as a smaller Mark VA radio telescope. Over the next few years, Lovell advocated building a 375 foot diameter radio telescope, but by 1974, it appeared that even this smaller radio telescope would cost at least $£ 17-20$ million. Finally, nearly 15 years after Lovell had first proposed constructing a very large radio telescope, the UK Science and Research Council informed the University of Manchester that it would be unable to fund the proposed Mark VA radio telescope. Lovell responded by soliciting support from the respective radio astronomy commissions of the IAU and URSI. Citing long standing tradition, both of these international scientific unions declined to get involved in any political funding issues. Feelers from Germany offering time on the Effelsberg telescope were interpreted by Lovell as intending to "delay and destroy his Mark VA project" and "prevent us from building a larger instrument than the 100-m Bonn telescope." (Lovell 1985, p. 170) Krupp offered to build a copy of the Bonn telescope for half of the estimated Mark VA cost, but this was rejected by Lovell, who did not want to abandon the Husband design and start a protracted new study. Moreover, he argued that the UK should not "inject so much money in another economy," and that British engineers would not accept such a radical proposal.

The Effelsberg 100 Meter Radio Telescope (Fig. 9.1) The MPIfR 100 meter Effelsberg Radio Telescope ${ }^{7}$ that so frustrated Lovell arose as a result of the visionary ambitions of the German scientist Otto Hachenberg, a generous gift from the German Volkswagen Foundation, and the recognition by the German 


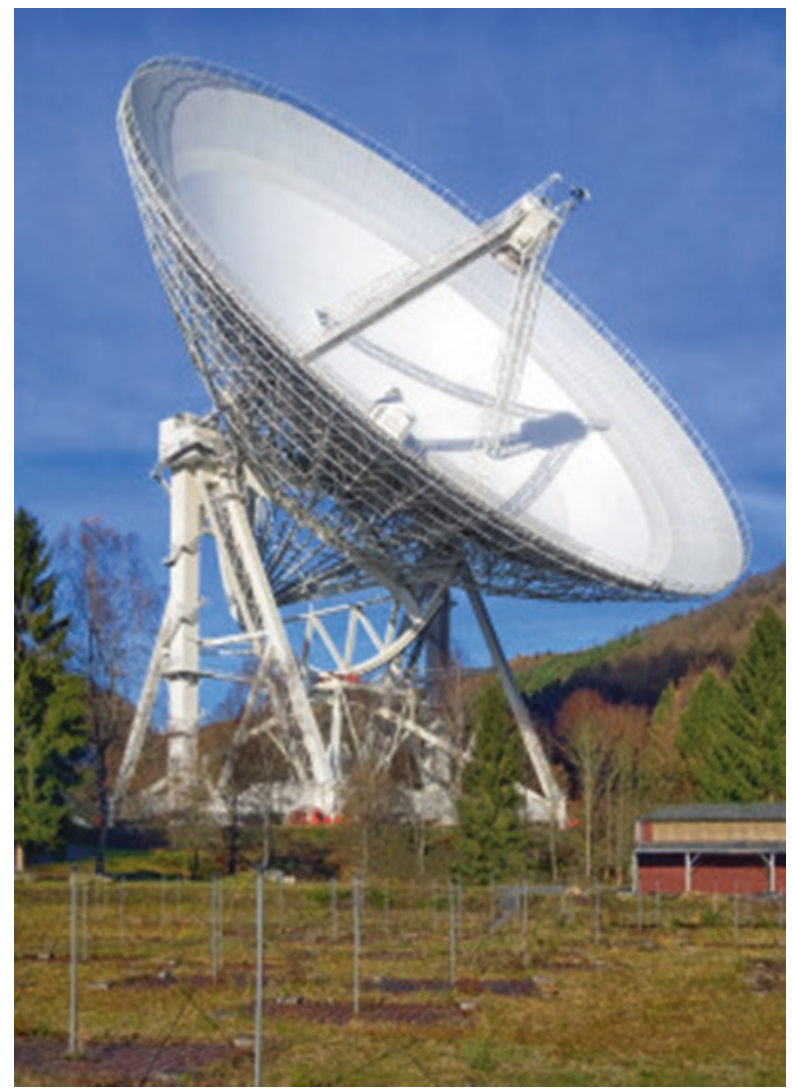

Fig. 9.1 MPIfR 100 meter radio telescope at Effelsberg, Germany designed by Otto Hachenberg. Elements of the International LOFAR Array can be seen in the foreground. Credit: Norbert Tacken, MPIfR

Max Planck Gesellschaft (MPG) of the growing opportunities in radio astronomy. Starting from the 1888 generation and detection of radio waves by Heinrich Hertz, through the WWII development of sophisticated radar systems, German radio research had a long and distinguished history. However, due to restrictions on all radio research imposed by the occupying American, French, and British military forces, radio astronomy was slow to develop in Germany. Among the major players in German wartime radar research were Leo Brandt and Otto Hachenberg, who had both worked at the Berlin-based Telefunken Company. After the war, Hachenberg became director of the East Berlin Heinrich Hertz Institute, and commuted between his home in West Berlin and his work in the East. But following the erection of the Berlin Wall on 13 August 1961, Hachenberg was unable to get to work and found himself without a job.

After the radio limitations were lifted in the 1950s, Bonn University built a 25 meter radio telescope on the nearby Stockert Mountain and in 1962 invited 
Hachenberg to become the director. Being on top of a mountain in one of the heaviest industrial areas in the world, the high level of RFI (radio frequency interference) limited the effectiveness of the Stockert radio telescope. Hachenberg initially began to develop plans for building a 65 meter dish, comparable to the Parkes radio telescope, to provide the university with a competitive research facility. Although he was unable to find the DM 8 million needed to construct the 65 meter antenna, Hachenberg went on to design an 80 meter, then 90 meter, and finally a 100 meter radio telescope. Then, teaming up with other Bonn University colleagues, Hachenberg finally received half of a DM 32 million (\$8 million) grant from the German Volkswagen Foundation to help build a 90 meter radio telescope at the University of Bonn.

By good fortune, Hachenberg's friend, Leo Brandt, had become a high ranking official in the German state of Nordrhein-Westfalen. Due to the Allied embargo, Brandt was unable after the War to find work in science and engineering, and began a career in politics. As Minister of Economy and Transport and later Secretary of State of Nordrhein-Westfalen, Brandt introduced the first speed limits within German cities. He was also able to help his old wartime friend Hachenberg by providing additional funds from the state and from the German Ministry for Research and Education to allow Hachenberg to build a 100 meter rather than 90 meter dish. Brandt also arranged to make a small plot of land available to build a radio telescope in a valley located near the small village of Effelsberg in the Eiffel Mountains about a one-hour drive from Bonn. A small river which marked the boundary between Nordrhein-Westfalen and the Rheinland-Pfalz had to be relocated to make room for the telescope. As a result, the state of Nordrhein-Westfalen became larger by about 2000 square feet.

Meanwhile, the MPG had become interested in the exciting new field of radio astronomy and invited Sebastian von Hoerner to become the director of the new institute for radio astronomy, located in Tübingen. As a young man, von Hoerner was drafted into the German army and sent to the Eastern Front where he participated in the German siege of Leningrad. After losing an eye at Leningrad, von Hoerner spent the rest of the War back in Germany in a research laboratory. In February 1945 he narrowly escaped the ravages of the Allied bombing of Dresden. Life in Germany did not get much easier after the War. Von Hoerner survived by collecting old tire tubes discarded by the occupying forces which he used to fabricate into rain coats that he then sold back to the US soldiers. Having no money, he then worked his way through his doctoral studies at Universität Göttingen by harvesting farm crops, in return for which he was allowed to take enough food to eat and was given a place to sleep. Initially he studied theoretical physics under Carl von Weizsäcker who guided him to problems in astrophysics. After receiving his $\mathrm{PhD}$, von Hoerner moved to Heidelberg. In 1960, he came to NRAO as a one-year visitor at the invitation of Otto Struve, who was looking to broaden the scientific perspectives of his staff, which was heavily oriented toward radio problems. After returning to Germany for a few years, von Hoerner went back to Green Bank as a permanent 
Fig. 9.2 Sebastian von

Hoerner, 1960. As a member of the NRAO

Scientific Staff, he laid the analytical foundations for the homologous design of radio telescopes, and, along with John Findlay, was an active participant in the NRAO LFST project. Credit: NRAO/ AUI/NSF

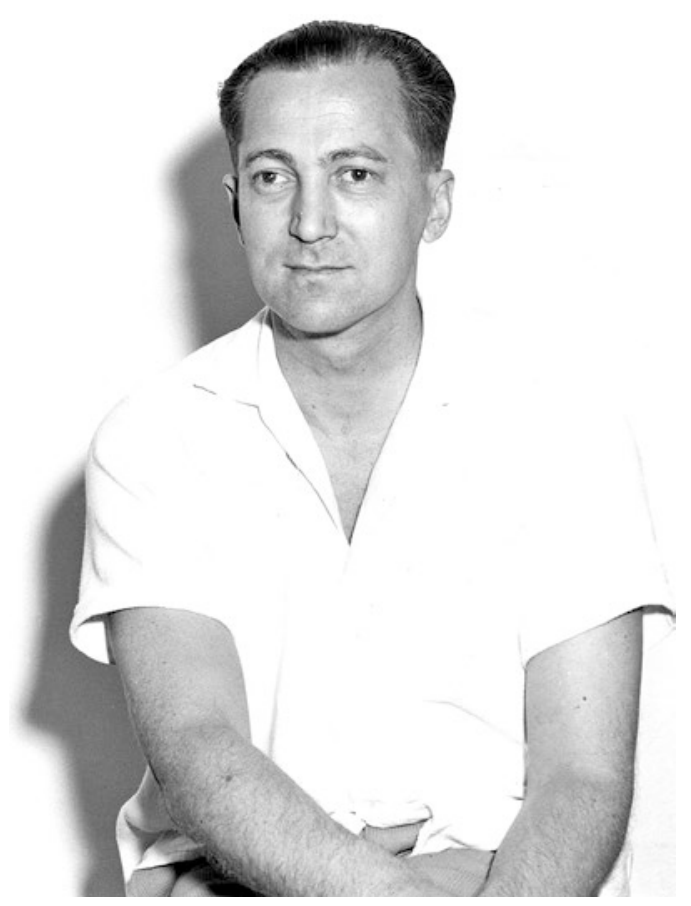

member of the NRAO scientific staff, only to be invited back to Germany to become co-director of the new Max-Planck-Institut für Radioastronomie (MPIfR), which was to be located near Tübingen (Fig. 9.2).

Although von Hoerner planned to go Tübingen, the Volkswagen Foundation awarded funds to Universität Bonn, and under pressure from Leo Brandt the MPG agreed to locate the new MPIfR in Bonn. As a result, von Hoerner declined the appointment at the MPIfR and remained at NRAO where, as described below, he went on to design, together with John Findlay, a series of large radio telescopes which were never built. The conflict between Bonn and Tübingen was further exacerbated by two factors. Von Hoerner and Hachenberg had mostly, but not entirely independently, developed the concept of homology whereby instead of trying to design a very rigid structure, the dish structure is allowed to deform to a new parabola as it is tipped to different elevations. ${ }^{8}$ Von Hoerner used an analytical approach compared to Hachenberg's more empirical approach in designing the 100 meter Effelsberg radio telescope (Hachenberg 1970; Hachenberg et al. 1973). But each felt that he alone was responsible for developing the homology concept. Also, von Hoerner and Hachenberg had competed for a fixed level of Volkswagen funding which was initially split between them. However, when von Hoerner decided to remain at NRAO, the full DM 32 million was made available to Hachenberg and the Bonn group, sufficient to plan for a 100 meter size radio telescope.

The Effelsberg telescope was constructed by a consortium of the German firms Krupp and MAN, and has been in operation since 1972. Hachenberg 
became the founding director of the MPIfR and was shortly joined by Peter Mezger and Richard Wielebinski. Hachenberg brought with him scientists from Bonn University while Mezger, a German scientist who had earlier worked at the Stockert radio telescope, brought back a number of young radio astronomers who had been part of his team at NRAO. Following several upgrades to the surface and pointing, the Effelsberg radio telescope operates well today at $1.3 \mathrm{~cm}$ and is even used at wavelengths as short as $3.5 \mathrm{~mm}$. Until the dedication of the Green Bank Telescope in 2000, the MPIfR 100 meter radio telescope remained the largest fully steerable radio telescope in the world.

Interestingly, many of the designers and builders of the large radio telescopes constructed in the 1950s and 60s made their reputation building bridges. Sir Charles Husband, who designed the Jodrell Bank 250 foot antenna, later went on to design the Britannia Bridge connecting the island of Anglesey with the Welsh mainland as well as the bridge featured in the movie The Bridge Over the River Kwai. The CSIRO 210 foot radio telescope and the Canadian 150 foot telescope were designed by Freeman Fox and Partners who had previously designed the Sydney Harbour Bridge. Ned Ashton, who built the NRL 50 foot radio telescope and later designed the 140 Foot Radio Telescope, had built several bridges over the Mississippi River. The 140 Foot project was initially contracted to the General Dynamics Electric Boat Company, the contractor for most of the US Navy's submarines, which may explain the windowless control room and submarine appearance of the room containing the declination bearing.

\subsection{The Sugar Grove Fiasco}

While AUI, the NSF, and US radio astronomers were still debating the size of the NRAO telescope, scientists at the Naval Research Laboratory, under the leadership of James Trexler, conceived a plan to build a 600 foot diameter fully steerable antenna that would be both a powerful tool for radio astronomy, as well as for a variety of intelligence gathering applications. A few years earlier, Trexler had led the NRL program which successfully bounced the first voice signals off the Moon (Trexler 1958), suggesting interesting possibilities for surveillance of Russian radio transmissions. Discussions between the NRL Radio Counter Measurers Branch led by Trexler and the Radio Astronomy Branch led by John Hagen and Ed McClain resulted in a proposal to build a 600 foot fully steerable parabolic antenna. The concept was promoted simultaneously in the scientific and popular media as a radio telescope and in the halls of the Pentagon and Congress as a tool for military surveillance (van Keuren 2001; Greenberg 1964). Funds for the 600 foot antenna became available in 1958, and due to a perceived military expediency during the height of the Cold War, construction started immediately. The publicly stated use of the proposed 600 foot antenna was to monitor Soviet radio communications and radar reflected off the Moon's surface and for radio astronomy. Coincidently, the Navy antenna was to be located near Sugar Grove, WV, only 30 miles from 
NRAO in Green Bank but a mountain range away. Subsequently this apparently led to considerable confusion among the public, if not the Washington bureaucracy, about the purpose of the Sugar Grove antenna and the distinction between Sugar Grove and Green Bank facilities. Indeed, in 1962, NSF Director Alan Waterman was chastised by Congressman Albert Thomas about "the real bear .... down there in West Virginia," (DeVorkin 2000, p. 56) and Harvard radio astronomer Edward Lilley referred to the Sugar Grove 600 foot antenna as "a radio telescope fiasco." In part, the use of the term radio telescope for the Sugar Grove facility, whether intended or not, contributed to the confusion and misunderstanding.

The Sugar Grove antenna specifications were first laid out in December 1957 and were revised several times up until October 1959. The antenna was to be built from 30,000 tons of steel, 14,000 cubic yards of concrete, 600 tons of aluminum, and would stand 665 feet high. The movable reflecting surface was equivalent to two football fields in diameter. All of this was to be accomplished without the aid of modern computer-based finite element analysis. ${ }^{10}$ Initial operation was anticipated for July 1962 (Figs. 9.3 and 9.4).

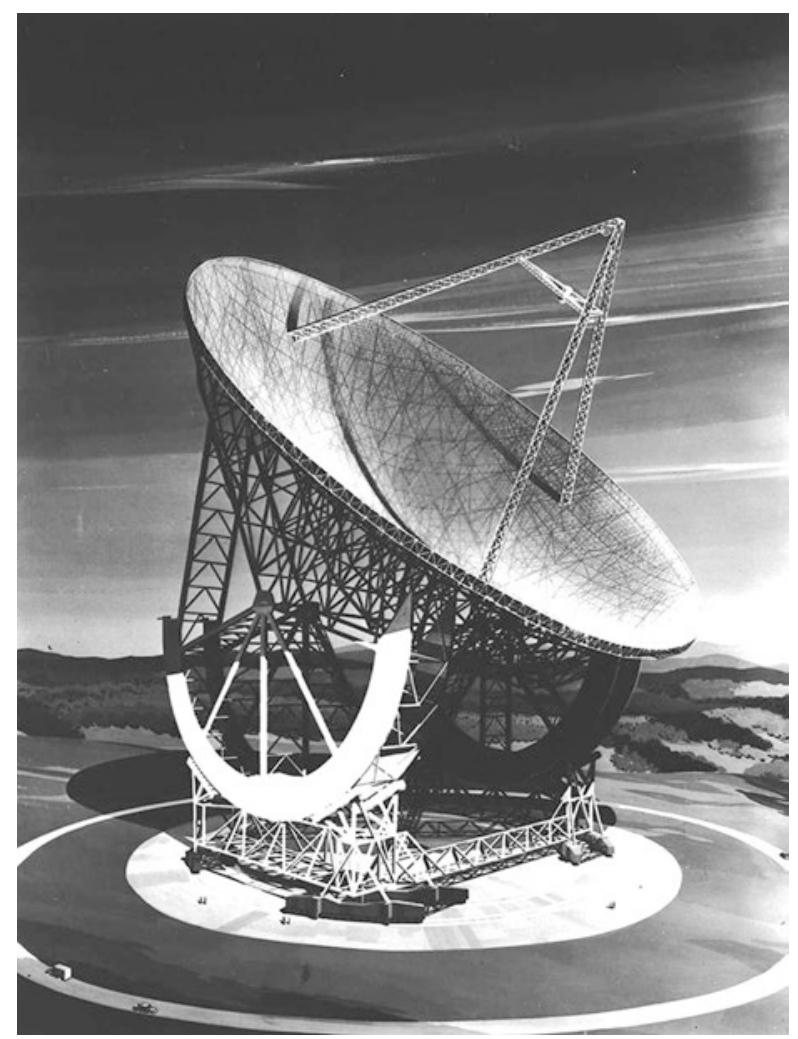

Fig. 9.3 Artist's conception of the US Navy's 600 foot Sugar Grove antenna. Credit: NRAO/AUI/NSF 


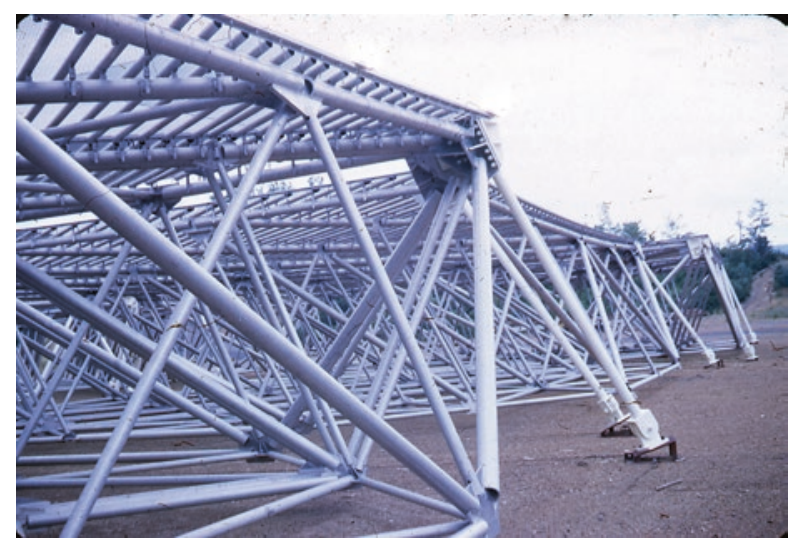

Fig. 9.4 Partially built 600 foot surface backup structures lie on the ground at Sugar Grove in mid-1965. Credit: KIK/NRAO/AUI/NSF

The terms "radio telescope" and "radio antenna" were used interchangeably in Navy documentation. The coordinate conversion and steering of the telescope were based on an inertial guidance system under computer control using punched cards as the normal means of inputting instruction and punched paper tape to provide a continuous record of the antenna positioning. However, there was also a provision for allowing manual keyboard or "digital dial" input. The antenna surface was specified to consist of "no more than 210 " individual panels. In order to maintain the precise surface and orientation of the dish in the sky under wind and thermal deformations, servo-controlled hydraulic jacks were designed to keep each panel within a planned 0.7 inch tolerance. Each panel was specified to be made of expanded, unrolled (non-flattened) aluminum alloy with openings not to exceed 0.625 by 1 inch, suggesting that operational frequency would not be greater than about $1 \mathrm{GHz}$. Provision was made to mount a four-inch optical telescope with a TV camera readout to point within 10 arcsec of the radio axis, presumably to support radio astronomy research. The antenna was to be painted with a white paint approved by the Navy's Bureau of Ships or BuShips for "top side" ship surfaces.

Although initially much of the activity surrounding the design and construction was classified, the existence of the project was publicly acknowledged, in fact even surprisingly well advertised (McClain 1960). The 1957/1959 antenna specifications document only carried the lowest classification level of "CONFIDENTIAL," which doesn't suggest a serious security concern, and was declassified in September 1962. A more detailed technical specification for the drive and control system, dated July 1962, was not classified. By this time, it was described only as a "radio telescope." A New York Times article stated that the Sugar Grove "telescope will be the largest ever built to tune in on the radio signals created in the stars and planets .... [and] will be able to look into space nineteen times further than the 200 -inch optical telescope on Mount 
Palomar." ${ }^{11}$ When construction began in early 1959 , the Navy apparently acted with typical military expediency to begin construction without waiting for detailed design, engineering, and cost evaluation or with any outside review or oversight. ${ }^{12}$ Rather than contract with a commercial organization with experience in building large antennas, responsibility for the construction was given to the Navy Bureau of Yards and Docks (BuDocks). According to Admiral Frank Johnston, the design and construction were to proceed concurrently in order to save three or four years for what he described as an important military facility.

The construction cost was initially estimated to be $\$ 20$ million, and it was expected that it would require about 30 people to operate the facility. A computer aided analysis of the structure made in 1959-1960 showed that the original design was faulty and had to be scrapped. Curiously, the 12,000 square-foot two-story antenna control and operations building was built underground, 500 feet away from the antenna. It was surrounded by two foot thick concrete shielding, ostensibly to provide RFI protection, although a simple Faraday Cage constructed of wire would have sufficed. One can only speculate about the true purpose of this underground concrete bunker. Interestingly, RFI specifications went down to $15 \mathrm{kHz}$ probably in recognition of other activities on the site such as communication with the US Naval submarine fleet. ${ }^{13}$

The 600 foot cost estimates continued to grow. By the middle of 1962, there was considerable doubt about the feasibility of constructing such a large fully steerable dish, and the projected cost had ballooned to $\$ 300$ million, while the estimated number of personnel that would be needed to operate the facility had increased by a factor of 30 to more than 1,000 . Nearly $\$ 50$ million had already been spent and another $\$ 50$ million had been committed.

As early as September 1960, George Kistiakowski, Science Advisor to President Eisenhower, received a memorandum from his staff discussing the growing costs of the NRAO Green Bank Observatory and the Sugar Grove Naval Research Station. ${ }^{14}$ In Green Bank, the projected cost of the 140 Foot Radio Telescope had risen to $\$ 5.5$ million or nearly twice the original cost. At the same time, $\$ 134.6$ million had been authorized to complete the Sugar Grove project, roughly 4.5 times the original estimate, but Kistiakowski was advised, "nobody believes it will" be completed. While the 140 Foot Antenna was expected to be exclusively used for radio astronomy, the Navy started to talk about Sugar Grove being available half of the time for radio astronomy, the remainder being for Navy operational requirements, including bouncing signals off the Moon, communication and electronic intelligence, and deep space probe communications. As late as October 1961, a New York Times article reported that McClain and Trexler had stated that "the major construction problems for the instrument had been solved," and that "construction is expected to stay within the latest authorized figure of \$135 million." 15 But the weight of the moveable structure had increased to 32,000 tons, about equivalent to a naval battleship, in order to maintain the surface accuracy needed to support the now claimed maximum observing frequency of $2.3 \mathrm{GHz}$. 
When Secretary of Defense Robert McNamara finally cancelled the Sugar Grove project in July 1962, the final cost to complete the construction was predicted to be $\$ 230$ million. McNamara only mentioned in passing the technical problems and escalating costs, and stated that satellites could now provide the intelligence that the 600 foot antenna was to have obtained. Curiously, that same month the Navy issued an amendment to the technical specifications for the drive and control systems, by which time the Sugar Grove antenna was being increasingly described as a "radio telescope" that "could spot the edges of the Universe." The amount of scientific use of the Sugar Grove antenna was variously described as 25 to 50 percent. Otto Struve had been recruited to head a committee to review proposals for astronomical observing time on the Sugar Grove antenna, and although it was speculated that any astronomical observing would be highly coordinated and under the control of NRL, AUI was concerned that the advertised existence of astronomical studies at Sugar Grove would compromise NRAO's own goals of building a very large antenna. ${ }^{16}$ As it turned out, the financial and technical embarrassment resulting from widely publicized cancellation of the ambitious 600 foot project, coupled with the apparent mismanagement, delays, and cost escalation of the 140 Foot project, became a serious black mark on US radio astronomy, and in particular on NRAO, that would take years to erase. The 17,000 cubic yard concrete foundation and 550 ton main bearing remain on the Sugar Grove site as a challenge to some future archeologists (Greenberg 1964).

Locally, residents of this small remote Appalachian Sugar Grove community had anticipated that the Navy's antenna project would bring in new employment opportunities with corresponding increases in land values. The resultant real estate speculation was premature and the ultimate cancellation of the 600 foot antenna project impacted the local economy as well as the image of US radio astronomy, especially at Green Bank.

Even after the 600 foot project was abandoned by the Navy, West Virginia Congressman Ken Hechler, a member of the House Science and Aeronautics Committee, asked the Navy to delay its "dismantling of the facilities" so that the NSF could consider a proposal by North American Aviation to use the already fabricated steel to build a less expensive 600 foot transit telescope at Sugar Grove for NRAO at a cost of only $\$ 20$ million. ${ }^{17}$ By this time the radio astronomers were wary of any involvement by the military, and NRAO declined to get involved. But West Virginia Senator Robert Byrd appealed to then President John Kennedy to maintain a presence at Sugar Grove, which continued until 2016 as the Navy Information Operations Command (NIOC), to conduct communications research and development for the Department of Defense. A quarter of a century later Senator Byrd would again intervene, this time to support radio astronomy in West Virginia.

Various antenna arrays, a 150 foot fully steerable antenna, ${ }^{18}$ as well as smaller antennas and arrays were later built at Sugar Grove to support the Naval operation. ${ }^{19}$ The Sugar Grove 150 foot antenna began as an investigation by John Findlay at NRAO to turn the NRAO 300 foot transit design into a fully 
steerable instrument, and was later pursued by Austin Yeomans at NRL who wanted to build a 300 foot antenna at Sugar Grove. Yeomans' planned 300 foot antenna never got built, but Yeomans later teamed up with Trexler and Edward Faelten to build a scaled down 150 foot version for Sugar Grove. Although built primarily for intelligence surveillance, in the 1960s and 1970s the 150 foot antenna was used infrequently for radio astronomy and was included in a number of VLBI programs.

Following the terrorist attacks on New York World Trade Center and the Pentagon on 11 September 2001, the Sugar Grove facility remained in operation by the National Security Agency for various intelligence surveillance applications. The continued presence of the NSA facility at the center of the National Radio Quiet Zone (NRQZ) has been important in preserving the NRQZ for radio astronomy in Green Bank. Half a century later, the contradiction between the classified nature of the project and the broad public dissemination of information about the project, along with the perhaps deliberately leaked confusion over the contrasting intelligence and radio astronomy goals, remains a mystery. After the project was canceled, a spokesman for the Defense Department acknowledged that "some of the capabilities from the beginning of the project had been overstated," and that "certain statements .... were scientifically inaccurate." An obvious limitation of using reflections from the Moon to warn of an impending Soviet rocket attack is that the Moon is visible at both Sugar Grove and Russia for only a few hours a day. One wonders about the real purpose of the Sugar Grove 600 foot antenna project and the massively shielded so-called telescope control building. ${ }^{20}$

By 2013 the NSA no longer had any need for the extensive domestic living facilities that had been built to support the large operational staff anticipated for the 600 foot antenna and other NIOC instruments. The General Services Administration announced the sale of the Sugar Grove Station including 80 single family homes, a 45 thousand square foot administration building, daycare and community centers, athletic facilities, and "much more." ${ }^{21}$ Bids started at \$1 million and on 25 July 2016 the NIOC was ultimately sold to an anonymous bidder for $\$ 11.2$ million. ${ }^{22}$

\subsection{The Largest Feasible Steerable Telescope Project}

Although AUI wisely decided not to initially stretch its technical and financial resources, the construction of a very large fully steerable radio telescope was clearly on the agenda for the new radio observatory. As early as October 1957, the NRAO Advisory Committee met in conjunction with a broader group of astronomers, radio astronomers, and physicists to discuss future research programs at the Observatory and approved the following statement:

The NRAO must continually anticipate the needs of and future developments in radio astronomy, and act promptly and decisively to provide for these needs. Because of the great time lag in the development of major instrumentation, the 
NRAO should through its scientific advisors and staff, look now at the general direction of radio astronomy development in coming years, and commence planning for the next stage of development beyond the $140-\mathrm{ft}^{23}$

Work on the 140 Foot Telescope had hardly started when Dave Heeschen requested \$250,000 from the NSF for "engineering studies and design of a very large antenna system." In this time period the acronym "VLA" was used to refer to the planned very large antenna rather than the Very Large Array, which came later (Chap. 7). In his proposal to the NSF, ${ }^{24}$ which ran just over two pages, Heeschen stated that while the 140 Foot "will solve many of the current problems in radio astronomy, [it will] undoubtedly make many new discoveries and open new fields for investigation, ... many of which will require still more powerful instruments for their study. This is the way science works." Heeschen went on to argue the virtues of an antenna with $10^{6}$ square feet of collecting area (equivalent to a 560 foot diameter dish). But faced with the construction of the first 85 foot antenna, the delays in the 140 Foot Telescope, and the construction of the 300 Foot Transit Telescope (Chap. 4), for the next five years, NRAO was not able to pursue these ambitious goals. In 1959, Heeschen again outlined the wide range of motivations for a very large antenna (VLA) ranging from the Sun and Solar System bodies to problems of galactic structure and dynamics and the structure and evolution of distant galaxies. ${ }^{25}$ Meanwhile, the NSF Advisory Panel on Radio Telescopes emphasized the emerging technique of aperture synthesis over the construction of a single large aperture antenna. ${ }^{26}$ (See Sect. 7.2). The Panel met three times. John Findlay and John Bolton were present as guests at the third meeting, which was held at the AUI office in Washington. Although Emberson was unable to attend, based on what he was told by others he informed the AUI Board that "John Bolton argued vigorously against the need for a Very Large Antenna, and that there seemed to be very little enthusiasm for the construction of such an instrument." ${ }^{27}$ Undeterred, Heeschen and Findlay prepared a report for the NRAO Director arguing for a very large antenna or VLA at the NRAO. ${ }^{28}$ Only with a VLA, Findlay and Heeschen claimed, could NRAO meet the instrumental needs of radio astronomy and support the research programs of staff and visiting observers alike. Findlay and Heeschen laid out a plan following the completion of the 300 Foot Transit Antenna to form a VLA design team consisting initially of 10 to 15 scientists and engineers starting in 1962.

In January 1963, following the successful completion and initial operation of the 300 Foot Transit Radio Telescope, Findlay and Robert Hall of Rohr Corporation discussed the possibility of constructing a 400 foot transit antenna with greater declination coverage and the capability to operate at shorter wavelengths than the existing 300 Foot structure. A month later, NRAO authorized the first phase of a design study by Rohr. Under Hall's leadership, Rohr completed their design work by June, but in view of the continuing issues with the 140 Foot Telescope, the estimated cost of more than $\$ 3.5$ million was more than NRAO could realistically hope to find. Only a few months later, 
however, NRAO entered into a new contract with Rohr, for a feasibility study of a 100 meter fully steerable radio telescope capable of operating up to $3 \mathrm{GHz}$ $(10 \mathrm{~cm})$. The Rohr study started with the design of the successful CSIRO 210 foot radio telescope which was the basis for the Rohr design of the 210 foot dish for the JPL Deep Space Network. Also under consideration was a 100 meter concept being developed by Harold Weaver at the University of California Berkeley.

As its first and second priorities for radio astronomy, the 1964 Whitford Report recommended the construction of the NRAO Very Large Array and the expansion of the Caltech Owens Valley Array (Sect. 7.2). However, as the third and fourth priorities, the Committee recommended the construction of two fully steerable 300 foot paraboloids at a cost of $\$ 8$ million dollars each, as well as "approximately $15 \ldots$ smaller special-purpose instruments." The panel also supported the need for the very large fully steerable telescope and recommended \$1 million for an engineering study for "the largest feasible steerable paraboloid" (Whitford 1964).

So even before the completion of the 140 Foot Telescope, US radio astronomers were looking past the 140 Foot to new possibilities. Succumbing to the pressure for observing time on the existing 300 Foot transit telescope, and buoyed by the Whitford recommendation, Heeschen sent a two-page letter to the NSF requesting that $\$ 2$ million be added to the NRAO 1965 budget to build a second 300 foot transit dish, one that would work to $10 \mathrm{~cm}$ wavelength and have a larger declination range than the existing 300 foot dish. ${ }^{29}$

In October 1964, shortly after the release of the Whitford Report, a group of 14 American radio astronomers met in Green Bank "to discuss the question of whether this is the time to start thinking about a design study for a very large steerable telescope." ${ }^{30}$ Although Heeschen, Director of NRAO, stated up front that NRAO's first priority was now the Very Large Array, he said that NRAO considered a large steerable radio telescope to be a second priority, and a millimeter wave telescope a third priority. The debate focused around a larger transit dish optimized for continuum work at centimeter wavelengths, and a smaller fully steerable antenna for spectroscopic studies working at somewhat shorter wavelengths. The group agreed at the end that radio astronomy needed a fully steerable telescope having a circular beam working down to at least $18 \mathrm{~cm}$ and preferably to $10 \mathrm{~cm}$.

Although modest about the wavelength requirements, the group was more ambitious about the possible size, and discussed the construction of antennas with dimensions up to 600 feet (183 meters) in diameter. Perhaps unrealistically encouraged by the rapid funding and construction of the successful 300 Foot Transit Telescope, Heeschen suggested that a 400 foot (123 meter) transit telescope could be in operation by the end of 1966, while "a 100 -m fully steerable dish could take about two years longer." ${ }^{31}$ In their final report, the committee concluded that "the meeting gave the NRAO a mandate to undertake a feasibility study of a steerable instrument with a circular beam, a diameter of at least $600 \mathrm{ft}$. useful down to $18 \mathrm{~cm}$ and hopefully down to $10 \mathrm{~cm} . "{ }^{32}$ 
The following January, NRAO Deputy Director John Findlay documented the scientific and technical case for using NRAO resources to investigate design concepts for a large fully steerable radio telescope to be located in Green Bank. ${ }^{33}$ Heeschen appointed a working group under Findlay (1965) to investigate the feasibility and options for constructing a very large fully steerable radio telescope as envisioned in the original NRAO planning discussions. ${ }^{34}$ Initially the group began as "The Largest Feasible Steerable Paraboloid Working Group," but morphed into the "Largest Feasible Steerable Telescope" or "LFST" Group when they realized that configurations other than a paraboloid might be feasible and more cost effective. The group met for the first time on 2 April 1965. Over a period extending until 1972, the working group issued 57 reports, 42 of which formed a numbered series. ${ }^{35}$ Engineers from interested industrial firms often attended the meetings.

A major result of these studies came from the work of von Hoerner, who investigated the fundamental principles and constraints for the design of large antennas. In an important paper, von Hoerner defined a "stress limit," a "gravitational limit," and a "thermal limit." Von Hoerner showed that for any given diameter there is a corresponding minimum wavelength, and stated that "any design that did not reach this limit was a waste of resources." (von Hoerner 1967). The stress limit, argued von Hoerner, is important only for diameters greater than 600 meters. Antennas larger than 40 meters are gravitationally limited, that is, they will deform under their own weight, while smaller ones are thermally limited due to temperature gradients across the structure, although thermal effects can be reduced at night, on cloudy days, or if the antenna is enclosed in a radome. However, he concluded that radomes are of no value for antennas larger than about 50 meters since they are limited by gravity, and even for smaller antennas, the value of a radome is "doubtful" (Fig. 9.5).

Another outcome of the LFST study, although one which was already subjectively understood by experienced observational radio astronomers, is that when pushed to shorter wavelengths, the performance of a radio telescope does not degrade as fast as theoretically predicted, assuming that the surface deviations from an ideal paraboloid are random. Moreover, it was recognized that, in practice, the effects of changing gravitational deformation result in a shift of the focal point of the dish as it folds up under gravity, and that the subsequent loss of gain experienced when the antenna is tipped in elevation can be partially mitigated by moving the antenna feed vertically to the new focal point. An extension of these ideas led to von Hoerner's "homologous deformation" concept described earlier. Traditional antenna designs required that the structure be as rigid as possible to minimize the impact of gravitational deformations. In homologous designs, the structure is allowed to bend, but in a carefully controlled way, so that under gravity, as the antenna is tipped, the surface bends into a new parabola, and the loss of gain can be recovered by merely moving the feed to the new focal point. But the price paid for a homologous design is that each structural member must be of a precise weight and 


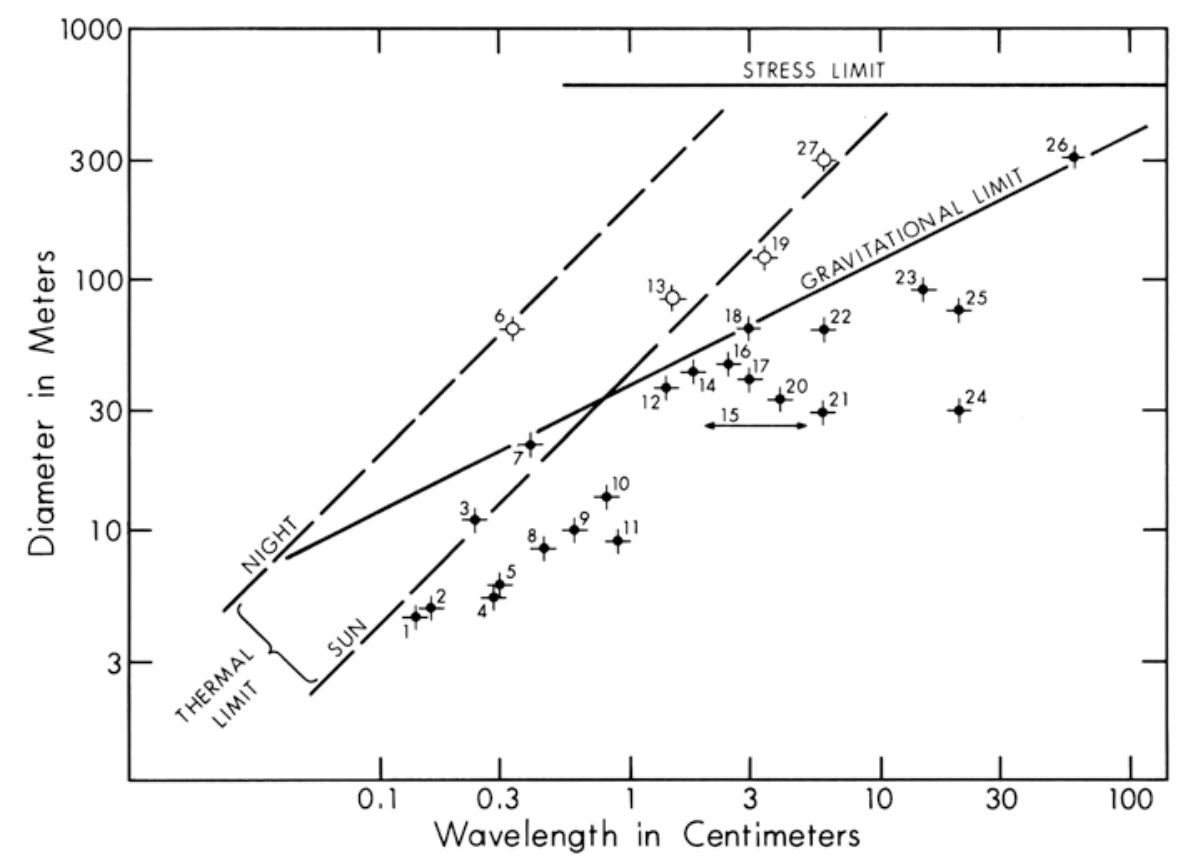

Fig. 9.5 Sebastian Von Hoerner's diagram showing the natural limiting size of antennas as a function of diameter and operating frequency due to gravitational and thermal distortions. The solid points show existing telescopes in 1972, while the open circles reflect planned new facilities. The proposed NRAO 65 meter millimeter-wave telescope shown in Fig. 9.7 is number 6 on the plot. Other major telescopes are Effelsberg (13), Arecibo before and after planned resurfacing (26 and 27), and the NEROC design (19). Credit: NRAO/AUI/NSF

cross section, so the use of standard structural steel is mostly precluded, thus increasing the cost.

The group also considered "ground supported antennas" such as the Arecibo 1000 foot antenna, as well as parabolic designs up to 200 meter in diameter with limited elevation movement which they argued could be built for about $\$ 60$ million. One of the first concepts studied was for a 650 foot diameter floating concrete sphere structure that would support a 600 foot diameter reflector that would be driven in azimuth while a moving feed allowed celestial sources to be tracked up to one or two hours. ${ }^{36}$ The motivating idea behind this concept was that in conventional radio telescopes, the limiting factor is the gravitational deflection as the dish structure is tipped. With a fixed elevation structure, gravitational deflections would not be relevant. Also, such a structure would have minimum wind and thermal loads as well as minimum maintenance and friction due to the lack of a mechanical bearing. Considerable effort was expended in developing the fixed spherical reflector concept with several commercial consultants as well as with University of Virginia civil engi- 


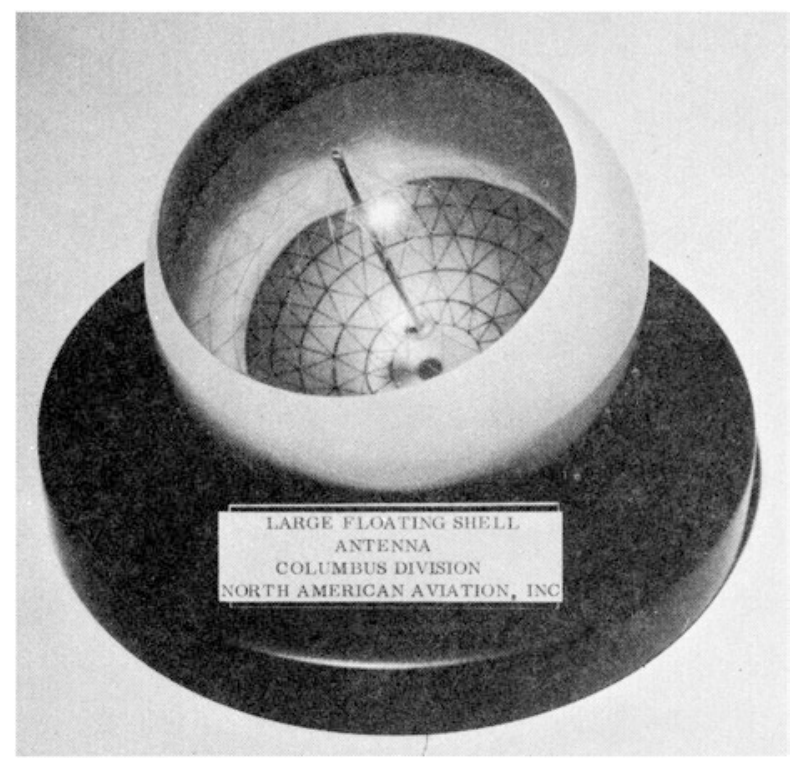

Fig. 9.6 Floating spherical antenna concept, North American Aviation. Credit: $\mathrm{NRAO} / \mathrm{AUI} / \mathrm{NSF}$

neers contributing to the design. Construction cost was estimated to be between $\$ 34$ and $\$ 50$ million to produce a structure capable of operating at wavelengths as short as $10 \mathrm{~cm}$. However, the massive structure suggested unusual construction and drive problems requiring "unusual solutions," such as the large amount of antifreeze that would be needed to prevent freezing of the supporting liquid (Fig. 9.6).

In the end, it was clear that a conventional alt-az mounted fully steerable dish represented the only practical means to build a large radio telescope that would meet the scientific requirements of full sky coverage and flexibility. Over a period of seven years, the LFST group produced reasonably advanced designs for three telescopes that were thought to meet the requirements for a scientifically strategic antenna. The first was for a 200 meter dish based on the Navy's Sugar Grove design. Although the LFST design was for a dish ten percent larger than the Sugar Grove antenna, had a solid instead of mesh surface, and a considerably more accurate surface and pointing accuracy, the LFST group estimated the construction cost of a 200 meter fully steerable radio telescope as $\$ 105$ million, or less than half of the estimated completion cost of the Sugar Grove 600 foot antenna.

Nevertheless, it was soon realized that a 200 meter antenna would be too heavy, too complicated, and too costly. The group went on to consider a 300 foot homologous dish that would operate with good performance down to 1 or $2 \mathrm{~cm}$ wavelength and could be built for only $\$ 8$ million. ${ }^{37}$ This was NRAO's answer to the radome enclosed 450 foot CAMROC antenna. However, the 
discovery of a variety of interstellar molecular species with transitions below $1 \mathrm{~cm}$ wavelength quickly made the 300 foot design appear obsolete, and the group turned its attention to the design of a radio telescope that could operate at millimeter wavelengths to exploit the new opportunities presented for studying interstellar chemistry. ${ }^{38}$ It would be another four years before the group would produce a fully homologous 65 meter radio telescope design with good performance down to $3.6 \mathrm{~mm}$, but only under "benign conditions" of temperature and wind (Findlay and von Hoerner 1972). The cost of constructing the 65 meter antenna was estimated to be just under $\$ 10$ million (Fig. 9.7). The 65 meter antenna was never built, and in fact was never even formally proposed, but for a short time it competed with the Very Large Array in the deliberations of Greenstein's (1973) Astronomy Survey Committee Radio Panel (Sect. 7.4). With the increased emphasis on shorter wavelengths, the LFST group turned their attention to a 25 meter radio telescope which was later proposed by NRAO for operation at wavelengths as short as $1 \mathrm{~mm}$ wavelength. Following review by the NSF, the 25 meter millimeter telescope actually made it into President Carter's FY1981 and 1982 budget requests, but was ultimately dropped in favor the VLBA (Chaps. 8 and 10).

Years later, von Hoerner commented that LFST should have been the Largest Fundable Steerable Telescope, noting that the project began with 200

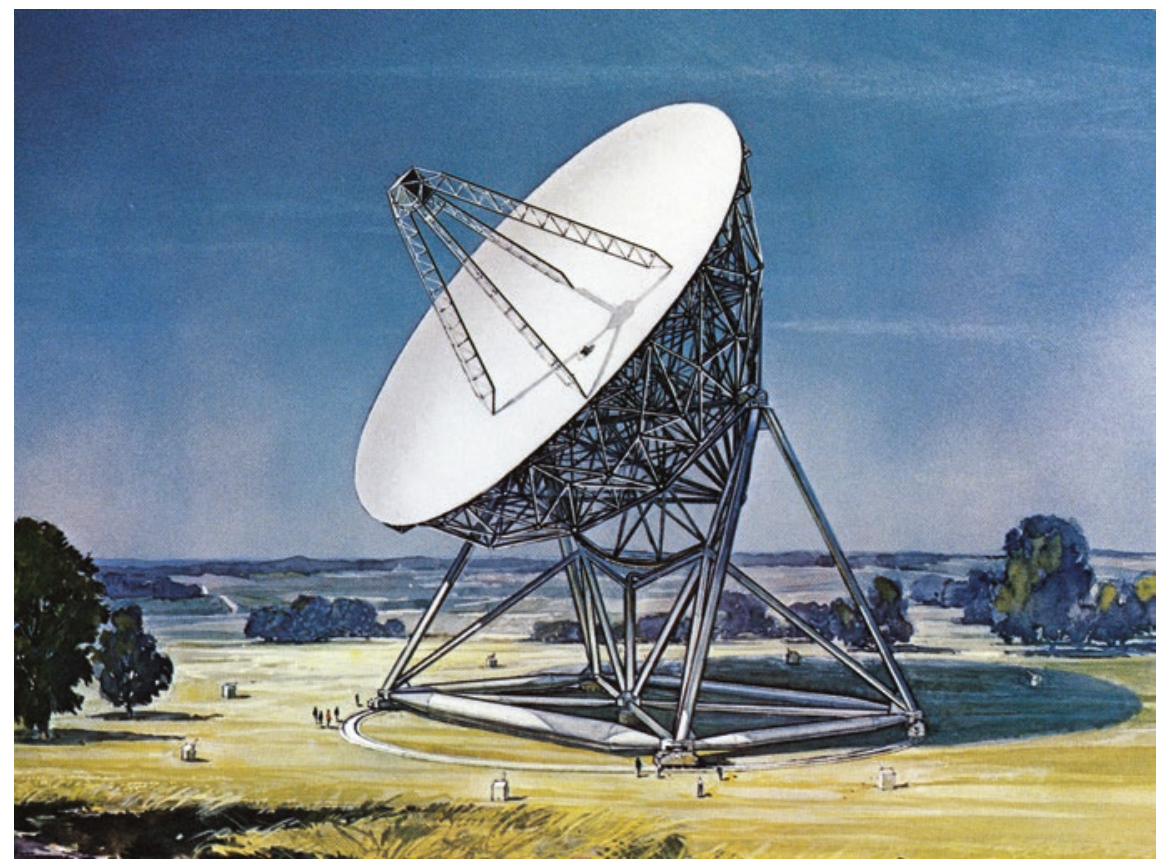

Fig. 9.7 Artist's conception of the 65 meter millimeter wave telescope. Credit: NRAO/AUI/NSF 
meter diameter, then went down to 100 , to 65 , to 25 meters, and finally converged to zero. Although meant in jest, there was a real message here that ambitions must be carefully weighed against funding realities or, more accurately, perceived funding realities, because in practice it is so difficult to realistically predict funding scenarios even a few years downstream.

As late as 1979, NRAO Director Morton Roberts asked Findlay for an updated cost estimate to construct a large, fully steerable antenna for future planning. However, there is no record that anything further developed as a result of this initiative.

\subsection{Challenges from California and Cambridge}

Planning for the next generation of large steerable radio dishes was not confined to NRAO. In 1965, around the same time as the NRAO LFSP/LFST program, two other independent initiatives appeared on the scene in apparent competition with the NRAO project as well as with each other. In the East, the MIT Lincoln Laboratory and the Smithsonian Astrophysical Observatory at Harvard University formed the Cambridge Radio Observatory Committee (CAMROC) to study designs for a large steerable radio/radar telescope to be located in the northeastern part of the United States. ${ }^{39}$ Around the same time, OVRO Director Gordon Stanley wrote to Harold Weaver at U.C. Berkeley and Ron Bracewell at Stanford suggesting collaboration among the three universities for the construction of a 100 meter antenna. Caltech, Stanford, the University of California Berkeley, and later the University of Michigan joined to form a consortium known as the Associates for Research in Astronomy (ARA) to develop a "western regional radio astronomy facility." In 1965, the newly formed Western Regional Facility submitted a proposal to the NSF to design a 100 meter dish good to $10 \mathrm{~cm}$ for a cost of $\$ 12.3$ million. ${ }^{40}$

The ARA antenna was to be located at the Owens Valley Radio Observatory where it could operate together with the proposed Caltech synthesis array (Chap. 7). Although it seemed expeditious to involve other universities in the proposal, Caltech was firm that they would maintain control. In particular, the OVRO site director, George Seielstad, questioned the added value of the consortium and urged construction and operation by Caltech alone, although he conceded that the antenna should be available for everyone with a "proposal to be judged solely on the basis of scientific merit" by a committee including representatives from outside Caltech but not confined to Stanford, Berkeley, and Michigan. ${ }^{41}$ However, the ARA proposal ran head up against the competing MIT-Harvard proposal for a 440 foot radome enclosed radio telescope. Just as Lovell found in the UK with his proposed Mark V antenna, the NSF was unwilling to fund a $\$ 350,000$ design study without some expectation of funding the construction, but they were also unwilling to consider construction funding without a detailed design and cost estimate. Moreover, both the NSF and Caltech were concerned that the proposed ARA 100 meter radio telescope would be in competition with the proposed expansion of the OVRO interfer- 
ometer which had already received good reviews, and so the plan for the proposed Western Regional Facility in Radio Astronomy did not attract much national interest. It was unceremoniously killed in August 1967 by the first Dicke Committee "because of the more revolutionary possibilities inherent in the Arecibo and NEROC concepts" ${ }^{42}$ (Sect. 7.4).

While it was noted that the US needed a large steerable radio telescope to keep up with the Jodrell Bank and Parkes radio telescopes, initially the motivation of the Harvard-MIT group was apparently to provide a competitive facility for Harvard, MIT, and other New England universities located close to home. Concerns about the extreme RFI environment in the New England area were dismissed as being no worse than anywhere else due to the increasing proliferation of RFI from aircraft and satellites which occur essentially everywhere.

Following the success of the Haystack 120 foot radome-enclosed antenna, the Lincoln Laboratory commissioned a study of even larger radomes. The report issued by Ammann \& Whitney, Consulting Engineers, concluded in 1965 that radomes in the range 550 feet to 1100 feet were feasible at costs ranging from $\$ 7.75$ million to $\$ 46$ million respectively, and that such structures would result in antenna cost savings greater than the cost of the radome. ${ }^{43}$ The CAMROC initial planning was for a 400 foot radome-enclosed structure working to $3 \mathrm{GHz}(10 \mathrm{~cm})$ wavelength. The actual CAMROC proposal, submitted two years later, discussed in two volumes the scientific merits of a large filled-aperture steerable dish, and the preliminary design of a 400 foot radomeenclosed dish with a surface good for operation up to $6 \mathrm{GHz}(5 \mathrm{~cm}) .{ }^{44}$

As has been characteristic of the radio astronomy community, at the same time as there was a certain level of competition between the CAMROC and NRAO LFST groups, there was good technical cooperation, with members of each group serving on the "competition's" design committees and a number of common commercial consultants serving both projects. Indeed, when the Smithsonian Astrophysical Observatory (SAO) initiated a meeting in 1968 to solicit community support for their antenna project, SAO Director Fred Whipple asked NRAO's John Findlay to chair the meeting held at the Smithsonian Museum of History and Technology located on the Washington Mall. ${ }^{45}$ The 31 meeting participants included representatives of Harvard, Smithsonian, MIT, Cornell, Ohio State, JPL, NRL, Caltech, the Universities of California and Maryland, NSF, and NASA. Whipple informed the group that given the "approval and endorsement" of the participants, the Smithsonian Institution would "attempt to take steps on their behalf to bring into being a national radio and radar filled-aperture telescope." According to Findlay, the Smithsonian was "ready to serve the national users." 46

However, the participants largely had their own priorities and gave less than enthusiastic endorsement to the proposed CAMROC radome-enclosed large radio telescope. Instead they prefaced their report by pointing out the need for both "large arrays and large dishes," and urged the timely completion of the Arecibo upgrade. The report did point out the "urgent need for a large filled aperture radio-radar telescope," but recommended that it be located at a "site 
selected primarily on the basis of scientific and technical criteria," thus effectively rejecting the Smithsonian arguments for a New England site. They also agreed to endorse the Smithsonian design as the basis for the final design, encouraged the SAO to submit a proposal to an unspecified "appropriate agency of the Federal Government," and said that the Smithsonian should "carry the general responsibility for the funding, design, construction, and operation" of the antenna as a national facility for radio-radar astronomy. ${ }^{47}$

In 1967, thirteen northeastern institutions, including the Smithsonian Astrophysical Observatory, Harvard, and MIT, formed the Northeast Radio Observatory Corporation (NEROC), a nonprofit consortium to plan an advanced radio/radar facility. In an attempt to circumvent the normal but lengthy NSF proposal review process, NEROC sought to have the telescope funding included in the FY1970 Smithsonian budget. The bill died in Congress, partly as the result of what was considered only a lukewarm endorsement from the two Dicke Committee reports $(1967,1969)$ (Sect. 7.4). In June 1970, NEROC submitted a new proposal to the NSF for the design and construction of a radome-enclosed 440 foot diameter fully steerable antenna capable of operating to wavelengths as short as $1.2 \mathrm{~cm}(25 \mathrm{GHz}) .^{48}$ But this time, after a heated battle within the NAS Greenstein Committee reviewing the needs for astronomy in the 1970s, the ambitious NEROC proposal to finally provide American radio astronomers with the long planned large steerable radio telescope lost out to the NRAO proposal to build the Very Large Array (Sect. 7.4) (Greenstein 1973). ${ }^{49}$

\subsection{A National Disaster Leads to a New Radio Telescope}

By the mid-1980s, the UK's Jodrell Bank 250 foot antenna had been upgraded several times with a new, more precise surface and a new precision pointing system which allowed operation at wavelengths as short as $6 \mathrm{~cm}$. Meanwhile in Australia, the 210 foot dish had also been upgraded, in part with funds received from NASA to support the Apollo lunar program. Australian scientists were using the inner part of the dish at $1.3 \mathrm{~cm}$ wavelength to study interstellar water vapor and ammonia. In Canada, the National Research Council was operating a 150 foot fully steerable alt-az mounted dish which had a better surface than the 140 Foot Telescope. The most visible competition came from the Effelsberg 100 meter fully steerable antenna operated by the Max-Planck-Institut für Radio Astronomie in Bonn, Germany.

The New Large Steerable Radio Telescope Study In September 1987, users of the 300 Foot Telescope and other radio astronomers gathered in Green Bank to celebrate 25 years of discoveries and to plan for future research programs. But with the still-unfinished VLBA construction and the growing interest at NRAO in millimeter astronomy, there appeared little prospect for the long- 
desired US 100 meter class fully steerable antenna of the kind that was envisioned when NRAO was formed in the 1950s.

At the suggestion of one of the present authors (KIK), MIT Professor Bernard Burke, a longtime NRAO user, AUI Board member, and supporter of NRAO, wrote to NRAO Director Paul Vanden Bout, suggesting that NRAO explore the possibility of replacing the aging 140 Foot Telescope with its "antique" equatorial mount, inferior surface, poor pointing, and high maintenance cost. In a prescient remark, Burke noted that, "It would certainly be prudent to have the plans in readiness as soon as possible, should the proper occasion arise on short notice." Burke suggested the formation of a working group at NRAO to examine the scientific motivation, size-wavelength tradeoffs, and cost of a 140 Foot replacement telescope..$^{50}$ The most likely funding source identified by Burke was support of the space VLBI missions planned by Japan and the USSR. Unable to convince NASA to support an American-led space VLBI mission (Chap. 8), Burke and others speculated that NASA might be willing to fund the construction of the large ground-based radio telescope that would be needed to complement the necessarily small orbiting space antenna, but at a small fraction of the cost needed to deploy a space-based radio telescope for VLBI.

Vanden Bout responded by appointing a committee to formulate a scientific justification for a new large antenna, to address the tradeoffs between size and short wavelength limit, and to consider concepts that would reduce the construction and operating cost. Since NRAO was still building the VLBA and was committed to the construction of the Millimeter Array (Chaps. 8 and 10) as the next NSF-funded major NRAO project, Vanden Bout instructed the committee to consider sources of funding other than the National Science Foundation. ${ }^{51}$ The committee was charged with reporting by the end of 1988 . Unable to come up with a reasonable descriptive name for a telescope that had not yet been designed, as a spoof on the LFST project, the prospective new telescope was provisionally named the NLSRT, the New Large Steerable Radio Telescope, "because that is so bad that there is no danger that it will, by default, become the final name." 52

The NLSRT Committee concentrated on antennas in the range of 70 meters to 120 meters that would operate with short wavelength limits from a few millimeters to a few centimeters wavelength with estimated costs of $\$ 5$ to $\$ 50$ million. By November 1988, in anticipation of meeting the Director's end of the year deadline, a draft report was in hand discussing two broad classes of radio telescopes: (a) a general purpose 70 to 100 meter class instrument operating with "full efficiency" up to $22 \mathrm{GHz}(1.3 \mathrm{~cm})$, but with good efficiency up to $43 \mathrm{GHz}(7 \mathrm{~mm})$ and with limited performance up to $86 \mathrm{GHz}(3.5 \mathrm{~mm})$, and (b) a larger 100 meter to 150 meter diameter antenna capable of working only up to $3 \mathrm{GHz}(10 \mathrm{~cm})$. Although it was appreciated that the Green Bank site had limited capabilities at millimeter wavelengths, with the continuing increase in RFI, the location in the National Radio Quiet Zone offered unique opportunities at longer wavelengths. 
Based on estimates received from various manufacturers and by scaling the cost of recently constructed radio telescopes ${ }^{53}$ including the effects of inflation, the construction costs of the proposed "Very Large Dish (VLD)" were estimated to be in the ballpark of $\$ 50$ million. ${ }^{54}$ Suggested cost saving measures included choosing a site with low wind speed, restricting the slewing velocity and acceleration, limiting the elevation to 10 or 15 degrees above the horizon, avoiding complex joints and hard to fabricate pieces, and using a simple, easy to control computer such as the IBM PC-AT. ${ }^{55}$ Understanding the Director's charge to the NLSRT committee that the next major NSF-funded NRAO facility was to be a millimeter array, the committee suggested that in view of their interest in SETI and in space VLBI, NASA might be the appropriate agency to support construction of the VLD. But a lot of work was still needed to understand the size/wavelength and conventional symmetric/unblocked aperture configuration trade-offs and their impact on the construction cost. In particular, the illumination efficiency and polarization properties of unblocked apertures, especially at the longer wavelengths, was not well understood. Community interest in the study was minimal. One prominent scientist wrote, "To be honest, I cannot justify spending any time on this now; the prospects for a positive outcome just seem too bleak." 56

Meanwhile, during the course of the NLSRT study, an added incentive to consider the next generation of steerable radio telescopes developed as a result of a new threat to the continued operation of the Green Bank facility, especially the 300 Foot Transit Telescope. By 1988, in addition to the NRAO facilities, the National Science Foundation was operating a number of radio telescopes throughout the country. In recognition of its increased use for astronomy and the corresponding decrease in Department of Defense funding resulting from the 1969 Mansfield amendment, funding for astronomy at Haystack transferred to the NSF, although an important Haystack VLBI program remained largely supported by NASA. In 1969, ownership of the Haystack antennas was turned over to MIT, and management of the Haystack Observatory was assumed by NEROC, although MIT continued to provide administrative support and the Haystack Observatory staff remained as MIT employees. Similarly, responsibility for the Arecibo Observatory was transferred from the Air Force to the NSF. Cornell established the National Atmospheric and Ionospheric Center to administer the Observatory operation as a national observatory, joining NRAO and $\mathrm{NOAO}$ as the third national facility for astronomy, but placing increased burden on the NSF operating budget. Elsewhere in the US, e.g. at Caltech, Michigan, and Ohio State, other radio astronomy programs were transferred from ONR or AFOSR to the NSF. It is always difficult to determine in such circumstances whether or not new money was actually added to the budget, since one never knows what the budget would have been in the absence of the new initiatives. Nevertheless, by this time there were a total of 12 radio astronomy facilities in the US which were receiving funds from the NSF, and 
there were no comparable facilities which were operated solely with private or state support.

Faced with the prospect of inadequate funds to operate two national radio astronomy observatories, as well as a growing number of university operated radio astronomy facilities, the NSF Astronomy Division Director Laura (Pat) Bautz convened a sub-committee of their standing Advisory Committee for Astronomical Sciences to identify those NSF funded radio facilities "having the highest scientific priority so that they could be supported at levels sufficient to exploit their capabilities with the resources available." 57 The sub-committee was asked to "recommend relative priorities" with the implication that less productive instruments could be closed with minimal loss to astronomy. Donald Langenberg, a former Deputy Director of the NSF, was appointed sub-committee chair. ${ }^{58}$ On 21-23 April 1988, representatives from all of the major US radio astronomy facilities gathered in Chicago at the Rosemont O'Hare Exposition Center to convince the Langenberg Committee, as the sub-committee was known, of the merits of continued operation of their facilities.

The Langenberg Committee weighed matters of frequency coverage, spatial resolution, versatility, future potential, ongoing research programs, impact to other disciplines, technology development, role in training students, and community access. Surprisingly, the Committee claimed it did not consider budgets and gave little weight to costs. The Committee reviewed and classified 12 US radio telescopes. Apparently not wanting to offend their radio astronomy colleagues and appear to be conspiring with the NSF to close radio telescopes, the Committee said nice words about each facility that they were asked to review and stated that "all currently funded facilities merit continued support." However, given the likely prospect of extremely limited funds for at least another year, and to be responsive to their charge, the Committee divided the NSF funded radio telescopes into three priority categories.

Group A contained those "deemed absolutely essential to the continued health of astronomy;" Group B facilities were "highly recommended ... under all but truly disastrous funding levels;" while Group C telescopes were declared to be marginally less competitive than those in Group B. Group A facilities included the VLA, VLBA, the Berkeley-Illinois-Maryland Array, the OVRO $\mathrm{mm}$ array, and the Caltech Submillimeter Observatory on Mauna Kea. Group B contained NRAO's 140 Foot Antenna and its 12 Meter Millimeter Wavelength Telescope on Kitt Peak, the 14 meter millimeter wave dish at the Five College Radio Astronomy Observatory (FCRAO), and the Arecibo Observatory. The NRAO 300 Foot, the Haystack 120 foot, and the OVRO 40 meter antennas were deemed "less competitive" and placed in Group C. In the case of the 300 Foot Telescope, the Langenberg Committee drew attention to the original limited goals and the subsequent upgrades which enabled a wide range of important contributions. "However," the Committee concluded, "if the NSF finds that it cannot support even the current minimal complement of radio telescopes, the Committee reluctantly recommends diverting resources 
from the 300 Foot to adequately support higher priority facilities." In particular, NRAO and the NSF were about to be faced with the appreciable costs required to operate the VLBA, which was still under construction. As a result of the anticipated budget limitations and given the mandate from the Langenberg Committee, NSF funding was withdrawn from both Haystack and FCRAO. Almost surely NSF funds for the 300 Foot, and perhaps the 140 Foot as well, would have been terminated within a few years. Not only were the prospects for building a new large steerable antenna bleak, but the long term prospects for the continued operation of the existing Green Bank telescopes were not encouraging. Without the 300 Foot and 140 Foot Antennas, the future of Green Bank and the National Radio Quiet Zone was in doubt.

Collapse of the 300 Foot Telescope All that suddenly changed on the night of 15 November 1988. At about 10:30 pm, George Seielstad (Fig. 9.8), the NRAO Assistant Director for Green Bank Operations, received a telephone call from the head of telescope operations, Fred Crews. ${ }^{59}$ "George," Crews reported, "You have a telescope down." Seielstad was not too alarmed. "The telescope is down," was standard radio astronomy-speak, generally meaning that telescope wasn't working properly because of some receiver or antenna malfunction, a not uncommon occurrence. However, Crews had a more serious message. At 9:43 pm that evening, the entire 300 Foot antenna structure had completely collapsed; all that remained was a tangle of steel members (Fig. 9.9). A later analysis reported that a large gusset plate which joined several members high up in the dish backup structure had cracked due to metal fatigue. That caused added stress on the adjoining members which then broke, spreading additional force to the surrounding structure, leading to the collapse of the whole antenna. Greg Monk, the 300 Foot Telescope operator that night, was working in the control building and noticed falling ceiling tiles and a steel member that had

Fig. 9.8 Green Bank site director, George Seielstad, played a major role in securing the support of West Virginia Senator Robert Byrd for the replacement of the 300 Foot telescope. Credit: NRAO/AUI/NSF

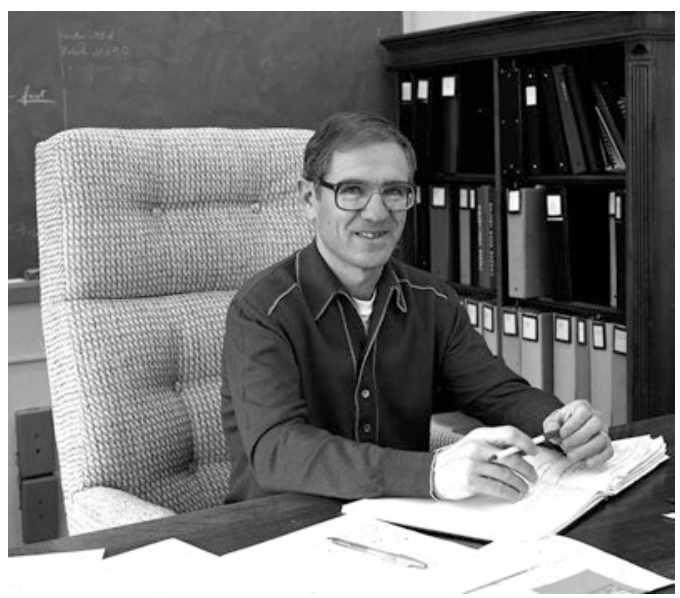




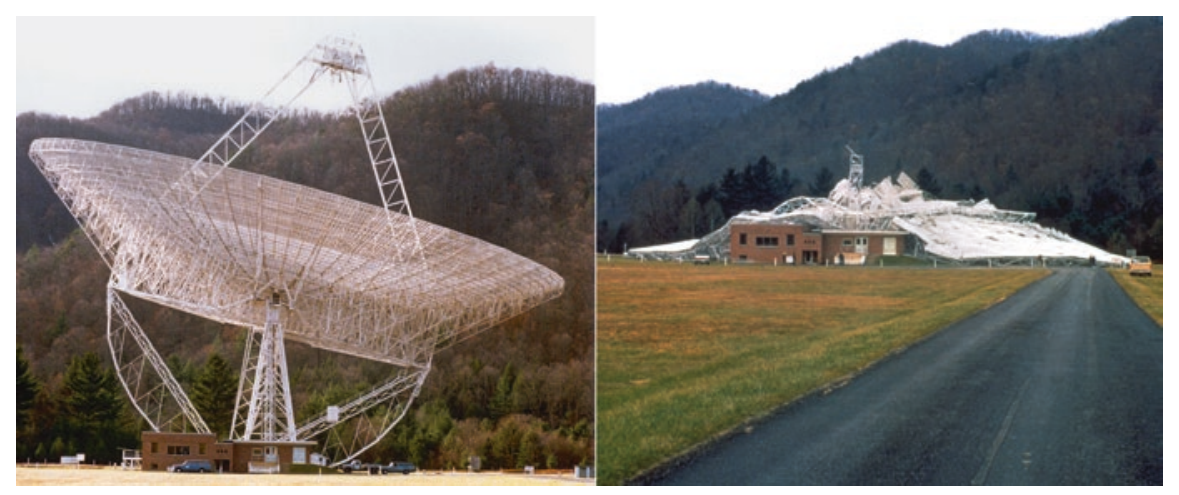

Fig. 9.9 Left: 300 Foot Radio Telescope photographed on 15 November 1988. Right: Remains of the 300 Foot Telescope on 16 November 1988, the morning after the collapse. Credit: Courtesy of Richard Porcas

crashed through the roof. Fortunately, no one was killed or injured in the accident. Only five months after the Langenberg Committee had sentenced the 300 Foot to death, the NSF was spared the administrative burden of withdrawing funds for the operation of the telescope, which they knew would mean dealing with West Virginia Senator Robert Byrd, who had been a consistent and staunch supporter of the NRAO Green Bank operation. Indeed, in previous years when NRAO wanted to consolidate administrative activities at the Charlottesville headquarters by moving the small NRAO fiscal division from Green Bank, Senator Byrd made clear that he did not approve.

In the 26 years since it went into operation, more than 1000 scientists had used the 300 Foot Telescope for 178,830 hours and published 429 peer reviewed scientific papers. Fifty-three students had used the telescope for at least part of their $\mathrm{PhD}$ dissertation research. About one-fourth of all known pulsars, including the Crab Nebula pulsar, had been discovered with the 300 Foot, and more than 100,000 discrete radio sources had been cataloged. This was more than all previously detected radio sources from all the radio observatories in the world. A total of $\$ 3.6$ million had been spent on 300 Foot construction, upgrades, and ancillary equipment. When the telescope collapsed on the night of 15 November 1988, the estimated replacement value was nearly $\$ 10$ million.

Like other US government facilities, NRAO carried no insurance, and the prospects for replacement appeared nil. All that might be recovered would be the salvage value of the nearly 500 tons of aluminum and steel lying in a West Virginia field. However, even that was not to be. The steel girders lay in a twisted mess under great tension. Releasing one member might release a dangerous spring that could cause serious, possibly fatal, injury. Indeed, over the next months, the interlocking pile of steel girders continued to flex and move. Salvage was dangerous. The best deal NRAO could get was from the Elkins 
Iron and Metal company, who agreed to take away the debris at no cost. Other companies wanted to be paid to clean up the mess. During the cleanup nine months later, an unanticipated danger surfaced when a four foot rattlesnake emerged after being evicted from its home within the tangled jumble of steel girders.

Just four days after the collapse of the 300 Foot Telescope, the NSF and AUI commissioned an extensive formal investigation of the accident. A blue ribbon Technical Assessment Panel was appointed to determine the cause of the telescope failure. The panel was chaired by former Cornell Vice President Robert Matyas. ${ }^{60}$ As frequently happens with such incidents, the NSF and AUI wanted to know if there was someone to blame. Contrary to some statements made immediately following the collapse, the 300 Foot Telescope was not built to physically last only 5 or 10 years, although the expected scientific lifetime was thought to be of that order before it would be superseded by a newer, more powerful instrument. However, the anticipated 100 meter class fully steerable telescope was never built. With the various improvements to receiver sensitivity, the two upgrades to the dish surface, the construction of the tracking feed, and the implementation of fast elevation scans, the 300 Foot Telescope remained scientifically productive until its collapse in 1988. There were no known structural compromises made at the time of construction that might have led to its collapse after more than 25 years, although a computer finite element analysis, which was not available a quarter of a century earlier, clearly indicated that the structure had been over-stressed. Specifically, the panel investigation showed that the gusset plate, which joined members of the backup structure to the elevation bearing mounted on one of the two towers supporting the structure, had what were called "micro-fractures" that may have been introduced during the telescope construction, and which slowly expanded under repeated stress. ${ }^{61}$

At the time of the collapse, the 300 Foot Antenna was being used by James Condon to survey the sky at $6 \mathrm{~cm}$ wavelength for new radio sources. Due to the great improvements in receiver sensitivity since the telescope was first designed, it was no longer necessary to wait for the sky to slowly drift through the antenna beams as the Earth rotated. Instead, in order to speed up their observations, Condon and his colleagues were rapidly scanning the telescope in elevation, which likely contributed to the ultimate failure of the structure. By an unfortunate coincidence, at the time, the NRAO computing staff were "upgrading" the software needed to analyze the telescope data. So, although Condon was nearing the end of a month long observing program, he had been unable to analyze his data. Months later, when he was able to examine the data, he realized that even early in the previous month, there was a large hysteresis between the apparent positions measured when the telescope was driving up and when it was driving down. "Even more ominous," Condon (2008) later said, "during the final week before the collapse, the north-south beamwidth had increased from 3 arcmin to 4 or 5 arcmin." With the benefit of hindsight, Condon later realized that this was an early indication of the failing structure. 
The review panel determined that the gusset plate which had suffered from metal fatigue "had been cracking for years and finally ran out of cross section." They also praised the original design and low cost construction of the antenna, as well as the quality of NRAO's continued inspections and maintenance, and concluded that there was no human error involved which could have prevented the incident. Nevertheless, with the benefit of hindsight, the stresses on a large number of structural members were perhaps as much as a factor of two higher than would be permitted by existing codes at the time the structure collapsed, and therefore the "structure was marginal with respect to structural failures." The panel concluded that the "failure of the telescope structure was not the result of inadequate maintenance or inappropriate operation of the telescope," and noted that there were no "unfavorable implications about the current ability to engineer future telescopes of this or larger size." These conclusions were met with a sigh of relief, not only at NRAO, but also over at the Naval Radio Station in Sugar Grove, where the staff was alarmed by the collapse of the 300 Foot Antenna as their 150 foot antenna was based on a similar design, and they worried that it might share whatever structural deficiency caused the destruction of the Green Bank 300 Foot.

Considering that the 1988 Langenberg Committee had declared the 300 Foot Telescope to be scientifically "less competitive," the response of the media and the scientific community was surprising if not startling. Washington newspapers sent helicopters to Green Bank to photograph the remains of the collapsed telescope. On his daily radio broadcast, Paul Harvey ${ }^{62}$ announced, "The science of astronomy has suffered a devastating setback!" News media from around the world reported on "a major blow to world astronomy." In a front page picture caption, The New York Times stated that "the 300 foot radio telescope was one of the most powerful instruments in the world." 63 Several newspapers, including one in South Africa, blamed the collapse on "hostile space aliens" who wanted to stop earthlings from eavesdropping on their activities. A front page headline declared "Space Aliens Destroyed Radio Telescope" (Fig. 9.10).

A Controversial Congressional Earmark A more serious and a more sober response came the day after the telescope collapse when West Virginia's Senators Robert Byrd (Democrat, West Virginia) and Jay Rockefeller (Democrat, West Virginia) contacted the NSF about replacing the telescope. At the time, then NSF Director Erich Bloch was in Antarctica. Bloch, the former IBM Vice President and winner of the 1985 National Medal of Technology for his contributions to the development of the IBM System/360 series of computers, was the first NSF director to come from industry and to not have a $\mathrm{PhD}$. He considered development of economic competitiveness to be a strong priority of NSF-sponsored basic research. ${ }^{64}$ On November 28, just after he returned from Antarctica, Bloch was summoned to an evening meeting in Senator Byrd's office to explain what he planned to do to replace the 300 Foot Telescope. Byrd, who was at the time the Senate Majority Leader, was joined by Senator Rockefeller who was a member of the Senate Committee on Science, 


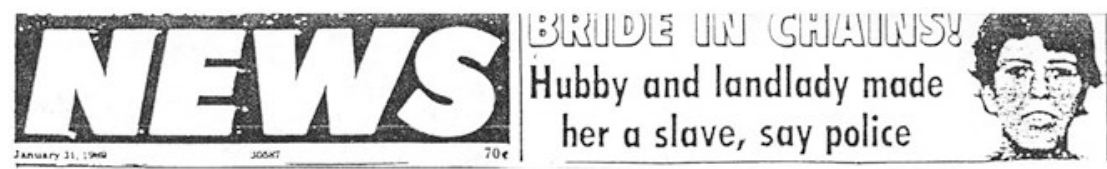
America's most powerful radio
telescope IS ...
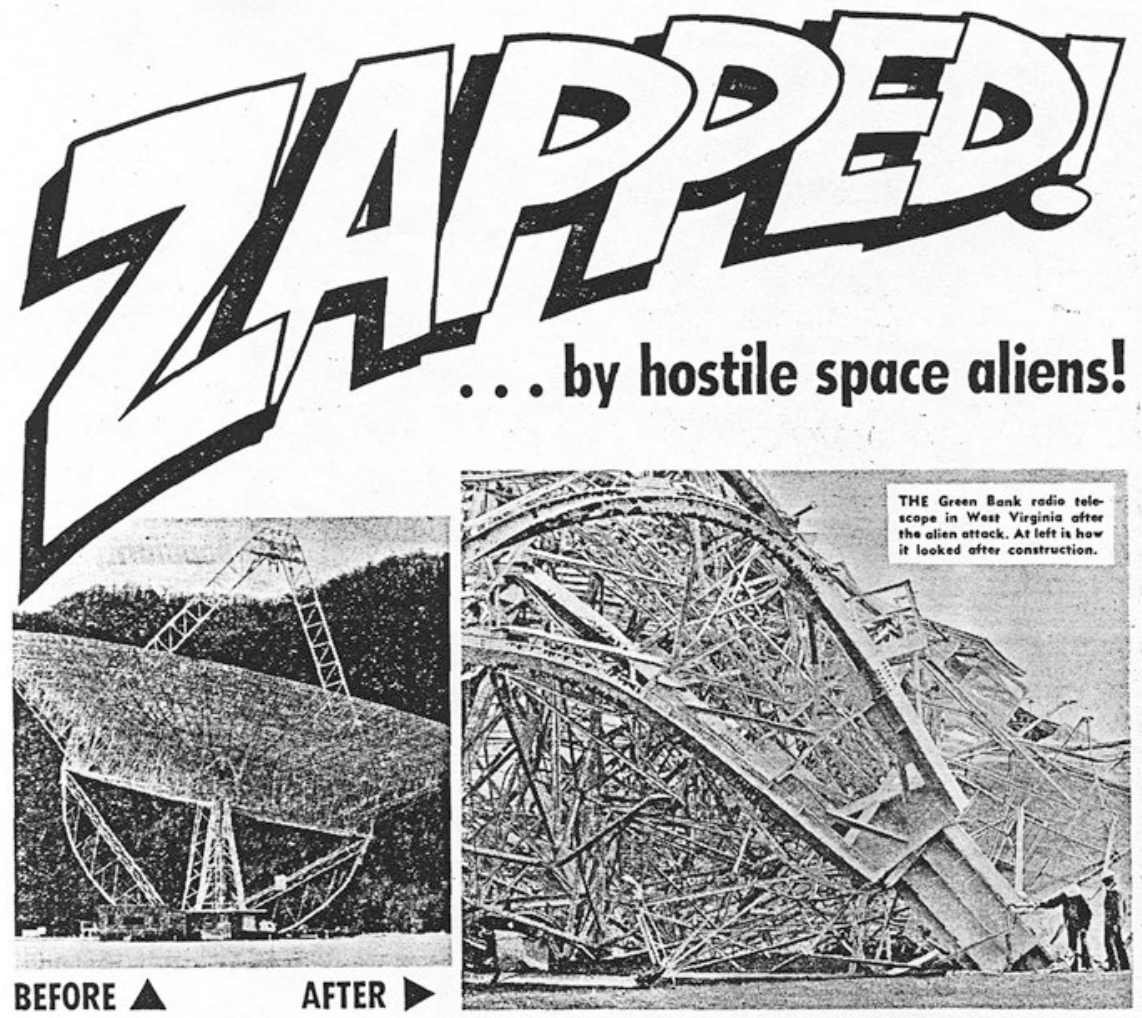

Spal alloped by extraterrestrials prove extraterrestrials toptelescope at Green Bank, W. Va., with a pow. World"s scientific cornmunity. who wanted to mask their ac. pled the telescope at Green erful laser to keep scientists from monitoring can talk about the Green Bank sard said. their activities in the northern hemisphere! disaster with authority re- "Any other explanation de- "Then we can take whatThat's the claim of Swiss astronomer Peter Voisard, lused thing more than "a mys. telescope had been in opera. prevent things like this from who says the destruction of the 300 -foot instrument on tery."

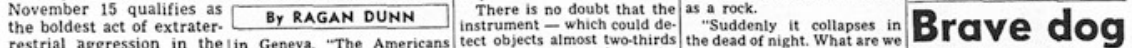
restrial aggression in the in Geneva. The Americans tect history of the world. must have been learning too of the way to the edge of the supposed to think? That the A German shepherd surtrials have thot down planes ued. "There is no other ra. tial to monitoring extraterres. French radio astronomer ing buried by an avalanche and abducted people but this tional explanation for such a trial activity in the northern Mare Kraemer was inclined to near Berne, Switzerland. is the first time they have strike as this. In some circles. skies. been brazen enough to destroy it might be considered an act And its devastation by a de- warned against jumping to dog wagged its tail and ap. a government research facili. of war."
ty." the expert told newsmen.

Fig. 9.10 Front page of Weekly World News, 31 January 1989, declaring the revenge of the aliens. Credit: Weekly World News, 31 January 1989 
Space, and Technology, NRAO Director Paul Vanden Bout, AUI President Robert Hughes, and George Seielstad, NRAO Assistant Director for Green Bank Operations, who, significantly, was the only resident of West Virginia from the NRAO delegation. However, Bloch, who was joined by Ray Bye, Director of the NSF Office of Legislative Affairs, was not intimidated by Senator Byrd. Vanden Bout explained that NRAO planned to propose to the NSF the construction of a new radio telescope to replace the collapsed 300 Foot Dish, but Bloch pointed out that any proposal to the NSF would need to be evaluated within the overall context of national needs and NSF priorities, and that such an evaluation would take considerable time. The Senators countered that they hoped for a "firmer commitment and a definite timetable." Clearly, more specifics were needed from NRAO including the cost and timescale for building a radio telescope to replace the fallen 300 Foot Antenna (Fig. 9.11).

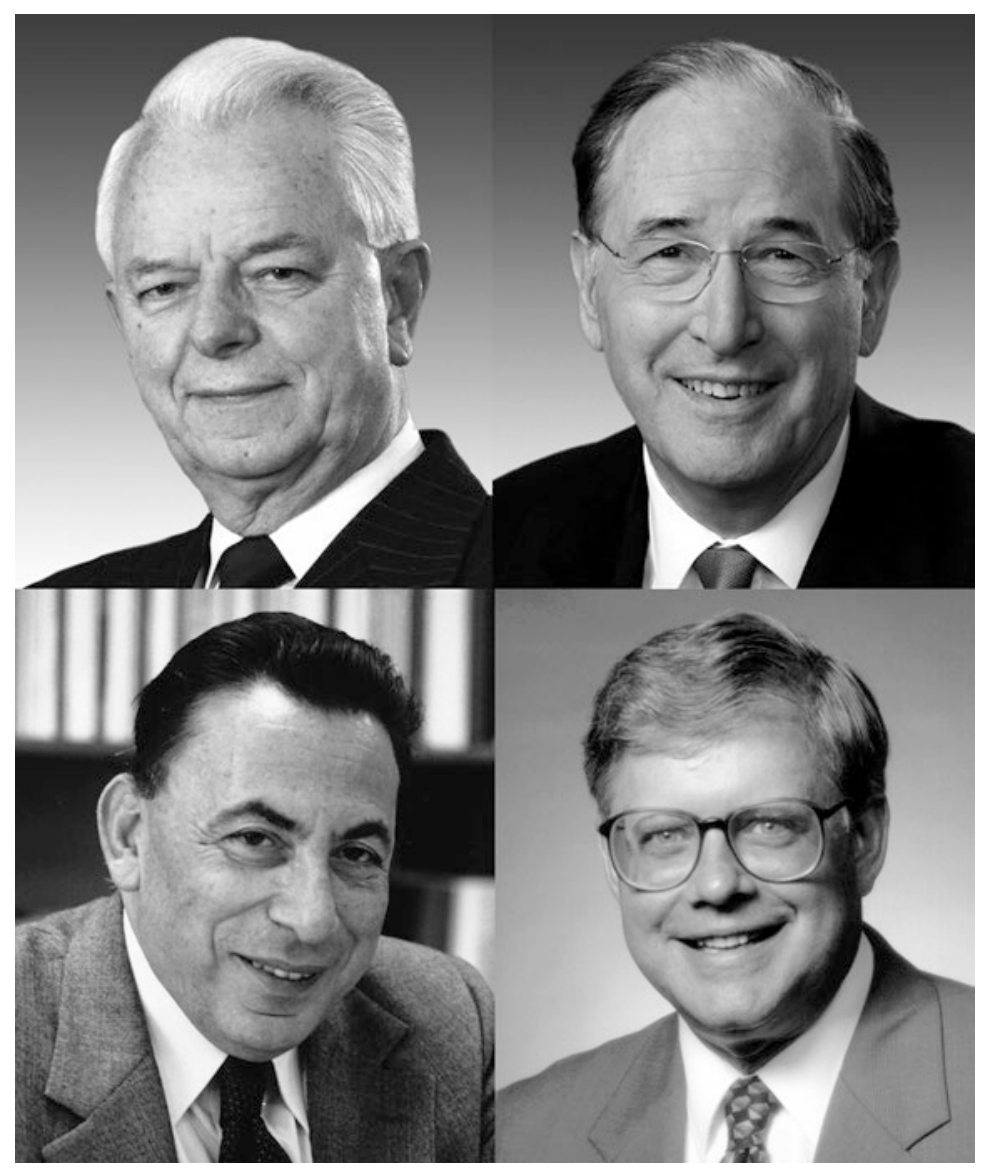

Fig. 9.11 Top: Senator Robert C. Byrd, (D-WV); Senator Jay Rockefeller, (D-WV). Bottom: NSF Director Erich Bloch; NRAO Director, Paul Vanden Bout. Credit: Rockefeller and Byrd-US GPO; Bloch—NSF; Vanden Bout-NRAO/AUI/NSF 
All NRAO had to offer, however, was the report of the NLSRT study with a "bench-mark" design for a 70 meter antenna operating to millimeter wavelengths, which was not intended to replace the 300 Foot Antenna but, as Burke had urged a year earlier, to replace the 140 Foot Radio Telescope, with its "obsolete equatorial mounting, its excessive gravitational deformations, nonrepeatable pointing errors, and poor surface accuracy." The NLSRT report, which was rushed to completion within a few weeks of the 300 Foot collapse, reflected an emphasis on the shorter wavelengths and correspondingly smaller aperture than the 300 Foot. $^{65}$ At least another year of engineering work was still needed before a Request for Proposals (RFP) could be prepared, and a ballpark figure of $\$ 50$ million was the only cost estimate available. Radiation Systems Inc. (RSI) president Richard Thomas saw an opportunity for new business, and within a few weeks of the 300 foot collapse, Thomas submitted an estimate of $\$ 9.6$ million to replace the 300 Foot with a fully steerable antenna. In a series of letters to members of Congress from states where RSI had manufacturing facilities, Thomas actively lobbied to replace the fallen 300 Foot antenna. Thomas did not give any detailed specifications, but implied that aside from steerability, the RSI antenna would have the same performance as the 300 Foot Transit Antenna. ${ }^{66}$ A re-evaluation of costs by the NLSRT committee using a wider range of data obtained from various manufacturers confirmed the NLSRT cost estimate of $\$ 50$ million, although numbers ranged from less than $\$ 10$ million (RSI) to nearly $\$ 100$ million (JPL/Ford Aerospace). ${ }^{67}$

Just two weeks after the 300 Foot collapse, MIT Professor Bernard Burke sent a memo to the American Astronomical Society's Committee on Astronomy and Public Policy to alert them to the circumstances surrounding the telescope collapse and the strong congressional interest in providing a replacement. ${ }^{68}$ Burke, who to a large extent had initiated the NRAO NLSRT study just a year earlier, wrote to reassure the AAS members that "powerful forces are at work" to fund a new radio telescope in Green Bank, but that it would be "disastrous" if the construction costs of a new telescope were to come from NRAO's limited operating budget. Burke pointed out that Senate Minority Leader (and former Senate Appropriations Committee chair) Pete Domenici (R-NM) would surely object if the Green Bank construction funds came at the expense of VLA operations in New Mexico or the then ongoing construction of the VLBA. Moreover, contended Burke, it was "absolutely essential" that Green Bank construction funds "not be borne by the NSF by taking resources from other areas of astronomy or physics without a supplement to the budget."

At the time, the next large NSF construction project was anticipated to be LIGO, the Laser Interferometer Gravity Wave Observatory, but LIGO construction was not yet funded. The NSF funding request for FY1990 only contained a nominal sum for continued LIGO research and development. LIGO was a very controversial project designed to detect the gravitational waves expected to be generated from the final stages of collapsing orbiting binary neutron stars. Although conceived by physicists, the label "Observatory" suggested to many that it was another expensive astronomy project. As a joint 
project of MIT and Caltech, LIGO had powerful support, but also strong opposition from many in the physics community who argued that LIGO would not have sufficient sensitivity to detect gravitational waves. There was also opposition from the astronomy community which had other priorities for new observatories. This was one instance where radio and optical astronomers were united against a perceived joint rival. ${ }^{69}$ There was considerable support, however, for LIGO from NSF Astronomy Section Director Pat Bautz, who perhaps saw that replacing the 300 Foot Telescope with LIGO was a way of preserving her astronomy priorities.

As planned, LIGO consisted of a complex system of mirrors spaced $4 \mathrm{~km}$ apart located at the ends of two orthogonal excavated tunnels. The mirror separation was monitored by a system of lasers, and calculations showed that a passing gravitational wave was expected to change the mirror separation by only about $10^{-15} \mathrm{~mm}$. In order to discriminate between a gravitational wave and disturbances from local vehicular traffic or seismic activity, the NSF planned to build two widely separated complexes, one of which was to be near Columbia, Maine. With the encouragement of the NSF, Caltech investigated the possibility of replacing the Maine site with Green Bank. In a report dated 31 January 1989, LIGO Principal Investigator Rochus (Robbi) Vogt reported that "it is technically feasible to build a LIGO installation" in Green Bank, but that due to the more difficult "topographical complexity" there would be a $\$ 7$ million to $\$ 18$ million increase in the cost compared with the alternate site in Maine. ${ }^{70}$

So when confronted by the senators, Bloch stubbornly ignored Rockefeller's offer to help, explained that the NSF had other priorities for astronomy, such as LIGO, and that, considering the Langenberg report, he did not plan to replace the Green Bank radio telescope. This apparently enraged Byrd who, reportedly red-faced, pointed his finger at Bloch claiming that in all his years in Washington he had never encountered such an uncooperative agency head. According to Vanden Bout, sensing that the situation was getting out of hand, Rockefeller then leaned over the table and, towering over the seated Bloch, said, "Leader is about to become Chair of Appropriations. He will have his finger on every dime of the Federal budget. Now, are you prepared to let us help you?"71 AUI President Hughes, recognizing the need for at least the semblance of peer review, offered to write a proposal. Apparently all this made an impression on the NSF Director, who responded that he "could work with the Senator," to which Byrd replied that he had "been waiting all evening to hear that." $" 72$

An accomplished fiddler, former butcher, welder, and in his youth a Ku Klux Klan organizer, Robert C. Byrd was first elected to the US Senate in 1959 after serving three terms in the House of Representatives, and became the longest serving member of the US Congress. Since 1977, Byrd had served either as the influential Senate Majority or Minority Leader, but with the new 101st Congress, starting in January 1989, Byrd became the powerful Chair of the Senate Appropriations Committee, a position which he used to bring billions of dollars in federal funds to West Virginia and, wherever he could, to protect 
every West Virginian job. Recognizing that both attrition and lay-offs can reduce the scope of an organization, Byrd engineered the 1988 NSF Authorization Bill to explicitly forbid the elimination of a handful of positions at Green Bank which NRAO had proposed to transfer to Charlottesville.

George Seielstad, the Green Bank site director, had received his PhD from Caltech in 1963 for his research on radio source polarization at the Owens Valley Radio Observatory (OVRO). Following his graduate work, Seielstad spent a year on the faculty of the University of Alaska, and then returned to Caltech as a member of the OVRO staff and to serve as OVRO site manager. Living with his young family in the nearby small town of Bishop, Seielstad became involved in local politics. In 1974 he took a leave of absence from Caltech to run for Congress as a Democratic candidate in California's $18^{\text {th }}$ Congressional District, representing the sparsely populated Inyo, Mono, and Alpine Counties. With what was probably a record low campaign budget, Seielstad easily won the Democratic primary, but lost the general election to the Republican incumbent, William Ketchum. Seielstad garnered $47 \%$ of the vote in this traditionally Republican district, and drew the attention of the Democratic National Committee. However, having spent significant personal funds to support his primary and general election campaigns, Seielstad gave up his political career to return to radio astronomy. But his service to the Democratic Party was not to be forgotten.

Both Senator Byrd and NSF Director Bloch were strong-minded individuals who normally got their way; neither wanted to be manipulated or, even worse, appear to be manipulated. Byrd was probably one of the most influential people to have served in Congress, having held all of the senior appointments in the Senate. Seielstad later described Bloch as an "acerbic, combative tough-guy personality." 73 Byrd was fascinated by astronomy and what astronomers knew about the existence of God. He was primarily motivated, however, by the opportunity to enhance the economy of West Virginia by bringing jobs to the state and more broadly raising the profile of West Virginia, which was widely perceived as an Appalachian backwater. He did not really care whether it was going to be a new radio telescope or LIGO that would be built in Green Bank, as long as it employed a lot of people and brought visibility to the state and to himself. ${ }^{74}$

However, before it could build a new radio telescope, NRAO and the radio astronomy community faced a long period of planning and construction. Characteristic of the solidarity shared by the global community of radio astronomers, Peter Mezger, Director of the MPIfR and former NRAO staff member, kindly offered to make time available to 300 Foot users on the Institute's 100 meter antenna, and the NSF made grants available to American users of the MPIfR telescope. This was a good deal for American radio astronomers, as well as for the NSF. Even if a different investigator were to fly to Germany each day to use the MPIfR telescope, it would only cost less than half a million dollars a year in plane fares and travel costs, or about an order of magnitude less than the annual operating cost of the German 100 meter telescope. 
Meanwhile, encouraged by the apparent support of the West Virginia Senators, NRAO moved rapidly to present a credible plan to the NSF. Typically, planning for new telescopes, whether radio or optical, involves many years of design and engineering, years of study to choose the optimum location, as well as years of "selling" the facility, first to the astronomical community, then to the funding agencies, the Administration, and finally Congress. In this case the location was clear: Green Bank, WV. Ironically, Congress, if not the NSF, appeared to be supportive. Yet there was no telescope design, nor even a consensus of what kind of instrument to build to exploit the apparent funding opportunity. All that was available was the hastily completed 28 November 1988 NGLSRT report.

On 2-3 December, NRAO convened the first of several meetings between NRAO staff and members of the NRAO user community to reach a consensus on a replacement for the ill-fated 300 Foot Telescope. Fifty-six individuals from 15 separate institutions, plus NRAO staff, participated in this hurriedly arranged meeting to discuss priorities for the replacement telescope. ${ }^{75}$ Many who could not attend, as well as those who did participate, wrote letters to NRAO and to the NSF presenting a variety of arguments supporting their particular scientific interest. Interestingly, strong support for the radio telescope came from Joseph Weber, who was the pioneer in developing instrumentation for the detection of gravity waves, but who saw LIGO as competition to his own search for gravity waves. ${ }^{76}$ Others wrote opposing the construction of any new NRAO facility at a time of great need for correcting the diminishing support for American university radio astronomy facilities, or opposing the apparent use of "pork-barrel" funding.

The meeting participants were able to inspect the remains of the collapsed telescope and heard a report from former NRAO Director Dave Heeschen on the investigation already underway to find the cause of the collapse. But the presentations and discussion quickly turned to understanding the scientific drivers and to reviewing what was learned from the NLSRT study of a Very Large Dish (VLD). Considering the interest of the West Virginia Senators, suggestions for a southern hemisphere site or a drier site near the VLA, or for an array of small dishes, were quickly dispensed with as not being realistic. Recognition that the areas of scientific opportunity years in the future could not be defined, the participants argued for maximum flexibility. The discussions quickly led to a large steerable antenna with full sky coverage working to relatively short wavelengths. A tentative schedule at the December meeting called for fixing the telescope characteristics by the end of 1988, one month away, developing a conceptual design by the end of 1989, and an engineering design by the end of 1990. This would allow construction to begin in 1992 with a very optimistic completion date by the end of 1993 .

Nevertheless, there remained several controversial areas to be settled immediately. For a given cost, there is a tradeoff between antenna size and the limiting operating wavelength. Based on established scaling laws, a 100 meter diameter telescope was expected to cost about six to seven times more than a 
50 meter telescope with the same performance specifications. For a fixed size, a telescope built to operate at $3 \mathrm{~mm}$ wavelength might be expected to cost about twice as much as one designed for only $1 \mathrm{~cm}$ operation. Reflecting the rapidly evolving scientific interests driven by the existing discoveries in molecular spectroscopy, the series of radio telescopes designed by the earlier LFST group had successively decreased operating wavelength and compensating smaller diameters to mitigate the cost, and this argued for a telescope capable of operation to about $100 \mathrm{GHz}$ (3 mm wavelength), where the Green Bank atmosphere becomes noisy and unstable. But other areas of research, mainly pulsar studies and $21 \mathrm{~cm}$ hydrogen research, argued for the largest possible size. Achieving a high operating frequency for pulsars was not important, as pulsars are strongest at lower frequencies, and it was considered fairly straightforward to meet the relatively easy performance specifications needed for pulsar studies. Scaling from the costs of existing antennas in size or wavelength limit, as well as estimates received from various manufacturers, cost estimates for antennas in the range of 70 to 100 meter diameter and operating at wavelengths as short as $3 \mathrm{~mm}$ ranged from less than $\$ 50$ million to more than \$100 million.

Following the 2-3 December Green Bank meeting, there was little agreement among members of the NRAO user community. Many argued for a very large dish operating at wavelengths of a few centimeters to replace the fallen 300 Foot for VLBI (especially in conjunction with a space-borne antenna), $\mathrm{H}$ $\mathrm{I}(21 \mathrm{~cm})$ and $\mathrm{OH}(18 \mathrm{~cm})$, pulsar, SETI, and studies of radio galaxy and quasar radio source distributions, luminosity functions, variability, and evolution. Others favored a smaller aperture that would work well at the shorter wavelengths needed for the rapidly growing field of molecular spectroscopy and searching for cosmic microwave background anisotropies. The proponents of the "big dish" argued that Green Bank was a terrible site for millimeter wave observations. The counter argument noted that important millimeter observations were being made at the FCRAO in central Massachusetts, where the weather conditions were comparable to those found in Green Bank. Spectroscopists and $21 \mathrm{~cm}$ workers argued for a clear aperture offset design to minimize reflections and sidelobes; others pointed out that no large offset antenna had ever been built and that it would be unreasonably costly to pursue this concept. Tor Hagfors, Director of the Arecibo Observatory, expressed concern about the impact that a new fully steerable radio telescope might have on the Arecibo Observatory, but noted that if the Arecibo Observatory were to be upgraded, the impact might be minimized. ${ }^{77}$

Yet others, such as Richard McCray from the University of Colorado and NOAO Director Sydney Wolfe, worried that any funds spent on a new NRAO antenna might come at the expense of other high priority programs or their own pet project, and argued against any 300 Foot replacement. Among the broader astronomical community, it had not escaped notice that the last two major NSF astronomy projects were for radio telescopes: the VLA and the VLBA which was still under construction. Optical astronomers had been wait- 
ing for the start of a national 8 meter telescope and wanted assurance that the "Byrd Antenna" would be "coupled with an overall improvement of funding for ground-based astronomy." 78

There were also clear applications of a large radio telescope to spacecraft tracking and to various military uses, with implications for possible broader funding support. To address some of the concerns of the astronomical community, NRAO actively solicited interest in supporting the construction of a new radio telescope from NASA, the US Naval Observatory, and the Jet Propulsion Laboratory (JPL). However, this raised the possibility that with reduced NSF funding, Green Bank might ultimately perish as a radio astronomy facility, a specter that would resurface several decades later. Nevertheless, following the Green Bank meeting, Vanden Bout wrote to the NSF Director apprising him of the strong scientific support for replacing the 300 Foot Antenna with a modern 100 meter class fully steerable radio telescope. Noting the "important role in the missions of other agencies," such as NASA and the US Naval Observatory, Vanden Bout suggested that it might be appropriate to share the construction cost and use of the telescope. ${ }^{79}$

Meanwhile, the NRAO scientific staff and external radio astronomers continued to debate the design options of a new radio telescope. In a 12 December 1988 staff meeting, the New Mexico VLA staff argued that a compact array of smaller dishes would be more powerful than a single large antenna. But Vanden Bout quickly dispensed with the array concept on the largely non-technical grounds of higher operating costs and the need for NRAO to maintain excellence in both arrays and single dishes ${ }^{80} \mathrm{~A}$ particularly controversial topic was the relative merits of an unblocked aperture with its greater cost and potentially poorer pointing precision but lower sidelobes, better aperture efficiency, and relative immunity to interference versus cheaper and better understood, more conventional designs. Conventional radio telescopes have the feed ${ }^{81}$ or subreflector mounted at the center of the dish supported by two, three, or four supporting legs. But, the feed or subreflector, as well as the feed supporting structures, partially block the aperture, decreasing the gain or sensitivity. Even more important, with conventional radio telescopes, the blocking structures set up reflections, or standing waves, between the dish and subreflector, which cause frequency ripples that greatly compromise spectroscopic observations. Moreover, the blockage generates antenna sidelobes that extend well outside of the main beam. Typically, about one third of the power received by a conventional radio telescope comes in through the sidelobes. This seriously impacts studies of widely distributed radiation, such as $21 \mathrm{~cm}$ studies of galactic hydrogen. Additionally, with lower sidelobes of an off axis feed/subreflector system, the telescope would be less subject to interference from satellites and aircraft. Off axis antennas had been built and were widely used in the telecommunications industry and for consumer satellite TV reception, but in 1989, the largest known antenna ever built with an unblocked aperture was only 7.5 meters in diameter. The construction of a large unblocked aperture antenna was a formi- 
dable challenge, as it required an asymmetric dish design, and many predicted a large but uncertain cost impact and likely reduction of antenna pointing accuracy due to inadequate stability of the feed-subreflector support structure.

A significant question was whether it was more appropriate for NRAO, the national radio observatory, to build a low cost specialized antenna or a general purpose antenna that would satisfy the needs of the large and diverse NRAO user community. Some argued that a general purpose instrument involves compromise so that it is not optimum for anything, while special purpose antennas, such as the old 300 Foot antenna, can have applications that often extend beyond the original design goals. Many letters were written to NRAO and to the NSF arguing one way or another. The arguments boiled down to a large dish of the order of 100 meters or larger but operating only at centimeter and longer wavelengths vs. a smaller but more precise antenna capable of operating at millimeter wavelengths. Green Bank astronomer and later NRAO Assistant Director for Green Bank operations, Jay Lockman, was probably the most vocal supporter of what he called a "Big Floppy Dish" (BFD) with an unblocked aperture and low sidelobes that would, among other advantages, be a unique instrument to study galactic $\mathrm{H} \mathrm{I}$, since all existing instruments suffered from stray radiation that contaminates $21 \mathrm{~cm}$ spectra. Burke protested that this was contrary to the consensus of the 2-3 December Green Bank meeting. With considerable prescience, he pointed out that a clear aperture asymmetric structure would introduce many design problems, cost risks, more complex feeds, and a delay in completion, which he argued NRAO and the radio astronomy community could ill afford. ${ }^{82}$

No matter how well designed, the effectiveness of optical telescopes is in practice limited by the environment, clouds, and "seeing," 83 while the performance of radio telescopes depends on locally generated radio frequency interference (RFI) and increasingly at shorter wavelengths to atmospheric water vapor. Although the location of the proposed new dish was in a sense a nonissue if NRAO wanted to exploit the enthusiasm of the West Virginia Senators, this did not dissuade the purists. While there was general support for locating the new dish at one of the existing NRAO sites to minimize site development and operating costs and to exploit the presence of a highly trained technical staff, many radio astronomers argued for locating the antenna at the 7,000 foot elevation VLA site, with its clear skies and low water vapor content needed for effective operation at millimeter and short centimeter wavelengths. On the other hand, due to its location in the National Radio Quiet Zone, the Green Bank site was probably the best place in the US for doing radio astronomy at longer wavelengths where protection from RFI is an issue. It was also realized that if the 300 Foot replacement were to be built in New Mexico, this would likely expedite the migration of NRAO activities to New Mexico and thus lead to the closing of the Green Bank facility and the subsequent loss of the unique 
capabilities of the National Radio Quiet Zone. However, with an average cloud cover rivaling the Northwest and upper Great Lakes areas, it was argued that the Appalachian Mountain area is a poor location for millimeter observations. George Seielstad mounted a vigorous defense of the Green Bank site, pointing out that on a clear cold winter night, the short wavelength observing conditions can be excellent. Although it was understood that there are not too many clear cold winter nights each year that could support short millimeter wavelength observations, realistically the choice was between a radio telescope in Green Bank or LIGO.

NRAO Director Paul Vanden Bout actively solicited support from American radio astronomers, support which ranged from enthusiastic to lukewarm. There was a wide range of opinions about how much the replacement telescope should cost and about the relative priorities of wavelength coverage and size. In a hastily convened presentation to the NSF on 21 December 1988, just five weeks after the collapse of the 300 Foot Antenna, and less than three weeks after the Green Bank meeting to define the proposed telescope, Vanden Bout discussed the long history of planning for a large steerable radio telescope and presented a conceptual plan for a 70 meter diameter radio telescope at an anticipated cost of about $\$ 50$ million dollars. In an effort to recognize the interests of millimeter astronomers, Vanden Bout suggested that the proposed antenna could have useful performance at millimeter wavelengths. Vanden Bout's strategy was to make the NSF comfortable with the Senate initiative. Bautz and others were clearly nervous about the appearance of pork and the expected resistance from the optical astronomy community, and from radio astronomers more interested in millimeter astronomy or arrays of smaller antennas, along with those concerned about the growing concentration of US radio telescopes at NRAO. In particular, the proposed 300 Foot replacement might threaten the planned Millimeter Array, also proposed by NRAO, or the planned upgrades of the Haystack and Arecibo radio telescopes. The latter was a particular concern, as Bloch and Bautz did not want to cause trouble with Cornell President Frank Rhodes, who was a member of the NSF National Science Board. ${ }^{84}$ Closer to home, even the AUI Board of Trustees was less than enthusiastic about exploiting Congressional interest in a non-peer reviewed project that might impact other planned astronomy or physics programs.

A week later Byrd and Rockefeller announced that they wanted to see a proposal for the replacement of the destroyed telescope by January. ${ }^{85}$ At the same time, NRAO learned that the NSF was seriously considering how to best exploit Senator Byrd's interest in Green Bank to satisfy the Foundation's own goal of building LIGO in Green Bank and perhaps closing down the radio astronomy operation. Vanden Bout was summoned by Byrd to appear in the Senate Appropriations Committee Room on 5 January 1989, along with NSF personnel. To their chagrin, Seielstad and AUI President Bob Hughes were initially not invited, but both managed to lobby for inclusion and ultimately did participate in the meeting. While waiting for Senator Rockefeller's late arrival, Senator Byrd explained to the NRAO/AUI participants how he had 
risen to such a powerful position in the Senate. ${ }^{86} \mathrm{He}$ made it clear that he expected to get whatever he wanted in Congress and from the NSF.

When the meeting began, the NSF presented their proposal to build LIGO in Green Bank instead of a new radio telescope. Vanden Bout produced a letter from Tony Tyson, a well-known astrophysicist from Bell Labs and long-time opponent of LIGO, who argued that LIGO was poorly conceived, but otherwise NRAO refrained from speaking against LIGO ${ }^{87}$ NRAO's position was difficult, as previously Seielstad had used his Caltech connections to try to convince Caltech's LIGO Director and former Provost and Vice President for Research, Robbi Vogt, to bring LIGO to Green Bank. But this was before the 300 Foot collapse and the threat that LIGO would compete with the proposed 300 Foot replacement radio telescope. Before the NRAO/AUI contingent was excused, Seielstad declared his preference for the new radio telescope over building LIGO in Green Bank. Nevertheless, following the meeting, Byrd's staff leaked that "NRAO blew it," by not coming down hard on LIGO. ${ }^{88}$ Subsequent discussions with Byrd's Director of the Senate Appropriations Committee, Terry Sauvain, indicated Sauvain's strong preference for LIGO, and that he had discussed with the NSF's Ray Bye how to best achieve their goal. However, Carol Mitchell of Byrd's personal staff leaned toward the radio telescope and kept Seielstad and Byrd informed of the behind the scenes maneuvering by Sauvain and Bye, all of which infuriated Byrd, who did not tolerate any disagreements among his staff.

Having second thoughts about not having been more critical of LIGO, and not informing anyone else, Seielstad arranged a private meeting with Byrd to explain that he had been too meek because NRAO did not want to offend Caltech. Byrd, in return, explained that he didn't have the knowledge to discriminate between the value of LIGO and a radio telescope, and depended on the scientists. ${ }^{89}$ Meanwhile, NRAO was instructed by Bloch to cooperate with a planned Caltech visit to evaluate the feasibility of placing LIGO in Green Bank. Not only was the proposed 300 Foot replacement telescope in danger, but Vanden Bout worried that NRAO would be "slaughtered" by Bloch in future NSF budgets. Another meeting was scheduled for 23 February, but no one was clear what that would achieve.

Hearing about the NSF proposal to "forego the building of a successor radio telescope to the lost 300 Foot Antenna at Green Bank, and instead to site one of the elements of the LIGO gravity experiment there," MIT's Bernard Burke, flexing his muscle as a new member of the National Science Board, wrote to Bloch addressing the unique importance of the National Radio Quiet Zone. Burke argued that the continuation of the NRQZ would be uncertain without a replacement telescope as well as important scientific contributions that would result from constructing a state-of-the-art 100 meter telescope in Green Bank. ${ }^{90}$ Seielstad and Vanden Bout were regularly kept informed by Byrd staffers Terry Sauvain and Carol Mitchell about the continuing discussions between Byrd and Bloch on the merits of building LIGO in Green Bank. Aside from producing the letter from Tyson, NRAO refrained from criticizing 
the Caltech/MIT LIGO project, but Bloch and the NSF continued to resist the idea of building a new radio telescope in Green Bank. NSF head of Math and Physical Sciences, Richard Nicholson suggested to Byrd that LIGO would produce a Nobel Prize for West Virginia. Bloch and Nicholson were certainly not oblivious to the fact that Byrd's counterpart Chair of the House Appropriations Committee was from Livingston Parish in Louisiana where one of the LIGO elements was to be sited. Following his visit to Green Bank, Vogt was impressed with the infrastructure although concerned about access, and reported back to Bloch that Green Bank was indeed a suitable site for LIGO.

Input from the Congressional Research Service The US Congressional Research Service (CRS) was originally organized in 1914 as a special reference unit within the Library of Congress. In 1946 it was renamed the Legislative Reference Service and in 1970, it received its present name. The CRS offers bipartisan confidential research assistance to Members of Congress and their staffs. Their reports, while not classified, are not public unless the requesting Member of Congress chooses to make them public. According to the CRS web site, ${ }^{91}$ the CRS is available to Congress $24 / 7$ to offer authoritative, confidential, and objective analysis of current policies and present the impact of proposed policy alternatives.

Richard Rowberg was the Chief of CRS Science Policy Division when, on a Saturday night, he received a telephone call at his home from Terry Sauvain. Senator Byrd, explained Sauvain, wanted the CRS to tell him which was better for West Virginia, LIGO or a radio telescope. ${ }^{92}$ Rowberg's background was in plasma physics, but he knew who was who in physics and astronomy. To respond to Byrd's request, he talked to a lot of people, including Tor Hagfors, director of the Arecibo Observatory, as well as scientists at the Lawrence Berkeley Laboratory in California.

On 17 February Rowberg sent Senators Byrd and Rockefeller a memorandum addressing the question of whether LIGO or a radio telescope would best benefit West Virginia. ${ }^{93}$ The CRS report made clear that the issue was not about the scientific merits of building LIGO, but the benefits to West Virginia and the nation's scientific enterprise, and argued that "LIGO is likely to be built in any case, so the principal scientific question centers on the consequences to radio astronomy of not replacing the 300 Foot Telescope." Rowberg went on to discuss the issues of the number of personnel that would be involved in each project; the attention and scientific prestige that each project would bring to Green Bank and West Virginia; the impact to astronomy of not replacing the 300 Foot; the number of scientific users; and the potential for including West Virginia University in collaborative research. Describing LIGO as "a high risk experiment," the report noted that the successful detection of gravity waves would be "a major step in physics," but that it "will require a substantial advance to the limits of current technology."

Meanwhile, Caltech's LIGO Director Robbi Vogt was not going to let an opportunity for a Congressional earmark slip past. In a 24 February telephone 
call with Rowberg, Vogt suggested that perhaps their previous concern about ground noise in Green Bank was unfounded and that one of the LIGO elements could be built on the Green Bank site. Since only signals detected by both LIGO elements would be considered as due to gravity waves, Vogt suggested that any ground noise generated by only one element of the observatory would be unimportant. The Green Bank site was attractive to Vogt since there appeared to be local opposition to constructing LIGO in Maine. Moreover, argued Vogt, it would save the NSF a lot of money if LIGO could make use of the infrastructure that would be provided by the Green Bank radio observatory. But he also worried that unless a new radio telescope were to be built, the Green Bank site might likely be closed. In a 27 February memo to Byrd and Rockefeller's staff, the CRS reported that for this reason Vogt "hopes that a replacement telescope is built" in Green Bank. However, others argued that ground noise must be reduced as much as possible, and that activities surrounding the operation of the radio telescope would have significant impact to the effectiveness of LIGO, and so even the 140 Foot would need to be closed if LIGO were located in Green Bank. ${ }^{94}$

As initially planned by Sauvain, a 23 February meeting, presumably to discuss the input from the CRS, was to exclude NRAO. The meeting was postponed to 6 March, and at Byrd's insistence Hughes, Seielstad and Vanden Bout did finally attend, along with Bloch and Ray Bye, head of the NSF Legislative Affairs staff. This meeting was held not in Byrd's Office, but in the luxurious Senate Appropriations Hearing Room. Again Rockefeller was late, which gave Byrd time to tell more stories about the Presidents he had worked with. As expected, Bloch made a strong push for LIGO, referring to potential prestige and increased jobs for West Virginia. NRAO countered with the important science anticipated from the new radio telescope and the many prestigious discoveries already made by radio astronomers. Vanden Bout played hardball, pointing out that without a new radio telescope in Green Bank, in the face of declining budgets and commitments to the VLA and VLBA, the Observatory would be forced to leave Green Bank. The meeting closed with the NRAO representatives being excused while the Senators and their staffs continued to speak with the NSF. Apparently it didn't go well for Bloch, because he stormed out of the meeting room ignoring Vanden Bout and Seielstad on the way out.

On 7 March, the Senators issued a joint statement extolling the virtues of both LIGO and a replacement radio telescope, but argued that the collapse of the 300 Foot "radio telescope created an emergency situation ... that requires replacement at the earliest possible time." Working from the CRS report, they went on to point out that "replacing the telescope is also important to West Virginia from the standpoint of jobs, payroll, education, tourism and scientific prestige." Byrd was quoted as saying that he intended to "aggressively pursue funding" for the telescope. ${ }^{95}$ Two days later the West Virginia Legislature unanimously passed a joint resolution urging Congress and the NSF to provide funding for a state-of-the-art fully steerable 100 meter diameter telescope to 
replace the collapsed 300 Foot. Discussion of the proposed bill on the floors of the WV House of Delegates and the Senate emphasized the economic impact to West Virginia and the additional jobs that the new telescope would bring to Pocahontas County.

On 14 March, the House Committee on Science, Space, and Technology held hearings on the NSF's 1990 budget request. Four radio astronomers, including Arecibo Director Tor Hagfors, testified on astronomy issues. There was agreement on the importance of replacing the 300 Foot, but concern that there were other higher priorities in astronomy that were already in the budget request. However, if new money were to be added to the FY1990 budget, the group felt that this would not be considered as circumventing the peer review process. ${ }^{96}$ A week later, in a private note to Terry Sauvain, Rowberg pointed out that the NSF FY1990 budget request included \$10 million for safety and environmental upgrades to the US Antarctic facility, as well as $\$ 250,000$ for the start of repairs to the 25 year old Upper Atmospheres Facilities, neither of which had undergone formal peer review.

Although Robert Byrd ruled the Senate with an iron fist and usually got his way, he had two potential challengers to his plans for Green Bank: Representative James Whitten (D-MS), Byrd's counterpart as Chair of the House Appropriations Committee, and NSF director Erich Bloch. While the NRAO director and AUI president were kept in the dark about where Byrd and Whitten stood on the issue of LIGO vs. the radio telescope, George Seielstad claimed only he, Byrd, and an unnamed informant knew that the decision had already been made in favor of the radio telescope. But Seielstad was worried that due to the lack of a public statement about the future of Green Bank, his staff were leaving, and he was anxious to get started on constructing the new telescope.

Each year the US Congress passes an emergency supplemental funding bill which normally covers the cost of repair and recovery from things like tornadoes, earthquakes, floods, and fires that had occurred during the previous year, but is also used as a catch-all for a variety of other funding issues of special interest to Members of Congress. The Dire Emergency Supplemental Appropriations and Transfers, Urgent Supplementals, and Correcting Enrollment Errors Act of 1989 or HR-2402 included, among other things, a prohibition on the use of Department of the Interior funds to place the Al Capone House in Chicago, Illinois, on the National Register of Historic Places.

Based on the NLSRT report, Seielstad and Vanden Bout had stated that a new telescope would be 70 meters (230 feet) in diameter and would cost about $\$ 50$ million. Either Byrd misunderstood, or deliberately chose to appear that he misunderstood, and with the agreement of White House Office of Management and Budget Director, Richard Darman, Robert Byrd inserted \$75 million into the FY1989 Senate Dire Emergency Act for the replacement of the NRAO 300 Foot Radio Telescope. In the House of Representatives, the radio telescope was competing with a pet project of the House Appropriations Committee Chair Jamie Whitten and a White House initiative for the war on drugs. 
In a compromise with the House of Representatives, the final bill, which became Public Law 101-45, spread funds for the radio telescope over two years. A similar amount was included for Whitten's project in Mississippi, as well as funds for the war on drugs. On 23 June 1989, the House bill passed by a vote of 316-8 and the Senate approved it by a voice vote. ${ }^{97}$ A week later, it was signed into law by President George H. W. Bush. However in 1990, as a consequence of the Gramm-Rudman-Hollings sequestration for FY1990, the GBT construction funds were reduced to $\$ 74,490,000$.

Trying to avoid the stigma of apparent "pork" that the NSF and especially Erich Bloch were so strongly opposed to, Byrd noted when introducing the bill in Congress the priority placed by radio astronomers in replacing the fallen telescope, which he described as a "calamity." In fact, replacing the 300 Foot was not the highest priority in radio astronomy, even at NRAO, which was trying to obtain funds to construct a new array that would give astronomers an unprecedented opportunity to study the Universe at millimeter wavelengths. Meanwhile, the NSF was faced with a quandary. To oppose the powerful Senators might risk future budget allocations, but to agree to building a new telescope apparently meant compromising their stated priority for LIGO as the next major NSF construction project, as well as their commitment to the merits of peer review and their opposition to Congressional "earmarks."

Unlike NASA, the NSF for years did not have a standing budget line item for new facilities. However, by unwritten agreement, the 1989/90 GBT funding became the first funding for what later became the NSF's Major Research Equipment (later called Major Research Equipment and Facilities Construction or MREFC) budget, which later funded LIGO, the Atacama Large Millimeter Array (ALMA), the Next Generation Solar Telescope (NGST), and most recently the Large Synoptic Survey Telescope (LSST). At first the MRE/ MREFC budget line was confined to the NSF's Directorate for Mathematical and Physical Sciences (MPS), but with time soon covered all of the NSF. Nevertheless, the NSF has always been on record as being opposed to Congressional earmarks, and subsequent declining NRAO budgets and consideration of closing the Green Bank facility as well as the Very Long Baseline Array (VLBA) may have reflected the Foundation's resentment of the perceived political pressure brought to bear in funding the new Green Bank Telescope.

\subsection{Building the Green Bank Telescope (GBT)}

Typically, before a large new scientific instrument is built, it takes years of proposals and committee reviews, accompanied by forceful lobbying of lawmakers, as well as getting other scientists on board, each of whom have their own priorities. Especially in the case of proposed national observatory projects by NRAO and NOAO, university-based scientists are particularly skeptical and concerned that the national observatory project may come at the expense of their individual research grants. Although NRAO had managed to finesse 
funding in what was surely a record time of only about six months, its problems were only beginning. By April 1989, with input from several prospective manufacturers, NRAO had completed a re-evaluation of the technical options for 100 meter antennas with both blocked and unblocked apertures. The goal was to have good performance at $7 \mathrm{~mm}$ wavelength, and perhaps at $3 \mathrm{~mm}$ wavelength under the most benign conditions of wind and solar illumination. Recognizing that the largest unblocked aperture antenna which had ever been built was only 7.5 meters effective diameter, the NRAO study group recommended that a more detailed structural analysis be carried out. A homologous design did not appear feasible due to uncertainties in the computer modeling, fabrication tolerances, and the high cost of fabricating the large number of different-sized back-up structure members.

In late April 1989, Vanden Bout appointed a small team under the leadership of Seielstad to prepare a proposal. On 30 June, the same day that Congress authorized GBT funding, AUI submitted a hastily prepared formal proposal to the NSF for the construction of a fully steerable radio telescope with an "aperture of at least 100 meters," two arcsec pointing accuracy under good conditions, an active surface control, and operating wavelengths from 3 millimeters to meter wavelengths. ${ }^{98}$ The proposal discussed, as an option, an unblocked aperture with an offset feed. It was no secret that, as a result of Senator Byrd's deft maneuvers in Congress, a total of $\$ 74.5$ million was available for the project. NRAO engineers estimated that the construction costs would be about \$58 million leaving somewhat less than the \$20 million needed for project management and to build state-of-the-art receivers and other instrumentation for the new radio telescope. But it was unusual that a project that was expected to take years to build would be funded over just two years. This meant that inflation would eat into the budget, especially if the design and construction were to take longer than anticipated, so there was some pressure to avoid delay in the subsequent procurement and construction process.

Although it was clear that the NSF would support the project and funds had already been appropriated by Congress, the NSF went through the motions of a formal peer review and appointed a review panel that met in Washington on 31 July-1 August 1989. Panel members noted the potential strong scientific impact, the value of the NRQZ, and the unequaled potential of a 100 meter unblocked aperture working to $3 \mathrm{~mm}$ wavelength. Both the mail reviews and the reports of review panel members gave strong endorsement to the GBT program. Indeed, none of the 15 reviewers who ranked the proposal gave it a grade below that of "excellent." Knowing that the project was already funded, the reviewers concentrated on technical tradeoffs such as frequency coverage, size, and the nature of the optics. Interestingly, nearly all reviewers argued for an unblocked aperture, despite the current existence of nothing with an unblocked aperture larger than the Bell Labs 7.5 meter mm antenna (Fig. 9.12).

Just six weeks after the proposal submission, the NSF added $\$ 500,000$ to NRAO's 1988 budget to "allow NRAO to begin a preliminary design study for the Green Bank Telescope." 99 However, it wasn't until 13 October 1989 

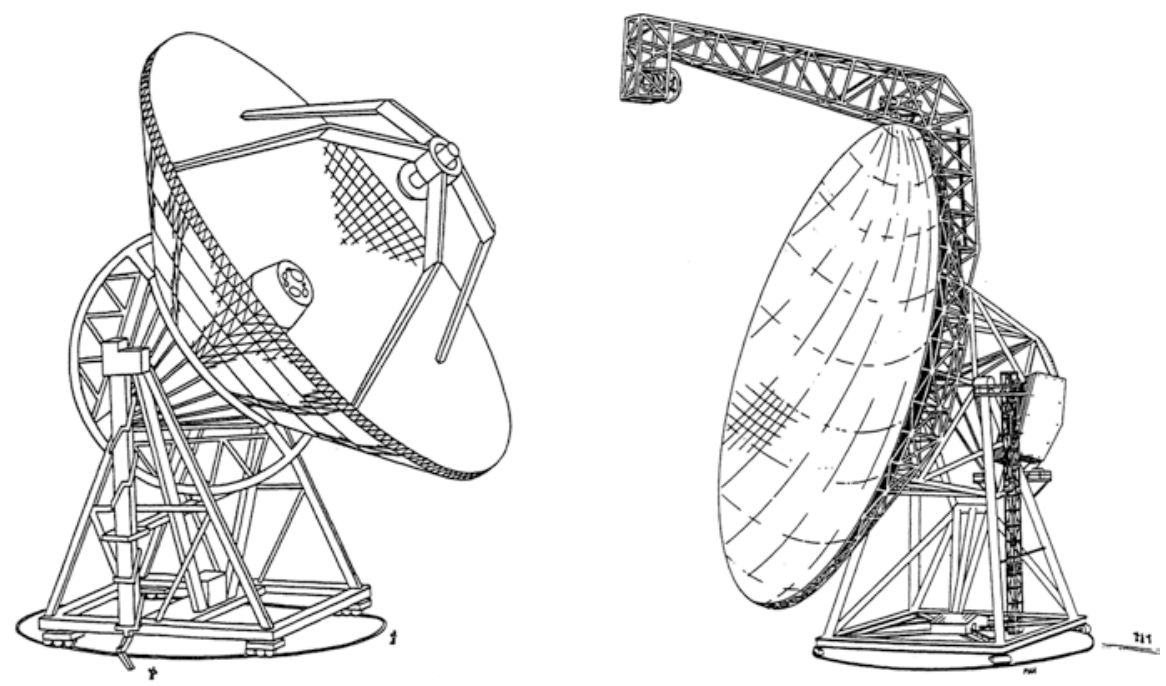

Fig. 9.12 100-meter telescope design concepts. Left: axially symmetrical design; Right: off-set reflector design. Credit: NRAO/AUI/NSF

that the NSF National Science Board got around to approving the funding for the preliminary design phase, after which a further $\$ 4.4$ million was added to the NRAO budget to complete the design phase of the GBT. A year later, the NSB unanimously approved the GBT construction for an amount not to exceed $\$ 69,590,000$ for a period of five years. Still nervous about the 300 Foot collapse, they requested "a complete design and structural review ... before manufacture and assembly of the telescope begins."100

NRAO did not want to merely duplicate existing radio telescopes, so proposed to build a novel state-of-the-art instrument that would have many years of productive life to deal with the wide range of scientific topics of interest to potential users. NRAO planned that the surface panels be controlled by a set of motorized actuators which would adjust the surface to compensate for the changing gravitational deflections as the telescope was moved in elevation, and ultimately to also compensate for the effects of wind and of thermal effects due to solar heating. In this way, it was argued the new telescope could be large and also have the precision to work at short wavelengths. More controversial was the issue of a well-understood conventional feed-sub-reflector support mechanism versus an asymmetric unblocked aperture. The asymmetric unblocked aperture offered reduced interference, improved spectroscopic capability, and higher efficiency, but at the expense of increased cost and complexity, as well as uncertain stability of the offset support structure which could introduce pointing uncertainties. The default was for a conventional symmetric structure, which was shown on the cover of the proposal to the NSF, but the possibility of an unblocked aperture and offset feed and asymmetric dish structure was 
also presented. It was estimated that an unblocked structure would cost about 12 percent more than for a conventional antenna of the same effective dimensions, but this would turn out to be far too optimistic. The main message from the astronomical community was to provide good high-frequency (i.e. $3 \mathrm{~mm}$ ) performance. Although a radome-enclosed structure was not seriously considered, Herbert Weiss, who played a major role in the design of the earlier CAMROC/NEROC 440 foot enclosed antenna, later argued that a radomeenclosed antenna with the same effective sensitivity would be as much as a factor of four less expensive. Weiss's argument, however, was based on an overly conservative estimate of receiver sensitivity resulting in a unrealistically small fractional increase in system noise from the radome. ${ }^{101}$

Due to the fast-track funding of the Green Bank Telescope, NRAO was in the probably unique but unenviable position where the funding was ahead of the design. Vanden Bout appointed a GBT Specifications Working Group, chaired by Seielstad, which met every two weeks. But it would be a year before NRAO was able to submit a call for proposals to construct a 100 meter equivalent projected area clear aperture telescope with an actively controlled surface. The manufacturer was held responsible for achieving an overall surface accuracy better than $1.25 \mathrm{~mm}$ rms. NRAO was to be responsible for the active controlled surface which had a goal of overall accuracy of $0.4 \mathrm{~mm}$ rms. Under perceived pressure to complete the construction and start a research program, the RFP called for the unrealistic completion of construction and the start of operations in 1995. ${ }^{102}$ During the debates about the antenna design parameters, the cumbersome term "NLSRT" was gradually replaced by reference to the generic "Green Bank telescope." When it came time to solicit proposals, George Seielstad declared, for the lack of a better name, that it be called the "Green Bank Telescope" or GBT, and that name stuck.

Former NRAO Director Dave Heeschen became the interim GBT project manager and stayed on as a consultant and advisor throughout the construction project. Heeschen made two difficult and far reaching decisions. Arguing that NRAO should not build just another telescope, he decided to go for the controversial off-axis asymmetric structure to give an unblocked aperture, and also to install an active surface that could be adjusted to compensate for gravity and ultimately the effect of solar heating induced effects of thermal gradients. Although there were some advantages to having the feed arm located at the bottom, such as improved accessibility and reduced spillover noise, the anticipated added cost of about $\$ 3$ million argued for placing the feed arm at the top of the structure. The additional complexity, weight, and cost suggested that a fully homologous structure be dropped, as the active surface could compensate for gravitational deflections to form a best-fit parabola on a partially homologous structure.

Faced with demanding antenna specifications and a fixed budget, NRAO needed an experienced person to oversee the GBT construction. Out of 40 applicants, NRAO appointed Robert Hall as the GBT Project Manager. Hall, who had been an infantry commander during WWII, had previously designed 
the NRAO 85 foot antennas and consulted on the design of the 140 Foot Telescope while working at Blaw-Knox, the NRAO 36 Foot mm Radio Telescope while working at Rohr Corporation, and contributed to the design of NRAO 300 Foot Transit Radio Telescope. Hall had also overseen the construction of a number of antennas of the JPL Deep Space Network, including the 210 foot antennas at Goldstone, California; Tidbinbilla, Australia; and Madrid, Spain. As was done for the VLA and VLBA antennas, NRAO, under the leadership of the Observatory's structural engineer, Lee King, and with support from JPL, prepared an engineering design which the prospective manufacturer was free to use. However, as was the case for the VLA and VLBA antennas, the request for proposals specified that the manufacturer would be responsible for all aspects of the design and for meeting the performance specifications. This aspect of the GBT proposal process was later controversial and part of the basis for claims against NRAO/AUI and the NSF for payments of nearly $\$ 30$ million, resulting from alleged changes in the GBT design made by NRAO after the construction contract had been signed.

On 1 June 1990, NRAO mailed a Request for Proposals (RFP) to prospective bidders, and three weeks later held a Preproposal Conference in Charlottesville. By this time, NRAO had become convinced that an unblocked clear aperture antenna was highly desirable and was feasible within the anticipated $\$ 55$ million construction budget. Some 60 individuals with interest in some aspect of the GBT construction participated in the Charlottesville conference. Proposals were due on 1 October. NRAO received three bids for the construction of the GBT: from Brown \& Root Services Corp., from the FruCon Corp, and from Radiation Systems Inc. (RSI), which had contracted with Ted Riffe, the retired NRAO Associate Director for Administration, to help prepare their bid. The bids ranged from a low of $\$ 57$ million from RSI, to a high of \$103 million from the Fru-Con Construction company. Fru-Con had teamed with the German MAN and Krupp consortium that had designed and built the MPIfR 100 meter Effelsberg radio telescope, while RSI partnered with Ford Aerospace and Electrospace Industries. The third proposal came from another consortium led by the Brown \& Root Services Corporation. Brown \& Root were joined by TIW Systems and the Vertex Communications Corporation to propose building the GBT for $\$ 83$ million. The large spread in bids raised flags, but with no prospects for an increased Congressional appropriation, the three "prime proposers" were asked to reconsider their bids and to suggest appropriate cost savings by 9 November. Although some changes were subsequently made, only the RSI bid was within the available funding, although in many areas, one or other of the competing but more expensive proposals were judged to be superior. ${ }^{103}$

Under the leadership of its dynamic and ambitious president Raymond (Dick) Thomas, RSI had considerable experience in constructing radio telescopes and had been involved in the 1970 resurfacing of the Green Bank 300 Foot and the 1973 resurfacing of the 1000 foot Arecibo radio telescope. RSI also constructed the panels for the 28 VLA antennas and was the prime con- 
tractor for the ten VLBA antennas. RSI itself was composed of a number of fiscally independent subsidiaries located in Texas, Illinois, Florida, New Jersey, Nevada, and Georgia, as well as at their headquarters in Sterling, Virginia, and an office in the UK. Antenna fabrication was done primarily at the Universal Antennas Division, which was licensed in Nevada but had its construction facility in Richardson, Texas. Interestingly, Thomas was first inclined to bid for the full $\$ 75$ million, which was widely known to be NRAO's budgeted amount, but Riffe pointed out to Thomas that the $\$ 75$ million would need to include instrumentation for the telescope as well as NRAO's project management costs, so Thomas reduced his bid first to $\$ 57$ million, and then under pressure from NRAO to $\$ 55$ million. ${ }^{104}$

On 6 December 1990, the NSF added \$65 million to the AUI cooperative agreement for the Green Bank Telescope project, ${ }^{105}$ and on 19 December, AUI signed a contract with RSI for a firm fixed price of \$55 million with an aggressive completion date of 31 August 1994 . $^{106}$ To keep within the \$55 million cost constraint, NRAO and RSI agreed to divide the project into two parts. First, a basic telescope that would be built by RSI using well understood engineering and construction practices and would operate up to $15 \mathrm{GHz}$, and second, a supplementary system designed and built by NRAO to enable operation first to $43 \mathrm{GHz}$ then to $100 \mathrm{GHz}$. To achieve the required performance, NRAO proposed to use a system of actuators to adjust the surface to compensate for gravitational deformations as the telescope was tilted. A second phase would compensate for thermally induced deformations. The even more demanding task of accurately pointing the huge structure at the desired position in the sky and maintaining that position as the Earth rotates was also divided into two phases; the first using "conventional techniques" to be implemented by the antenna manufacturer, and the second to be developed by NRAO, using an elaborate system of lasers and retroreflectors to achieve the "precision pointing" and surface accuracy required for operation at the shorter wavelengths. It later turned out the RSI concept for the GBT did not meet the required surface accuracy by an order of magnitude, and RSI had underestimated by a significant amount the weight of the antenna. ${ }^{107}$ Recalling the embarrassing collapse of the 300 Foot Telescope, members of the NSF's National Science Board Committee on Programs and Plans expressed concern about the structural integrity of the GBT design and called for a design and structural review that was held at the NSF on 10 October 1991. In order to provide scientific support to the GBT project, Jay Lockman was appointed as GBT Project Scientist, but was later replaced by David Hogg after Lockman replaced Seielstad as Green Bank Site Director in 1993.

Behind Schedule, Over Budget Groundbreaking for the ambitious GBT project occurred on 1 May 1991, and construction work began a few weeks later (Fig. 9.13). However, it would be ten years before the GBT was completed, and even longer before the challenging project was fully instrumented and operational at the planned shortest wavelengths. Not having adequate in-house 


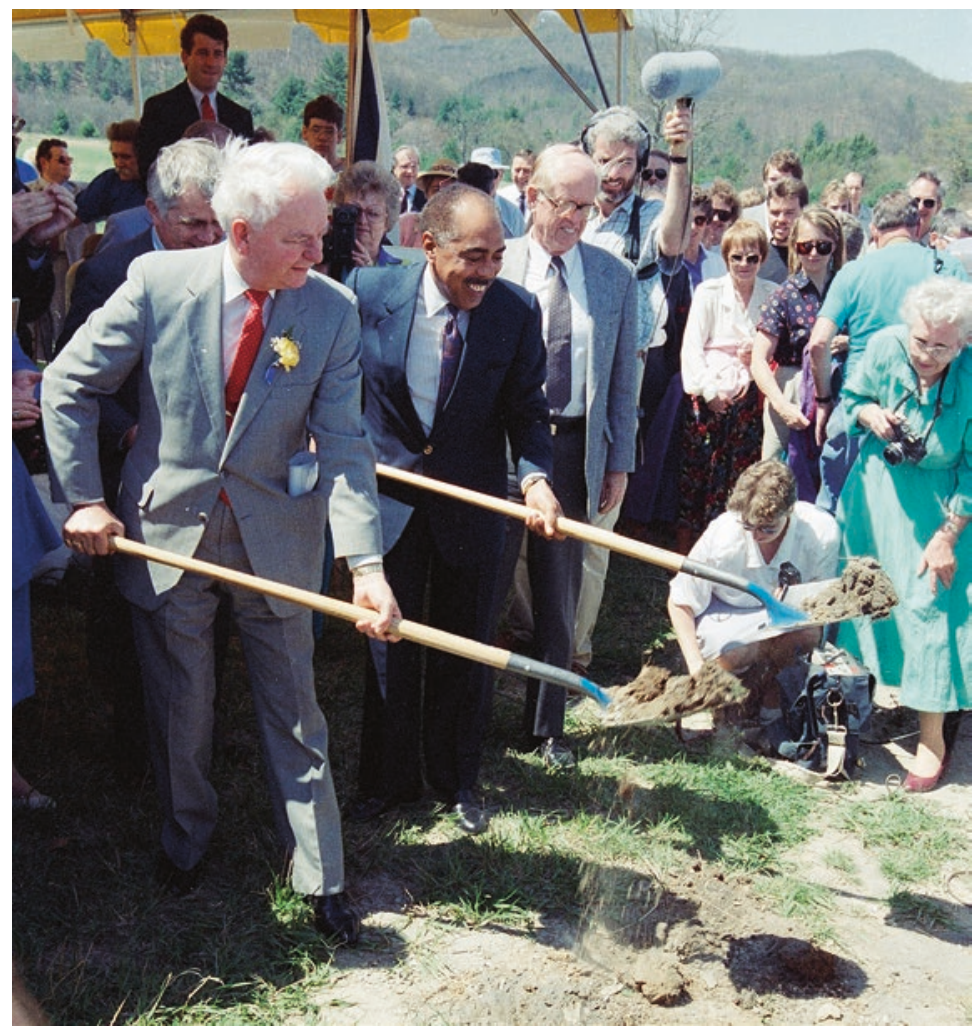

Fig. 9.13 Groundbreaking for the Green Bank Telescope on 1 May 1991. From left to right are Senator Byrd, NSF Director Walter Massey, and AUI President Robert Hughes. Credit: NRAO/AUI/NSF

engineering expertise, RSI sub-contracted the design to the California-based Loral Aerospace Corporation (previously Ford Aerospace), which had extensive experience in the design of radio telescopes. The Loral design, according to NRAO, did not meet the contract performance specifications, and NRAO offered its own optimized design.

In early 1991, Dave Heeschen expressed concern about "various suggestions to modify and/or expand some of the telescope specs" and cautioned against trying to evaluate or optimize the RSI design. ${ }^{108}$ In 1992, NRAO called attention to a number of apparent deficiencies in the RSI design, and expressed "concern about the marginal aspects of the designs presented." 109 Already in 
1992, in view of the optimistic completion date in 1994, Green Bank staff were building receivers and other instrumentation, and optimistically planned to return the NRAO GBT project team back to Green Bank operations by the end of 1994. But by now problems began to appear with the telescope construction. The actuators needed to correct the surface for deformations due to gravity were found to be causing radio frequency interference (RFI) which if not corrected would limit the performance of the radio telescope. Also, testing of the actuators indicated that they would not meet the lifetime specifications due to excessive internal wear. In mid-1992, Loral discovered that some of the tipping structure members would collide with the fixed alidade structure, requiring an altered geometry of the tipping structure, which in turn led to overstress in some structural members. By mid-1993, the design of the tipping structure by Loral was still not complete, and in June, RSI informed NRAO that the GBT completion would be delayed by a year until the end of 1994. In response, NRAO/AUI sent RSI a notice that RSI had defaulted on the contract, to which RSI reacted by sending a similar notice of default on the design contract to Loral. In an effort to mitigate the Loral design deficiencies, NRAO, with the assistance of JPL, offered an optimized design which met all specifications and was incorporated by Loral/RSI, ostensibly with RSI assuming responsibility for the design. Later this proved to be contentious as RSI interpreted the NRAO/JPL optimized design as a change order that they argued increased the construction costs and should be at the expense of NRAO/ AUI. Within NRAO, the impending delay was not considered all that bad, as it would give NRAO more time to develop, fabricate, and test all the electronics systems including the active surface and precision pointing system.

Even with the projected delays, it was not expected that these in-house tasks would be completed by the antenna delivery time, although as noted by GBT business manager William Porter, "they will be more mature than if there were no delay." 110 Nor was the delay completely unexpected, since as early as 1989 , following discussions with TIW's Louis Becker, NRAO Engineer Larry D'Addario had called attention to the unrealistically short planned construction schedule. He then predicted that it would be late 1995 before the antenna would be completed. In 1994, the antenna contractor reported a new completion date in late 1996, which was later further delayed to March 1997. Following a series of review meetings, the re-baselined schedule placed the GBT delivery date at 15 December 1996, which later slipped to April 1998, and then due to safety issues with the derrick needed to lift the structural members "no sooner than the end of 1998." By April 1998, RSI reported that the GBT would be completed in October 1999, which became the end of 1999. These delays naturally resulted in increased personnel costs which NRAO had to absorb outside the fixed GBT project budget. In spite of the numerous delays in completing the antenna structure by the contractor, NRAO realized that due to poor NRAO management, it would be difficult to have the necessary software ready in time to support the commissioning of the GBT. ${ }^{111}$ Moreover, development of receivers, spectrometers, and other ancillary instru- 
mentation was delayed, as the small Green Bank engineering staff was continually called upon to support existing and ongoing Green Bank telescope operations at the expense of developing GBT instruments. The GBT was not handed over by RSI to NRAO/AUI until the end of 2000, some months after the formal dedication, whose schedule was apparently set by Senator Byrd's reelection campaign.

With the new design, the weight of the moving structure was only slightly over 9 million pounds, roughly 15 percent less than the Loral design, and was estimated to save RSI more than \$1 million in the cost of steel. But a problem appeared following the analysis of the dynamic pointing model which indicated that following the repositioning of the antenna, the off axis feed arm would vibrate for up to one minute with an unacceptably large amplitude that would limit the performance of the telescope, particularly at high frequencies where the primary beamwidth is as small as ten arcseconds. It would be years before this problem was adequately resolved. As described by Dave Heeschen, "new problems arise as fast as older ones get resolved, and it is not at all clear that any real progress is being made." With great prescience, Heeschen added, "in the case of RSI we need a paper trail in case we ever get into a legal hassle with them." 112

Meanwhile, the AUI Board of Trustees requested a written report from the NRAO director to explain the "causes and consequences of the delay in the GBT schedule." 113 The Board also noted with some unease the use in the GBT construction project of personnel paid from NRAO operating funds. A routine audit of the project by the Government Accounting Office (GAO) expressed alarm about statements in a letter from Hall to RSI "regarding the unacceptability of portions of the design and NRAO's concern about the overall safety and performance of the structure." 114 Hall defended his letter by telling Vanden Bout that "such statements are characteristic of tough contract management and should not be over interpreted by those outside the project," and concluded that "the final design will show a structure which is safe and will perform to specification." $" 115$

The construction of the unconventional complex structure presented many unanticipated challenges. Two-thirds of the welders applying for jobs were deemed not qualified for the task. During the course of construction, an unfortunate accident led to the tragic death of one of the RSI ironworkers. On 16 November 1993, as several workers were lowered from the structure, they lost communication with the crane operator, apparently due to the failure of the batteries in their radio. While changing batteries, the basket carrying the workers apparently hung up on a rope safety line. The basket tilted, and one of the workers fell 120 feet to the ground and was killed. The subsequent investigation by OSHA uncovered a variety of alleged safety violations, mostly unrelated to the accident, but which incurred various monetary penalties.

In a rush to demonstrate that they were on schedule for the proposed 1994 completion date, RSI hastily began work by building the telescope foundation, just four months after the start of the Loral design work and well before the 
design was finalized. The foundation design was based on an estimated moving weight of about 12 million pounds. However, the foundation was only marginally adequate for a 12 million-pound load, and by the time the design was finished another 5 million pounds had been added to the structure, in the form of welding, paint, and the additional members needed to strengthen the structure to meet performance specifications. Pressured to meet the ambitious construction schedule, joints and backup structure beams were fabricated before the design was optimized by NRAO, creating a challenge to find appropriate locations to place the prefabricated members. This led to later litigation about whether NRAO's introduction of the optimized design constituted a change order leading to increased costs. In a further effort to speed up the construction, RSI did not accept Bob Hall's urging to trial-erect some of the antenna substructures at their plant in Mexia, Texas, and as predicted by Hall, this resulted in schedule delays and further increased costs. Tensions between NRAO and RSI staff, as well as among Green Bank Site Director Jay Lockman, Project Scientist Harvey Liszt, and Project Manager Bob Hall became a further challenge to completing the radio telescope and meeting the design specifications. Meanwhile, a heated debate arose within NRAO about the location of the GBT control building. Some argued for a location well removed from the telescope to minimize interference by people coming and going; others, led by Jay Lockman, argued for a more conventional location close to the telescope, where scientists and engineers could best interact with the instrumentation. In the end, a committee appointed by Vanden Bout recognized that there were no funds for a separate control building, and opted to place all the control in the new wing of the Jansky Laboratory, a decision which led to the resignation of Lockman as the Green Bank Site Director.

In June 1993, when RSI acknowledged that the GBT delivery date would be delayed by one year to 31 December 1995 and hinted that even this might be optimistic, NRAO refused to approve the delay, telling RSI to find a way within two weeks to explain what measures RSI would take to recover the schedule. RSI responded that they had already taken all possible options to reduce the completion time, and that the end of 1995 represented a reasonable schedule. Already, NRAO and RSI were setting the stage for what would prove to be a lengthy and costly litigation.

Faced with schedule slippage and escalating costs, in June 1994 RSI was acquired by the Communications Satellite Corporation (COMSAT) which formed COMSAT RSI Technical Products (CRSI or CRSI-TP) to handle their antenna business, including the completion of the GBT. But in July 1996, COMSAT CEO Bruce Crockett was ousted by the controversial Betty Alewine, who had her own agenda for COMSAT. Within a year, half of the 3,000 member COMSAT staff had left. Faced with their own financial troubles, and unable to find buyers for its shares in the Denver Nuggets basketball and Colorado Avalanche hockey teams, COMSAT sold CRSI to a subsidiary of TBG Industries Inc. But COMSAT was unable to divest the GBT contract which was then transferred to a newly formed COMSAT subsidiary, COMSAT 
Radiotelescopes Inc. ${ }^{116}$ However, CRSI-TP still retained the subcontract for the 2004 precision surface panels as well as for the drive motors and servo systems. COMSAT Radiotelescopes Inc. set up a new office in Herndon, VA, close to the CRSI facility in Sterling, whose sole responsibility was to oversee the completion of the GBT. John Evans, the former director of the MIT Haystack Observatory and one of the pioneers of radar astronomy, became the COMSAT Vice President and Chief Technology Officer and was given direct responsibility for the GBT construction until its completion in 2000. In 1998 COMSAT became part of Lockheed-Martin Global Telecommunications which had previously absorbed Loral, the company that did the complex GBT engineering design for RSI.

Claims and Counterclaims In the autumn of 1995, CRSI lodged a claim that, as a result of multiple continuing design changes, NRAO/AUI was responsible for a significant cost overrun of \$14 million. Later, CRSI increased their claim to $\$ 29$ million. Not receiving any resolution of their claim after more than a year, the new CRSI president Raymond Thomas (no relation to the former RSI President Dick Thomas) first threatened to stop work on the telescope, but then wrote to NSF Director Neal Lane, suggesting that the NSF provide additional funding for the GBT project, and that COMSAT would not be able to complete the telescope without additional funding. ${ }^{117}$ A few months later, Thomas followed up with a letter to Senator Byrd arguing that NRAO had modified the specifications and "requesting your support for increased funding of approximately $\$ 29,000,000 \ldots$ for the GBT." 118 The COMSAT claim was based on alleged unnecessary design work, an unreasonable life cycle specification, and inappropriate wind-load requirements. In response, NRAO/AUI argued that the design changes were necessary to meet the performance specifications as outlined in the construction contract. Moreover, parts were shipped to Green Bank in the wrong order, and poor workmanship resulted in time consuming repeated welds, structural elements that needed to be returned to the factory for reworking, or work that had to be done in the air after beams or joints had been erected. A particularly contested item was the number of expected antenna cycles and the corresponding impact to metal fatigue. NRAO/AUI countered with claims of $\$ 12$ million for six years of increased project management costs, lost research time, the cost of operating the 140 Foot Radio Telescope for an additional six years, and the impact to science and NRAO's reputation. ${ }^{119}$ Dave Heeschen described what he referred to as CRSI "bungles," which led to a 30 percent increase in weight, which in turn led to a greatly increased cost and a "telescope dangerously close to its survival and performance limits." 120

Nevertheless, NRAO/AUI realized that the legal costs associated with a protracted dispute could well approach $\$ 5$ million, and suggested that it might consider settling at a level of "something more than one million dollars," but not at "the thirty odd million dollars sought," and then only if it led to an early completion of the telescope construction. ${ }^{121}$ In August 1997, Vanden Bout 
offered to settle for $\$ 4.5$ million, but this was rejected by COMSAT, which made a counter-offer to settle for $\$ 15$ million. ${ }^{122}$ NRAO later offered to settle for $\$ 9$ million, but it was rejected by COMSAT as being insulting. ${ }^{123}$ To support their position, NRAO/AUI contracted with the accounting firm of Ernst \& Young to audit CRSI's records to determine the merit of the claimed increased GBT construction costs. A later dispute arose when AUI accused Ernst \& Young of excessive charges. Meanwhile, CRSI was involved in a similar dispute with Cornell University. CRSI had contracted with Cornell to upgrade the Arecibo radio telescope, but claimed that their cost overrun of $\$ 7$ million was because Cornell had not fully disclosed "complete and accurate" information about the upgrade project and associated site limitations. ${ }^{124}$

During this same period, there was a major upheaval at AUI. For decades NRAO had enjoyed the valuable stewardship of AUI, which also managed the much larger Brookhaven National Laboratory under a contract with the Department of Energy. Brookhaven had about ten times as many employees as NRAO and a corresponding budget that was an order of magnitude larger than the NRAO budget. Not surprisingly, the membership of the AUI Board was dominated by scientists with interests and experience in nuclear physics, and many of the activities of the AUI Board were devoted to Brookhaven affairs. But traditionally, the AUI Board members, and especially the AUI President, were always available to help with particular issues that might arise at NRAO. Since 1980, Robert Hughes had served as AUI President working effectively with the NSF and Department of Energy (DOE) to help both Brookhaven and NRAO. Prior to assuming his position at AUI, Hughes had been a Professor of Chemistry at Cornell University, and in 1975 he became NSF Assistant Director for Astronomical, Atmospheric, Earth and Ocean Science, until he returned to Cornell in 1977. Hughes stepped down as AUI President in 1996, and Lyle Schwartz, who was formerly at the National Institute of Standards and Technology and the University of Maryland, became the new AUI President in March 1997.

By this time, rumors were circulating around Long Island that Brookhaven was dumping radioactive tritium which was contaminating the local drinking water. New York Senator Jacob D'Amato took up the war against Brookhaven, which argued that even if one drank a bathtub full of the local water every day, the radiation exposure would be less than that of a dental x-ray. But D'Amato persevered and following an investigation, the new DOE Secretary Frederico Pena, acting under pressure from the Senator, unilaterally dismissed AUI as the manager of Brookhaven, citing careless handling of a 12 year leak of radioactive tritium into the local ground (drinking) water. ${ }^{125}$ The loss of 90 percent of its financial basis and embarrassing discredit raised questions at the NSF as to whether AUI would be able to continue to perform its obligations to NRAO. ${ }^{126}$ The subsequent defections of a number of AUI Board members led to a restructuring of the AUI corporate structure as a self-perpetuating not-forprofit corporation. No longer were Board members representing their home universities, but rather were independent scientists and administrators. With 
only NRAO left to manage, the Board became more dominated by astronomers, some of whom had their own agendas, and after the Brookhaven experience, AUI naturally took a heavier hand in managing NRAO. Within a year, Schwartz resigned as AUI President, and Cornell Professor and AUI Trustee Martha Haynes became Interim President in April 1998, in the midst of the NRAO/AUI-CRSI dispute. Following a national search, Riccardo Giacconi, a pioneer of x-ray astronomy and later winner of the 2002 Nobel Prize in Physics for his pioneering work leading to the discovery of cosmic $\mathrm{x}$-ray sources, was appointed AUI President in July 1999. Giacconi was well known as a strongwilled, no-nonsense individual who had previously served as the first director of the Space Telescope Science Institute and later the director of European Southern Observatory.

In case of dispute, the NRAO-RSI contract called for binding arbitration in lieu of a lawsuit. AUI had hired William (Randy) Squires, who later joined the Seattle based Summit Law Group, to represent NRAO/AUI. By the end of 1997, CRSI had submitted a demand for arbitration to settle their claim of \$29 million. NRAO/AUI denied responsibility for any increased CRSI costs and submitted a counter claim for $\$ 3.8$ million that CRSI moved to dismiss and which Squires described as "bereft of legal gunpowder." 127 Paul Vanden Bout recognized the need to keep the litigation issues from impacting ongoing construction work, so he appointed Dave Heeschen to lead a separate litigation team, which included NRAO scientists Dave Hogg and Harvey Liszt. They worked for several years with the legal team attorneys and staff to gather all relevant materials to reconstruct the decade-long record of design changes, delays, and communications between the manufacturer and subcontractors as well as between NRAO and the manufacturer. This included internal communications within NRAO and within RSI/COMSAT. Altogether NRAO/AUI spent over $\$ 5$ million to prepare their legal defense.

Jacob Pankowski, of McKenna \& Cuneo L.L.P., was the primary attorney for COMSAT, but at various times COMSAT used two other Washington, DC-based law firms to develop their case. COMSAT argued that "the requirement for 400,000 antenna cycles was unreasonable and unprecedented and that the impact to the design greatly increased the weight of the structure and extended the schedule," thus adding to the cost. Moreover, COMSAT claimed that the 400,000 cycles requirement was not specified in the request for proposals, that they were given inadequate guidance on how to calculate wind loads on the structure, and that after the design was nearly complete, AUI imposed an additional optimization process that was not a contract requirement and caused additional design effort which stretched out the program. COMSAT also rejected AUI's claim for damages suffered as a result of additional management costs associated with the delay and for the costs of using the less effective 140 Foot Telescope on the grounds that AUI would be reimbursed for these costs by the NSF. ${ }^{128}$

AUI contended that based on "excessive pride and self-confidence RSI had aggressively sought the contract to design and build the GBT, although they 
appeared to lack the understanding of the project's requirements and the capability to complete the design and construction of the GBT. Specifically, AUI argued that RSI/COMSAT's claims were "afterthoughts, dreamed up" to permit COMSAT to recoup their losses and argued that "RSI burdened its illconceived concept with a combination of poor or non-existent planning, lengthy and ineffective lines of communication and inexperienced managers." Furthermore, contended AUI, "RSI was hamstrung by the fact that its various subsidiaries utilized different, and apparently irreconcilable cost accounting systems that prevented project management from receiving accurate project fiscal performance information," and that "RSI did not recognize the magnitude of its overruns as they occurred." 129

NRAO's Associate Director for Administration, James Desmond, summed up AUI's position:

It is not often that the complexities of construction resolve in a way that permits a bona fide argument that a particular claims $[s i c]$ should be denied in its entirity $[s i c]$. This is one of those unusual cases. Under the circumstances, COMSAT cannot be blamed for hoping that the size of its loss would overcome the paucity of its proof. It has failed to make the required showing, however, and the claims should be rejected. ${ }^{130}$

COMSAT responded, "Only now, without a shred of evidentiary or other support, does AUI make its mean-spirited and bizarre attack." 131

As part of the "discovery" process, all records, notes, correspondence, technical calculations, etc. relevant to the GBT construction at both COMSAT and NRAO/AUI were made known to the other side. This involved copying costs at NRAO amounting to more than $\$ 100,000$. More than 100 boxes of papers lined the halls at NRAO's Charlottesville headquarters waiting for CRSI staff and their attorneys to review and copy as needed. Following some administrative reshuffling within the American Arbitration Association, the AUICRSI case was moved from the Washington Regional Headquarters to a new Case Management Center in Atlanta, Georgia, and placed on the "Large Complex Case Track." In January 1998, Alan Kent, who was an experienced government procurement attorney, was appointed by the American Arbitration Association as the Arbitrator. The arbitration hearing, which was scheduled to last only four weeks, was originally scheduled to begin on 18 January 1999 (later realized to be a federal holiday), but was repeatedly delayed at the request of the COMSAT attorneys. The hearing finally began on 23 October 1999 at a Hyatt hotel in Reston, Virginia, and did not conclude until late January 2000. During the hearing, it was revealed that Judge Kent and AUI Trustee Claude Canizaries had been college roommates, which almost resulted in a mistrial. Perhaps more important, Judge Kent was a WWII history buff and relished Bob Hall's tales of how he had served as an infantry officer under General George Patton. 
NRAO/AUI presented nearly 50 depositions taken from various experts and non-experts. Preparation of post-hearing briefs and responses to the posthearing briefs took nearly another six months, and review and deliberations by the Arbitrator yet a further six months. Finally, on 8 February 2001, Kent awarded COMSAT \$6.62 million for its claim and NRAO \$2.55 million for its counter claim. The Arbitrator recognized AUI's claim of the additional project management costs due to the COMSAT delays, but denied the claim of lost scientific data. Although the net cost to NRAO/AUI was only $\$ 4.07$ million, the real cost to CRSI for building the GBT was independently estimated by both NRAO and COMSAT to be about $\$ 120$ million, or $\$ 65$ million over the contract value. COMSAT received only the $\$ 55$ million contracted construction fee plus the $\$ 4$ million arbitration award. Vanden Bout noted that $\$ 4$ million amounted to only $5.5 \%$ of the total project cost and it was just that amount that he had offered COMSAT to settle in lieu of arbitration. But NRAO/AUI had also spent over $\$ 5 \mathrm{M}$ in preparing for the defense, most of which was in legal costs. The fee for the arbitration alone was $\$ 230,000$ and was equally shared by AUI and COMSAT. The NSF took a hard line, and refused Vanden Bout's request for supplemental funding in FY98 and FY99 to cover the litigation expenses. While AUI agreed to loan NRAO \$750,000 in FY98 to cover some of the litigation expenses, even more of a concern at that time was the possibility of an unfavorable judgment against AUI/NRAO of as much as \$29 million.

Following the relatively modest adverse judgement, in early 2001 NRAO/ AUI still faced bills totaling more than $\$ 9$ million. Aside from issues of whether or not the cost of settling the claim was allowable under the terms of the AUINSF Cooperative Agreement, there were no funds available within the NSF Astronomy Division to cover such a large unplanned cost. Nor could budget funds be moved from other NSF divisions without express approval from the cognizant Congressional appropriation committees. There was a real possibility that NRAO/AUI would need to find the $\$ 9$ million within the NRAO annual operating budget or from AUI corporate funds, and Vanden Bout started to implement a number of NRAO budget adjustments to at least cover the litigation expenses. However, following extensive strategy discussions, the NSF deftly adjusted the 2002 NRAO fiscal year to begin on I October 2001 instead of 1 January 2002, so in calendar year 2001, NRAO received 15 months of funding or an effective budget supplement of $25 \%$. This was enough to pay the litigation costs, as well as to support other long overdue activities at the Observatory. Much to the chagrin of Che Kim, the powerful Clerk of the Senate Appropriations Committee, who was already at odds with NSF Director Rita Colwell, the NSF had cleverly and legally maneuvered a budget change without the required Congressional approval.

To their credit, even during the ongoing lengthy and sometimes bitter litigation process, COMSAT and NRAO engineers continued to work together to finally bring the GBT construction to a satisfactory completion by the end of 2000. Vanden Bout wisely allowed the project team to focus on completing 
the antenna, while enlisting others to support the lengthy legal proceedings. When finally dedicated in August 2000, the GBT became the largest movable structure on the surface of the Earth, weighing 17 million pounds and extending $100 \times 110$ meters across. ${ }^{132}$ It has an unblocked aperture containing 2004 surface panels positioned by 2209 remotely controlled actuators or jack screws to constantly adjust the surface to compensate for thermal and gravitational distortions and keep the surface sufficiently accurate to a few tenths of a millimeter to allow operation at $86 \mathrm{GHz}(3.5 \mathrm{~mm})$. The planned innovative precision pointing system and adaptive surface, based on the use of lasers to measure the path length from various parts of the structure to fixed points on the ground, was never perfected. However, the finite element analysis gave such a good description of the structural behavior that the dish distortions under the effects of gravity are effectively removed by the active surface and a straightforward look-up table. Precision pointing is achieved by the use of tilt sensors located at strategic points in the structure, and feeding this information back into the pointing equations achieves a pointing accuracy of about one second of arc, equivalent to the thickness of a human hair at a distance of 15 feet. Paradoxically, when rejecting an application for funds to make a documentary film about the GBT construction, the NSF responded that, "unlike an optical telescope, a radio telescope is not very visual." 133 (Fig. 9.14).

Due to the various design changes implemented during the construction process, and the non-negligible weight of the weldings that had been neglected in the early weight calculation, the GBT, as delivered from the manufacturer, weighed between 17.0 and 17.5 million pounds, or about $30 \%$ more than the original design weight. Although the weight was thought to be within the required safety margins at the mid-span of each track segment, there had been no consideration of stresses at the joints or dynamic loading effects. Owing to the excess weight, some of the azimuth track plates began to slip and show excessive wear shortly after the completion of the GBT; numerous hold down bolts were shearing off, and gaps in the grout were filling with water and draining off grout particulate. As a result, the azimuth wheels were tilting and causing even more excessive wear of the track. NRAO engineers were concerned that, without repairs, the rate of track degradation would lead to a shutdown of GBT operations in 6-12 months.

Following a series of reviews of the extent of the damage, AUI submitted a claim to Lockheed Martin for $\$ 9,053,126.35$ to cover their accrued costs and the expected cost of repairs. Lockheed Martin responded that AUI had been the "windfall beneficiary" of a telescope that cost $\$ 110$ million to build and yet for which AUI paid only approximately $\$ 55$ million but "regrettably took a 'throw in the kitchen sink' approach and that the AUI was unreasonable."'134 Lockheed claimed that the proposed AUI repairs were actually an upgrade of the original specifications for which they were not responsible.

Noting that the proposed upgrades were necessary to meet the original 20 -year warranty, AUI was unwilling to settle for the $\$ 1.5$ million offered by Lockheed. But following a visit to Lockheed by AUI Vice President Pat 


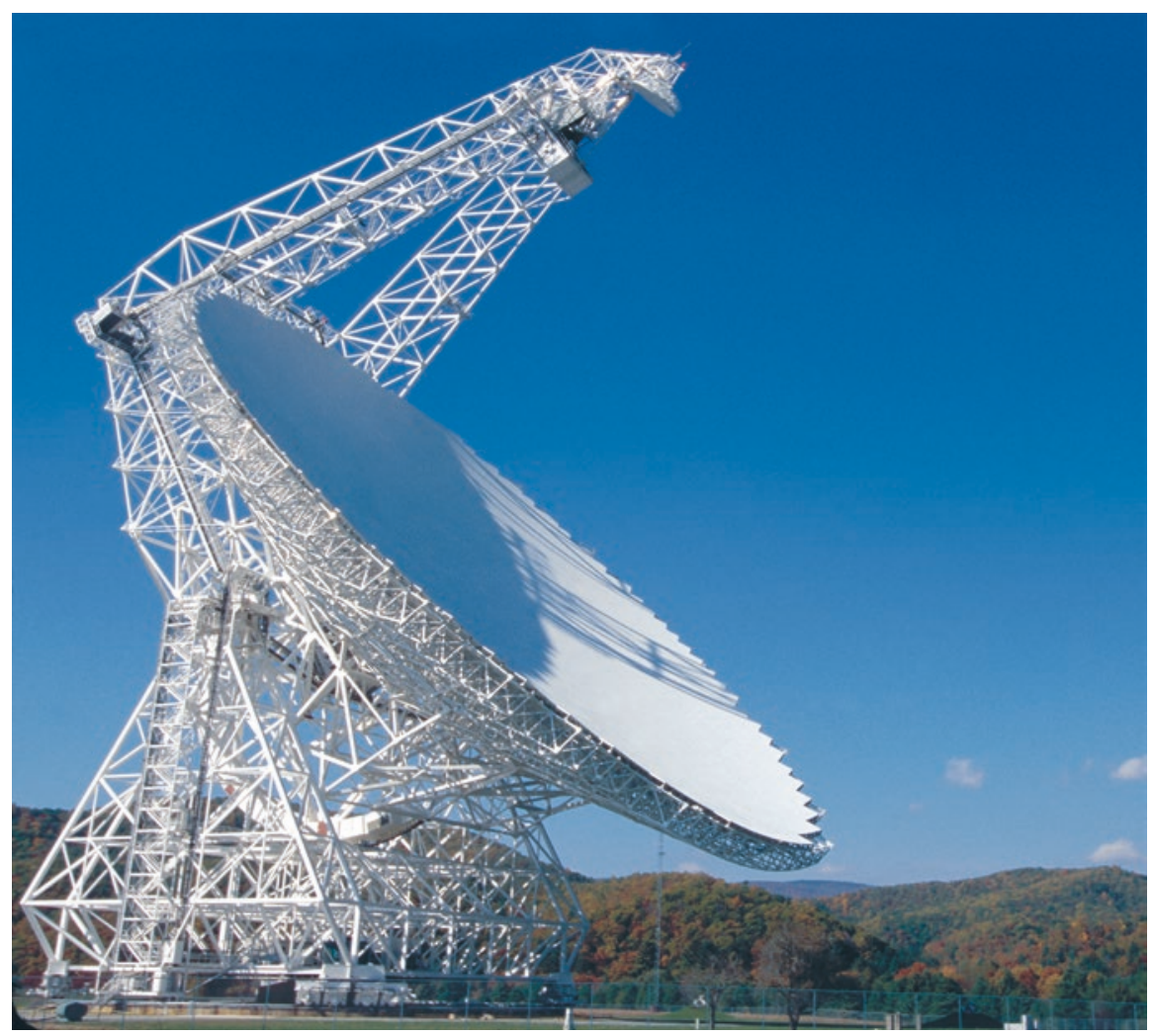

Fig. 9.14 Completed Green Bank Telescope. Credit: NRAO/AUI/NSF

Donahue, Green Bank Assistant Director Phil Jewell, and the AUI attorney Randy Squires, AUI accepted Lockheed's check for \$4 million to cover the cost of the track repairs.

Epilogue After the completion of the project, NRAO held a postmortem to evaluate how and why the GBT problems occurred. ${ }^{135}$ Basically, it was agreed that nothing like this had ever been done before, and no one at NRAO, AUI, RSI, or the NSF, nor the distinguished members of the advisory committees, had ever built a 100 meter clear aperture structure with an active surface and with the GBT's exacting specifications. Clearly the initial cost estimates and schedule agreed to by both NRAO and RSI were overly optimistic. But the bidders proposed to meet the schedule because that is what the RFP demanded. Only RSI came even close to meeting the NRAO budget allocation, whether in ignorance or naivety, or perhaps in expectation of later negotiating a new cost. It was clear from the size of the Brown \& Root Services Corp. and from the Fru-Con Corp. bids that the RSI bid was unrealistically low. However, NRAO's hands were tied. They could have rejected the RSI bid and redesigned 
the antenna, but RSI wanted the job and had apparently submitted a responsible bid consistent with the publically known budget and NRAO's own estimate. Had NRAO rejected the RSI bid, RSI would likely have protested. Alternately, NRAO could have gone back to the NSF for more funds, but considering the history of the funding process, that was not a viable choice. So NRAO chose to go ahead with RSI, which had a good reputation and whose bid was close to the NRAO budget estimate. On several occasions, NRAO threatened to hold RSI in default, but this was never a real option, since an alternate contractor would have required at least as much money, and the appropriated funds were already largely gone. NRAO took a calculated risk that RSI would not just walk off the job, as they were dependent on other existing and future government contracts. GBT Business Manager Bill Porter speculated that had there been time for a proper Design and Development phase, it would have been realized that the construction cost would be much higher than the RSI bid, but, he added, "had the real price been known, we might never have built the GBT."136

It took nearly half a century of discussion and debate, and numerous NSF and National Academy committees, but in the end it was a freak accident, coupled with the ambitions of a powerful Senator, a fiercely competitive radio astronomer with political connections, and a hungry, possibly naïve or unscrupulous contractor, to finally build the largest and most powerful fully steerable radio telescope in the world.

Why did it take half a century before the United States could finally build a large fully steerable radio telescope? As pointed out by John Findlay in April 1988, it was not for the lack of design effort nor the lack of skilled people either in industry or academia. ${ }^{137}$ But the NRAO 140 Foot and the 600 foot Sugar Grove fiascos were both embarrassments to the US radio astronomy community, from which it would take decades to recover. The 140 Foot itself was smaller than the Jodrell Bank or Parkes radio telescopes, both of which had been in operation for several years before the 140 Foot was finally completed, and the 140 Foot structure turned out to have serious limitations which impacted its short wavelength performance. The proposals for building a large fully steerable telescope in the US were led, or were perceived to be led, by engineers, not by an astronomer prepared to put his or her reputation on the line. By the mid-1960s, planning for the VLA was already dominating discussions at NRAO and AUI, and the LFST project was on the back burner. Finally, the scientific returns from the interferometric arrays at Cambridge, then OVRO, Westerbork, and later the VLA dwarfed the productivity of the large fully steerable radio telescopes at Jodrell Bank, Haystack, Effelsberg, and Algonquin Park, although the 210 foot Parkes antenna has been widely recognized as highly productive. Within both NRAO/AUI and the broader US radio astronomy community, the top priority was first the VLA, then the VLBA, and finally a millimeter array. A large fully steerable radio telescope for centimeter wavelengths remained a high priority for over a half a century, but never rose to first priority, normally a necessary, but by no means sufficient condition for obtaining federal funding for constructing a new scientific facility. 
It is perhaps interesting to speculate that if Jim Condon had been able to inspect his 300 Foot survey data on a daily basis, he would have spotted the changing performance of the 300 Foot Telescope, which might have immediately been recognized as due to the increasing deformations of the structure. Further observations would have been halted; the 300 Foot Telescope, which was already earmarked for closure, would probably not have collapsed, but would have been closed for lack of funding and dismantled; Senators Byrd and Rockefeller would not have been alarmed; and the GBT would have never been built.

\section{Notes}

1. Radio-Craft: January 1930, 312; October 1934, 213; May 1934, 648; Short Wave Craft: June-July 1931, 10; October-November 1930, 204; May 1934, 8; September 1935, 262; December 1935, 466; June 1936, 70. We are grateful to Bill Liles for bring these publications to our attention.

2. Patent Application filed on 23 June 1928 and granted US Patent No. $1,831,011$ on 10 November 1931. We are grateful to Bill Liles for bringing this to our attention.

3. Reber to Struve, 16 July 1946, NAA-GR, General Correspondence I. https:// science.nrao.edu/about/publications/open-skies\#section-9

4. Reber, 11 March 1955, Large Mirror Design, NAA-GR, Notes and Papers. https://science.nrao.edu/about/publications/open-skies\#section-9

5. AUI Advisory committee on Radio Astronomy, Minutes of 16-17 October 1956, NAA-NRAO, Founding and Organization, Meeting Minutes.

6. Lovell relates in The Jodrell Bank Telescopes his surprise in reading the article by Wielebinski, R. 1970, 100 m Radio Telescope in Germany, Nature, 228, 507.

7. Material in this section describing the German 100 meter radio telescope is based on Wielebinski, R., Junkes, N., Grahl, B.H. 2011, The Effelsberg 100-m Radio Telescope: Construction and Forty Years of Radio Astronomy, JAHH, 14 3; Hachenberg, O., Grahl, B.H., Wielebinski, R. 1973, The 100-meter radio telescope at Effelsberg, IEEEP, 61, 1288; Wielebinski, R. 1970, $100 \mathrm{~m}$ Radio Telescope in Germany, Nature, 228, 507; Wielebinski, R. 2003, The new era of large paraboloid antennas: the life of Prof. Dr. Otto Hachenberg, AdRS, 1, 321; Wielebinski, R. 2007, Fifty years of the Stockert Radio Telescope and what came afterwards, $A N, \mathbf{3 2 8}, 388$; and also on the 22 February 1973 Sullivan interview of Otto Hachenberg (NAA-WTS). https://science.nrao. edu/about/publications/open-skies\#section-9

8. Based on experience with existing radio telescopes, many observational radio astronomers became aware that while an antenna is tipped the parabolic surface deforms, changing the focal point, so that by moving the feed, some of the loss of gain with elevation can be recovered. Hachenberg's 100 meter design was based on a series of iterative computer simulations intended to optimize the structure so that it maintains a precise paraboloid when subject to gravitational deformations. Von Hoerner showed analytically that with the right choice of structural members, a so-called homologous solution can be found. 
Hachenberg and von Hoerner certainly met each other over a period of years in connection with the proposed new Max Planck Institute that they planned to jointly lead, but it is not clear if they ever discussed homologous antenna designs or to what extent either man consciously or unconsciously influenced the other.

9. Quoted by Butrica (1996, pp. 67-68).

10. Finite element analysis is a computer-based technique by which complex structures are broken down into a number of finite elements for subsequent analysis.

11. New York Times, 19 June 1959.

12. Charleston Gazette-Mail, 23 August 1964.

13. At the time, the Navy used very low frequency (VLF) radio to communicate with submarines around the globe.

14. D.R. Lord to President Eisenhower's Science Advisor, G.B. Kistiakowski, 8 September 1960, DDE, Radar and Radio Astronomy, Box 5, Records of the U.S. President's Science Advisory Committee.

15. New York Times, 15 October 1961.

16. AUI-BOTXC, January 1960.

17. Newspaper article of unknown source, 3 October 1963, NAA-NRAO, GB-LSFT, Box 6.

18. The Sugar Grove 150 foot steerable dish was designed by Ed Faelten who was also responsible for the design of the NRAO 300 Foot transit dish in Green Bank and who was later an active participant in the NRAO LFST program.

19. http://coldwar-c4i.net/Sugar_Grove/history.html

20. The politics of the Sugar Grove 600 foot antenna program are discussed in more detail in a publication by James Bamford (1983), The Puzzle Palace.

21. Washington Post, 22 May 2016.

22. Charleston Gazette-Mail, 26 July 2016.

23. DSH, Proposal for the development of a Large Antenna, 16 December 1957, NAA-NRAO, Founding and Organization, Planning Documents. https://science.nrao.edu/about/publications/open-skies\#section-9

24. Ibid.

25. DSH, Comments on a Very Large Antenna, 21 August 1959, NAA-NRAO, Founding and Organization, Antenna Planning. https://science.nrao.edu/ about/publications/open-skies\#section-9

26. G. Keller, Report of the NSF Advisory Panel for Radio Telescopes (1960).

27. AUI-BOTXC, 19 February 1960.

28. J. Findlay and D. Heeschen, The National Radio Astronomy Observatory and a Very Large Antenna, 27 May 1960, NAA-NRAO, Founding and Organization, Antenna Planning. https://science.nrao.edu/about/publications/open-skies\#section-9

29. DSH to Wilson, 17 December 1963, NAA-NRAO, Green Bank Operations, LFST, Box 4.

30. Gart Westerhout from the University of Maryland chaired the meeting which included Ron Bracewell from Stanford, Bernard Burke (see NAA-BFB) from DTM, John Kraus (see NAA-JDK) from Ohio State, Edward Lilley from Harvard, Richard Read from Caltech, George Swenson from Illinois, and Harold Weaver from the University of California at Berkeley. Frank Drake, 
David Heeschen, John Findlay, and Morton Roberts represented NRAO, and Geoffrey Keller represented the National Science Foundation.

31. Wade notes from Green Bank Meeting to Discuss Next Large Paraboloid for NRAO, NAA-NRAO, Green Bank Operations, LSFT, Box 4.

32. Report on Ad Hoc Meeting of Radio Astronomers: Largest Feasible Steerable Filled-Aperture Telescope, Green Bank, 30 October 1964, NAA-NRAO, Green Bank Operations, LFST, Box 4.

33. J. Findlay, The Largest Feasible Steerable Filled-Aperture Telescope, 14 January 1965, LFSP/JWF/1. NAA-NRAO, Green Bank Operations, LFST, Box 9. https://science.nrao.edu/about/publications/open-skies\#section-9

34. Other members included E. R. Faelten and Otto Heine, consulting engineers; NRAO engineers John Hungerbuhler and Max Small, and NRAO Scientist, Sebastian von Hoerner; and Richard L. Jennings a civil engineer from the University of Virginia.

35. LSFP, LFST and 65 Meter Reports. http://library.nrao.edu/65r.shtml See also the series of LFSP, LFST, and 65 Meter Unnumbered Reports. http:// library.nrao.edu/65u.shtml

36. NAA-NRAO, Green Bank Operations, LFST, Boxes 8-12.

37. A 300 Foot High Precision Radio Telescope, January 1969, NRAO report. See also Youmans (1969).

38. A 25-Meter Radio Telescope for Millimeter Wavelengths, vol. 1, NRAO, September 1975.

39. Harvard Crimson, 17 January 1966.

40. Papers of Alan Moffet (unprocessed), CITA.

41. Stanley to Bonner, 27 December 1966, Papers of Gordon Stanley, CITA.

42. National Science Foundation Report of the Ad Hoc Advisory Panel for Large Radio Astronomy Facilities, 14 August 1967.

43. Large Diameter Radomes, a report prepared for MIT Lincoln Laboratory by Ammann \& Whitney Engineering Consultants, April 1965 [Appendix IV to CAMROC Engineering Design Objectives for a Large Radio Telescope, October 1965], NAA-JWF, LFST.

44. A Large Radio/Radar Telescope, CAMROC Design Concepts, Vol I and Vol II, Cambridge Radio Observatory Committee, 1967.

45. Findlay later testified in Congress in support of the NEROC proposal which he claimed was "very unpopular within the NRAO management," JWF notes to KIK from April 1988, KIK, Open Skies, LFST.

46. Minutes of the 30 November-1 December 1968 Radio and Radar Astronomers meeting, NAA-JDK, Notes and Papers, US Radio Astronomy, Smithsonian Large Telescope.

47. Ibid.

48. "A Large Radio-Radar Telescope Proposal for a Research Facility" submitted to the National Science Foundation on 30 June 1970 by the Northeast Radio Observatory Corporation.

49. The saga of the CAMEROC/NEROC attempt to construct a large steerable radio telescope is discussed in more detail in Butrica (1996), 69-83.

50. Burke to PVB, 21 July 1987, NAA-NRAO, Green Bank Operations, GBT Planning and Design, Box 1.

51. PVB to KIK, 25 November 1987, NAA-NRAO, Green Bank Operations, GBT Planning and Design, Box 1. 
52. NLSRT Memo No. 1, New Large Steerable Radio Telescope (NLSRT), NAANRAO, Green Bank Operations, GBT Planning and Design, Box 1. http:// library.nrao.edu/public/memos/nlsrt/NLSRT_001.pdf

53. Experience from building a variety of fully steerable radio telescopes suggests that the cost varies approximately as (Diameter) $)^{2.7}$ and as the (limiting wavelength $)^{-0.7}$.

54. NLSRT Memo No. 39, A Very Large Dish (VLD) Radio Telescope, 28 November 1988, NAA-NRAO, Green Bank Operations, GBT Planning and Design, Box 1. http://library.nrao.edu/public/memos/nlsrt/NLSRT_039. pdf

55. The IBM PC-AT was at the time an advanced personal computer using an 80286 processor running at $8 \mathrm{MHz}$ with $18 \mathrm{MB}$ of memory, and $20 \mathrm{MB}$ hard disk drive.

56. Shapiro to KIK, 10 February 1988, NAA-KIK, Open Skies.

57. Langenberg, 1988. Report of Subcommittee on NSF Radio Astronomy Facilities, Advisory Committee for Astronomical Sciences, NAA-NRAO, NSFAdvisory Committees.

58. Other committee members were J. Gallagher (Univ. of Wisconsin), P. Kronberg (Univ. of Toronto), R. Mutel (Univ. of Iowa), J. Piper (Univ. of Rochester), B. Rickett (Univ. California San Diego), R. Wagoner (Stanford) and R. Wilson (Bell Labs).

59. The following section reporting on the impact of the collapse of the 300 Foot antenna and the subsequent negotiations between NRAO and the NSF is based in part on unpublished recollections of George Seielstad and Paul Vanden Bout, as well as on materials in NAA-NRAO, Green Bank Operations, GBT Planning and Design.

60. Matyas was a construction and management consultant. Other panel members were Edward Cohen, managing partner with Amman and Whitney, a structural engineering firm, and George Mechlin, retired Vice President for Research and Development of the Westinghouse Electric Corporation.

61. Report of the Technical Assessment Panel for the 300 Foot Radio Telescope at Green Bank WV, March 1989, NAA-NRAO, Green Bank Operations, 300 Foot, 300 Foot Collapse, Box 2. http://library.nrao.edu/public/memos/ nlsrt/NLSRT_053.pdf

62. Paul Harvey broadcast a daily "News and Comment" show on the ABC radio network which was carried by more than 1200 national radio stations and 300 newspapers.

63. New York Times, 17 November 1988.

64. National Science Foundation. http://www.nsf.gov/about/history/bloch_ bio.jsp

65. NLSRT Memo 39, op. cit.

66. NLSRT Memo 37, Richard Thomas to Richard Fleming, NAA-NRAO, Green Bank Operations, GBT Planning and Design, Box 1. http://library.nrao.edu/ public/memos/nlsrt/NLSRT_037.pdf

67. NLSRT Memo 36, Typical Antenna Costs, NAA-NRAO, Green Bank Operations, GBT Planning and Design, Box 1. http://library.nrao.edu/public/memos/nlsrt/NLSRT_036.pdf

68. Burke to AAS CAPP, I December 1988, NAA-NRAO, Green Bank Operations, GBT Planning and Design, Box 2. 
69. Many prominent scientists argued against LIGO as being too expensive and with minimal chances of success.

70. Report of R. E. Vogt to the NSF, 31 January 1989, NAA-NRAO, Green Bank Operations, GBT Proposals and Contracts, (Fact Sheets folder).

71. KIK interview with Vanden Bout, December 2016.

72. Unpublished notes of George Seielstad, NAA-KIK, Open Skies.

73. Ibid.

74. Even after the GBT was approved, Byrd continued to pressure the NSF to build LIGO in Green Bank. NRAO went on to prepare a pro-forma proposal which purposely contained the fatal flaw that if LIGO interfered with the operation of Green Bank radio telescopes then NRAO could shut down LIGO.

75. NLSRT Memo 32, Proceedings of a Green Bank Workshop, December 2-3, 1988, NAA-NRAO, Green Bank Operations, GBT Planning and Design, Box 1. http://library.nrao.edu/public/memos/nlsrt/NLSRT_032.pdf

76. Weber to Vanden Bout, 2 March 1989, NAA-NRAO, Green Bank Operations, GBT Planning and Design, Box 1.

77. Hagfors to Bloch, 30 December 1988, NAA-NRAO, Green Bank Operations, GBT Planning and Design, Box 1.

78. Schmidt to KIK, 21 December 1988, NAA-KIK, Open Skies.

79. Vanden Bout to Bloch, 19 December 1988, NAA-NRAO, Green Bank Operations, GBT Planning and Design, Box 1.

80. Vanden Bout, 1988, NAA-PVB, Journals and Calendars.

81. Traditional filled aperture antennas have a receiver connected to a simple antenna such as a horn or dipoles located at the focal point of a parabolic reflector. The expression "feed" comes from the early use of parabolic dishes for radar. Although a radio telescope works in reverse, the radar terminology is still in common use. Many modern radio telescopes as well as communication and satellite TV dishes use a so-called Cassegrain or Gregorian focus which uses a sub-reflector located near the focal point to reflect the incoming signal to the receiver and feed located near the dish surface. A Cassegrain system utilizes a convex hyperbolic sub-reflector located in front of the focal-point, while a Gregorian system uses a concave hyperbolic reflector located outside the focal point. Cassegrain and Gregorian configurations have been used in optical telescopes since the seventeenth century.

82. Burke to KIK, 27 March 1989, NLSRT Memo No. 56, NAA-NRAO, Green Bank Operations, GBT Planning and Design, Box 1. http://library.nrao.edu/ public/memos/nlsrt/NLSRT_056.pdf

83. The resolution of optical telescopes is typically limited not by diffraction, but by tropospheric turbulence that is called "seeing."

84. NAA-NRAO, Green Bank Operations, GBT Planning and Design, Box 1.

85. Charleston Gazette, 30 December 1989.

86. Vanden Bout 1989, NAA-PVB, Journals and Calendar.

87. The original letter was handed to Bloch; no copies have been found in either the NRAO files nor in Tyson's personal files.

88. Vanden Bout, 1989, NAA-PVB, Journals and Calendars.

89. KIK interview with Seielstad, 17 February 2017.

90. Burke to Bloch, 26 January 1989. Copies were sent to Senators Byrd and Rockefeller as well as to NRAO. NAA-NRAO, Green Bank Operations, GBT Design and Construction, Box 1. 
91. http://www.loc.gov/crsinfo/about/

92. Rowberg interview with Kellermann and Brandt, 14 November 2013.

93. The CRS report, which was co-authored by CRS member James Mielke, was addressed to both Byrd and Rockefeller with copies to Carol Mitchell and Amy Berger from Byrd's and Rockefeller's staff respectively. NAA-NRAO, Green Bank Operatioins, GBT Planning and Design, Box 2.

94. 27 February 1989 memo from the CRS to Carol Mitchel and Amy Berger, NAA-NRAO, Green Bank Operations, GBT Planning and Design, Box 2.

95. Pocahontas Times, 9 March 1989.

96. Rowberg to Carol Mitchell and Amy Berger, 14 March 1989, NAA-NRAO, Green Bank Operations, GBT Planning and Design, Box 2.

97. The following year, Congress appropriated the first funding for LIGO. In 1992, sites at Hanford, Washington, and Livingston, Louisiana, were selected. Following 15 years of cost escalation, schedule delays, and management upheavals the project had grown to include more than 1000 scientists from 75 institutions in 15 countries. On 11 February 2016, after more than 25 years of development and construction costing more than one billion dollars, the LIGO collaboration announced the unambiguous detection of gravity waves on 24 September 2015, from a pair of coalescing massive black holes. Abbot et al. 2016, Phys. Rev. Lett. 116, 241103. Barry Barish, Kip Thorne, and Ray Weiss later received the 2017 Nobel Prize in Physics for their contributions to LIGO and the observation of gravitational waves.

98. A Radio Telescope for the Twenty-First Century, June 1989, NAA-NRAO, Green Bank Operations, GBT Proposals and Contracts.

99. Asrael to Hughes, 17 July 1989, NAA-NRAO, Green Bank Operations, GBT Construction, Box 1.

100. 297th Meeting of the National Science Board, 16 November 1990, NAANRAO, Green Bank Operations, GBT Construction, Box 1.

101. Weiss to Vanden Bout, 4 November 1989, 12 November 1989, NAA-NRAO, Green Bank Operations, GBT General, Box 1.

102. NRAO/AUI Request for Proposals, Green Bank Telescope, I June 1990, NAA-NRAO, Green Bank Operations, GBT Proposals and Contracts.

103. AUI Post-Hearing Brief to the American Arbitration Association, 16 May 2000, p. 17, NAA-NRAO, Green Bank Operations, GBT Litigation, Box 4.

104. KIK interview with Riffe, 7 November 2016.

105. Asrael to Hughes, 6 December 1990, NAA-NRAO, Green Bank Operations, GBT Construction, Box 1 . This was later supplemented by an additional $\$ 4.56$ million bringing the total amount close to the $\$ 75$ million promised by Senator Byrd.

106. Contract No. AUI-1059, 19 December 1990, NAA-NRAO, Green Bank Operations, GBT Proposals and Contracts.

107. KIK and ENB interview with Liszt, 6 July 2016, NAA-KIK, Oral Interviews.

108. DSH to Hall, 26 February 1991, NAA-NRAO, Green Bank Operations, GBT Proposals and Contracts.

109. Hall to Hawkins, 9 October 1992, NAA-NRAO, Green Bank Operations, GBT Construction, Box 1.

110. Porter, Undated internal memorandum, NAA-NRAO, Green Bank Operations, GBT General, Box 1. 
111. GBT Software Report of the Review Committee, NAA-NRAO, Green Bank Operations, GBT General, Box 2.

112. DSH to Hall, 7 June 1993, NAA-NRAO, Green Bank Operations, GBT Construction, Box 1.

113. NAA-NRAO, Green Bank Operations, GBT Construction, Box 1.

114. NAA-NRAO, Green Bank Operations, GBT Construction, Box 1.

115. Hall to Vanden Bout, 18 February 1993, NAA-NRAO, Green Bank Operations, GBT Construction, Box 1 .

116. Letter from Hawkins, COMSAT RSI, to Porter, GBT Business Manager, 1 April 1998, NAA-NRAO, Green Bank Operations, GBT Litigation, Box 1.

117. Letter from Raymond Thomas (CRSI) to Lane, 16 May 1997, NAA-NRAO, Green Bank Operations, GBT Litigation, Box 1.

118. Letter from Raymond Thomas to Byrd, 5 February 1997, NAA-NRAO, Green Bank Operations, GBT Litigation, Box 1.

119. AUI Post-Hearing Brief to the American Arbitration Association, op. cit.

120. Memo from DSH to Squires, 9 January 1997, NAA-NRAO, Green Bank Operations, GBT Litigation, Box 1.

121. Squires to Pankowski, 17 June 1997, NAA-NRAO, Green Bank Operations, GBT Litigation, Box 1.

122. Vanden Bout to Dickman, 5 August 1997, NAA-NRAO, Green Bank Operations, GBT Litigation, Box 1.

123. KIK interview with Vanden Bout, 22 July 2016.

124. COMSAT RSI Inc. v. Cornell University, United States District Court, N.Y., 20 June 1996, NAA-NRAO, Green Bank Operations, GBT Litigation, Box 1.

125. Government Accounting Office report to Congressional Requesters on the Department of Energy Information on the Tritium Leak and Contractor Dismissal at the Brookhaven National Laboratory, 1997. Interestingly, only a year earlier DOE gave AUI an "excellent" rating for "environmental compliance and reactor safety."

126. Schwartz to Lane, 18 June 1997, NAA-NRAO, Green Bank Operations, GBT General, Box 2.

127. Respondents Memorandum in Opposition to Claimant's Motion to Respondent's Dismiss Second Amended Counterclaim, p.2, 13 April 1998, NAA-NRAO, Green Bank Operations, GBT Litigation, Box 1.

128. COMSAT Post-Hearing Brief to the American Arbitration Association, 15 May 2000, NAA-NRAO, Green Bank Operations, GBT Litigation, Box 4.

129. AUI Post-Hearing Brief to the American Arbitration Association, 15 May 2000, NAA-NRAO, Green Bank Operations, GBT Litigation, Box 4.

130. AUI's Post-Hearing Reply Brief, 30 July 2000, NAA-NRAO, Green Bank Operations, GBT Litigation, Box 4.

131. COMSAT's Claimant's Reply Brief, 30 June 2000, NAA-NRAO, Green Bank Operations, GBT Litigation, Box 4.

132. Since that time, the $\$ 1.5$ billion Chernobyl Arch, built to confine the remains of the Chernobyl number 4 reactor, became the largest movable structure on earth, but it was only moved once to cover the destroyed reactor.

133. Summary of reviews, appended to J. Vanski to M. Haynes, undated (fax receipt date 20 July 1993), NAA-NRAO, Green Bank Operations, GBT General, Box 1.

134. O'Dea to Squires, 20 July 2006, NAA-NRAO, Green Bank Operations, GBT General, Box 3. 
135. Vanden Bout notes, NAA-NRAO, Green Bank Operations, GBT General, Box 3.

136. Porter notes, NAA-NRAO, Green Bank Operations, GBT General, Box 1.

137. Findlay notes for a 29 April 1988 invited talk at Ithaca, NY that apparently was not presented. NAA-NRAO, Green Bank Operations, GBT Planning and Design, Box 1.

\section{BIBLIOGRAPHY}

\section{REFERENCES}

Bamford, J. 1983, The Puzzle Palace. (New York: Penguin)

Butrica, A.J. 1996, To See the Unseen: A History of Planetary Radar Astronomy, NASA SP 4218 (Washington DC: NASA)

Condon, J.J. 2008, ZAPPED! ... by Hostile Space Aliens! In ASPC 398, Frontiers of Astrophysics: A Celebration of NRAO 50th Anniversary, ed. A.H. Bridle, J.J. Condon, and G.C. Hunt (San Francisco: ASP), 323

DeVorkin, D.H. 2000, Who Speaks for Astronomy, Historical Studies in the Physical and Biological Sciences, 31 (1), 2000

Dicke, R.H. 1967, Report of the Ad Hoc Advisory Panel for Large Radio Astronomy Facilities (Washington DC: National Science Foundation)

Dicke, R.H. 1969, Report of the Second Meeting of Ad Hoc Advisory Panel for Large Radio Astronomy Facilities (Washington: National Science Foundation)

Field, G. 1983, Astronomy and Astrophysics for the 1980's, Report of the Astronomy Survey Committee (Washington DC: National Research Council)

Findlay, J.W. 11 February 1965, The Largest Feasible Steerable Paraboloid, NRAO internal report https://library.nrao.edu/public/memos/65/65U/65U_100.pdf

Findlay, J.W. and von Hoerner, S. 1972, A 65-Meter Telescope for Millimeter Wavelengths (Charlottesville: NRAO)

Greenberg, D.S. 1964, Big Dish: How Haste and Secrecy Helped Navy Waste \$63 Million in a Race to Build a Huge Telescope, Sci, 144, 1111

Greenstein, J.L 1973, Astronomy and Astrophysics for the 1970's, Report of the Astronomy Survey Committee, Vol 2 (Washington DC: National Research Council)

Hachenberg, O. 1970, The New Bonn 100-Meter Radio Telescope, SerT, 40, 338

Hachenberg, O., Grahl, B.H., Wielebinski, R. 1973, The 100-meter radio telescope at Effelsberg, IEEEP, 61, 1288

Keller, G. 1960, Report of the Advisory Panel on Radio Telescopes, ApJ, 134, 927

Kraus, J.D. 1984, Karl Guthe Jansky's Serendipity, Its Impact on Astronomy and Its Lesson for the Future. In Serendipitous Discoveries in Radio Astronomy, ed. K.I. Kellermann and B. Sheets (Green Bank: NRAO/AUI), 59

Lovell, A.C.B. 1985, The Jodrell Bank Telescopes (Oxford: Oxford University Press)

McClain, E. 1960, The 600-Foot Radio Telescope, SciAm, 202 (1), 45

Reber, G. 1958, Early Radio Astronomy in Wheaton, Illinois, Proc. IRE, 46 (1), 15

Sullivan, W.T. III 2009, Cosmic Noise, A History of Early Radio Astronomy (Cambridge: CUP)

Trexler, J. H. 1958, Lunar Radio Echoes, Proc. IRE, 46, 286

van Keuren, D. K. 2001, Cold War Science in Black and White: US Intelligence Gathering and its Scientific Cover at the Naval Research Laboratory 1948-1962, Social Studies of Science, 31 (2) 207 
von Hoerner, S. 1967, Design of Large Steerable Antennas, AJ, 72, 35

Whitford, A. 1964, Ground-Based Astronomy: A Ten Year Program (Washington DC: National Academy of Sciences)

Youmans, A.B. 1969, The Design of a 300-ft Research Antenna. In Structures Technology for Large Radio and Radar Telescope Systems, eds. J.W. Mar and H. Liebowitz (Cambridge: MIT Press), 5

\section{FurTher READING}

Prestage, R.M. 2006, The Green Bank Telescope, Proc. SPIE, 6267 (12), 1.

Prestage, R.M. et al. 2009, The Green Bank Telescope, Proc. IEEE, 97, 1382

Lovell, A.C.B. 1968, The Story of Jodrell Bank (New York: Harper \& Row)

Lovell, A.C.B. 1974, Out of the Zenith (New York: Harper \& Row)

Lovell, A.C.B. 1987, Voice of the Universe (New York: Praeger)

Saward, D. 1984, Bernard Lovell: A Biography (London: Robert Hale)

Open Access This chapter is licensed under the terms of the Creative Commons Attribution 4.0 International License (http://creativecommons.org/licenses/ by/4.0/), which permits use, sharing, adaptation, distribution and reproduction in any medium or format, as long as you give appropriate credit to the original author(s) and the source, provide a link to the Creative Commons licence and indicate if changes were made.

The images or other third party material in this chapter are included in the chapter's Creative Commons licence, unless indicated otherwise in a credit line to the material. If material is not included in the chapter's Creative Commons licence and your intended use is not permitted by statutory regulation or exceeds the permitted use, you will need to obtain permission directly from the copyright holder. 